\title{
Female genital mutilation/cutting in Senegal: Is the practice declining? Descriptive analysis of Demographic and Health Surveys, 2005-2017
}

Dennis Matanda

Population Council

Glory Atilola

Zhuzhi Moore

Paul Komba

Lubanzadio Mavatikua

See next page for additional authors

Follow this and additional works at: https://knowledgecommons.popcouncil.org/departments_sbsr-rh

Part of the Demography, Population, and Ecology Commons, Family, Life Course, and Society Commons, Gender and Sexuality Commons, International Public Health Commons, and the Medicine and Health Commons How does access to this work benefit you? Let us know!

\section{Recommended Citation}

Matanda, Dennis, Glory Atilola, Zhuzhi Moore, Paul Komba, Lubanzadio Mavatikua, Chibuzor Christopher Nnanatu, and Ngianga-Bakwin Kandala. 2020. "Female genital mutilation/cutting in Senegal: Is the practice declining? Descriptive analysis of Demographic and Health Surveys, 2005-2017," Evidence to End FGM/C: Research to Help Girls and Women Thrive. New York: Population Council. 


\section{Authors}

Dennis Matanda, Glory Atilola, Zhuzhi Moore, Paul Komba, Lubanzadio Mavatikua, Chibuzor Christopher Nnanatu, and Ngianga-Bakwin Kandala 


\section{Evidence to End FGM/C}

Research to Help Girls and Women Thrive

\section{FEMALE GENITAL MUTILATION / CUTTING IN SENEGAL: IS THE PRACTICE DECLINING? DESCRIPTIVE ANALYSIS OF DEMOGRAPHIC AND HEALTH SURVEYS, 2005-2017}

February 2020 


\title{
FEMALE GENITAL MUTILATION / CUTTING IN SENEGAL: IS THE PRACTICE DECLINING? \\ Descriptive Analysis of Senegal Demographic and Health Surveys, 2005-2017
}

\author{
DENNIS MATANDA \\ POPULATION COUNCIL \\ GLORY ATILOLA \\ NORTHUMBRIA UNIVERSITY \\ ZHUZHI MOORE \\ INDEPENDENT CONSULTANT, POPULATION COUNCIL \\ PAUL KOMBA \\ LUBANZADIO MAVATIKUA \\ CHRISTOPHER CHIBUZOR NNANATU \\ NGIANGA-BAKWIN KANDALA \\ NORTHUMBRIA UNIVERSITY
}

FEBRUARY 2020 
The Evidence to End FGM/C: Research to Help Girls and Women Thrive generates evidence to inform and influence investments, policies, and programmes for ending female genital mutilation/cutting in different contexts. Evidence to End FGM/C is led by the Population Council, Nairobi in partnership with the Africa Coordinating Centre for the Abandonment of Female Genital Mutilation/Cutting (ACCAF), Kenya; the Global Research and Advocacy Group (GRAG), Senegal; Population Council, Nigeria; Population Council, Egypt; Population Council, Ethiopia; MannionDaniels, Ltd. (MD); Population Reference Bureau (PRB); University of California, San Diego (Dr Gerry Mackie); and University of Washington, Seattle (Prof. Bettina Shell-Duncan).

POPULATION COUNCIL

Ideas. Evidence. Impact.
The Population Council confronts critical health and development issues-from stopping the spread of HIV to improving reproductive health and ensuring that young people lead full and productive lives. Through biomedical, social science, and public health research in 50 countries, we work with our partners to deliver solutions that lead to more effective policies, programmes, and technologies that improve lives around the world. Established in 1952 and headquartered in New York, the Council is a non-governmental, non-profit organisation governed by an international board of trustees. www. popcouncil.org

Suggested Citation: Matanda, D, G Atilola, Z Moore, P Komba, L Mavatikua, CC Nnanatu and NB Kandala. 2020. "Female Genital Mutilation / Cutting in Senegal: is the Practice Declining? Descriptive Analysis of Demographic and Health Surveys, 2005-2017."Evidence to End FGM/C: Research to Help Girls and Women Thrive. New York: Population Council.

This is a working paper and represents research in progress. This paper represents the opinions of the authors and is the product of professional research. This paper has not been peer reviewed, and this version may be updated with additional analyses in subsequent publications. Contact: Dennis Matanda dmatanda@popcouncil.org

Please address any inquiries about the Evidence to End FGM/C programme consortium to:

Dr Jacinta Muteshi, Project Director, imuteshi@popcouncil.org

Funded by:

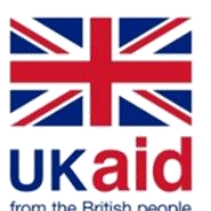

This document is an output from a programme funded by the UK Aid from the UK government for the benefit of developing countries. However, the views expressed and information contained in it are not necessarily those of, or endorsed by the UK government, which can accept no responsibility for such views or information or for any reliance placed on them. 


\section{Table of Contents}

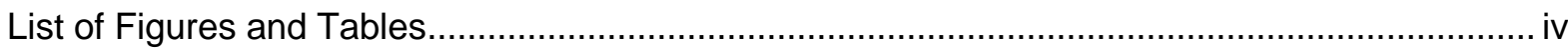

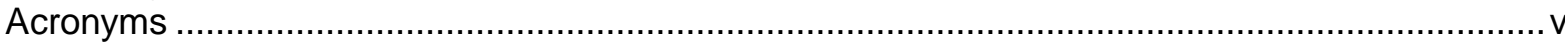

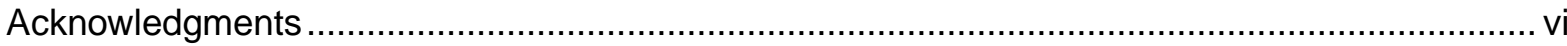

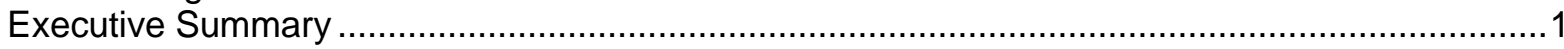

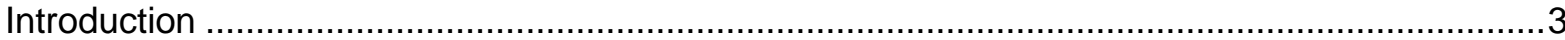

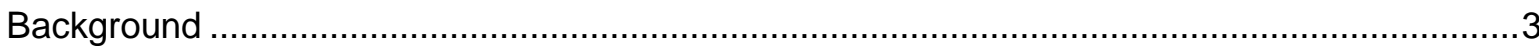

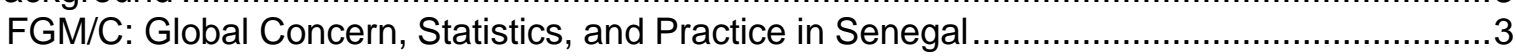

Efforts to Accelerate FGM/C Abandonment in Senegal ...................................................

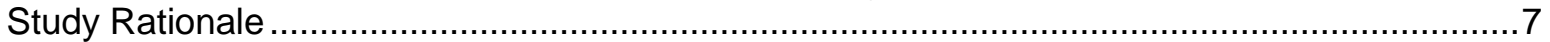

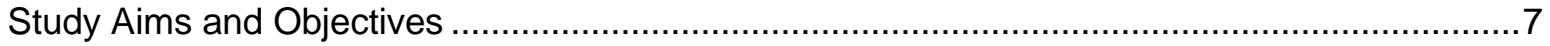

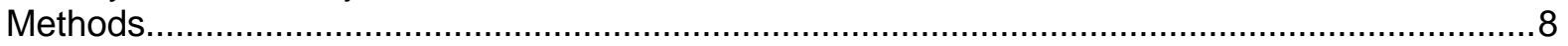

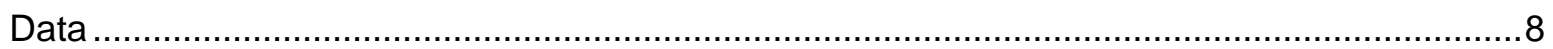

FGM/C Modules and Variables in Senegal Demographic and Health Surveys ........................8

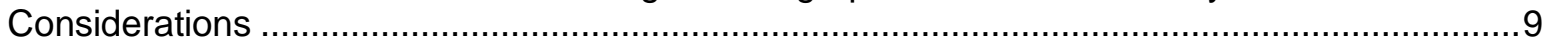

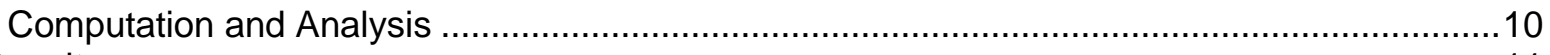

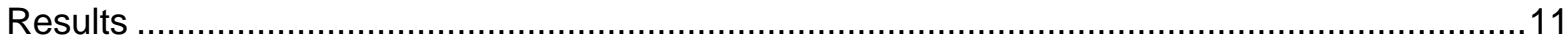

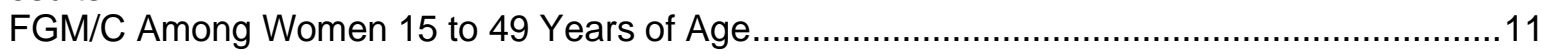

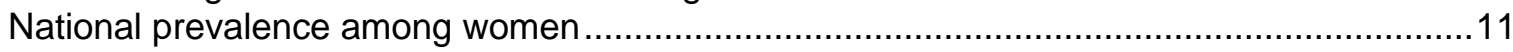

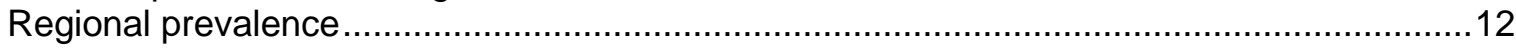

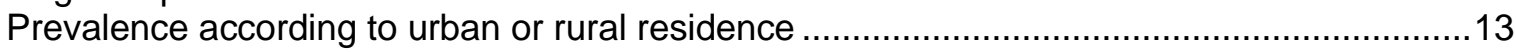

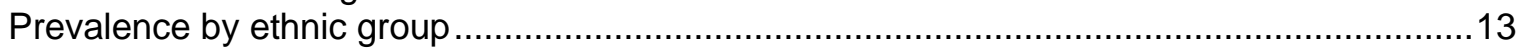

Prevalence by socio-demographic characteristics ............................................................ 16

FGM/C prevalence by social norms associated with FGM/C continuation............................17

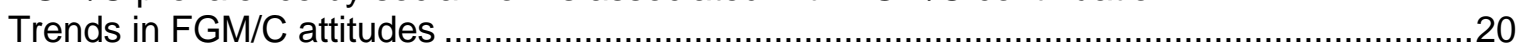

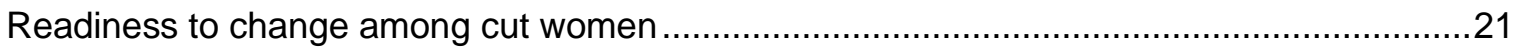

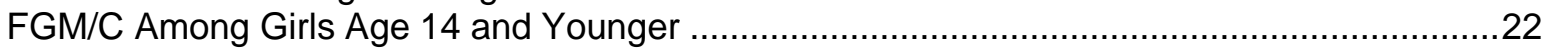

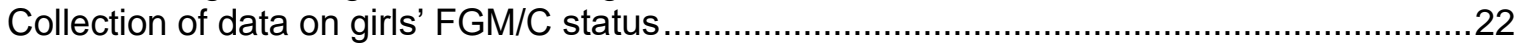

Considerations for analysis of complete daughter data: understanding the difference between

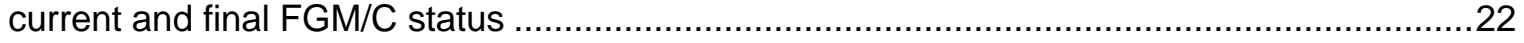

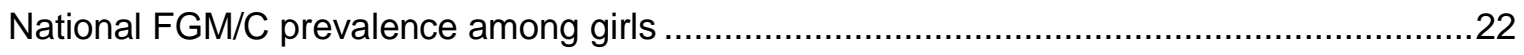

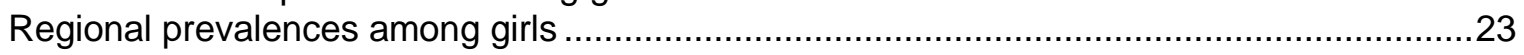

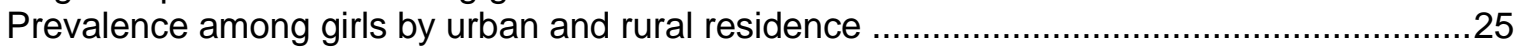

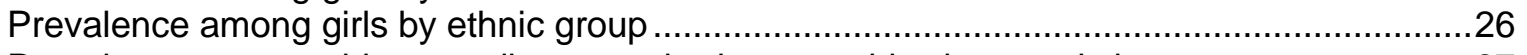

Prevalence among girls according to socio-demographic characteristics ............................27

Prevalence among girls according to social norms associated with FGM/C continuation .......28

Inter-Generational Changes: Mother and Daughter Comparisons..........................................31

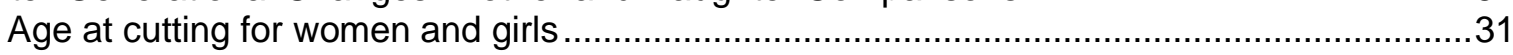

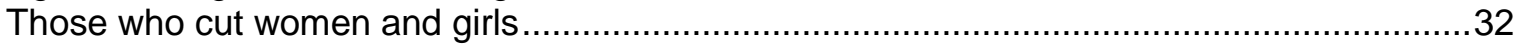

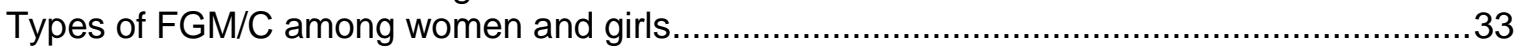

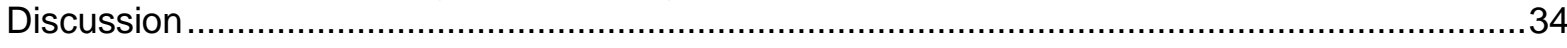

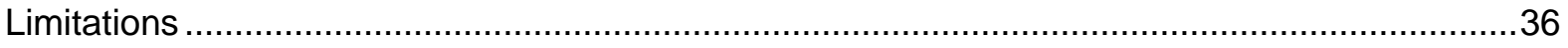

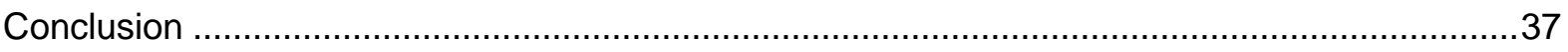

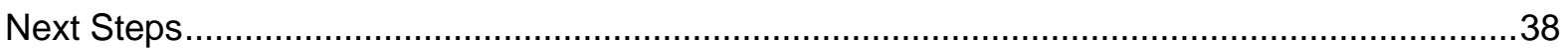

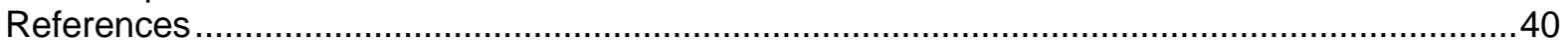

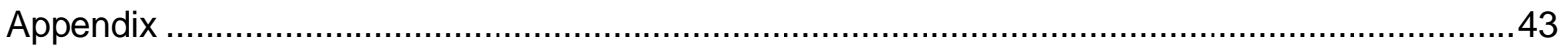




\section{List of Figures and Tables}

Figure 1. National FGM/C prevalence among women, SDHS 2005-2017................................11

Figure 2. FGM/C prevalence among women by age group, SDHS 2005-2017 …........................ 12

Figure 3. FGM/C prevalence among women by region, SDHS 2005-2017 .................................. 12

Figure 4. Evolution within regions of FGM/C prevalence among women, SDHS 2005-2017 ........ 13

Figure 5. FGM/C prevalence among women by residence, SDHS 2005-2017............................. 13

Figure 6. FGM/C prevalence among women by ethnicity, SDHS 2005-2017 ............................... 14

Figure 7. FGM/C prevalence among women by age cohort and ethnicity, SDHS $2017 \ldots \ldots \ldots \ldots . . . .15$

Figure 8. Opinions about the continuation of FGM/C among women, SDHS 2005-2017 ..............20

Figure 9. Trends in prevalence of and support for FGM/C, SDHS 2005-2017 ..............................21

Figure 10. Among cut women, percentage in each of the assigned stages of readiness to change based on at least one cut daughter, SDHS 2005-2017 ................................. 21

Figure 11. National FGM/C prevalence among girls, SDHS 2005-2017 ......................................23

Figure 12. FGM/C prevalence among girls by age group, SDHS 2005-2017 ................................23

Figure 13. FGM/C prevalence among girls years by region, SDHS 2005-2017 ............................ 24

Figure 14. Evolution within regions of FGM/C prevalence among girls, SDHS 2005-2017 ............. 25

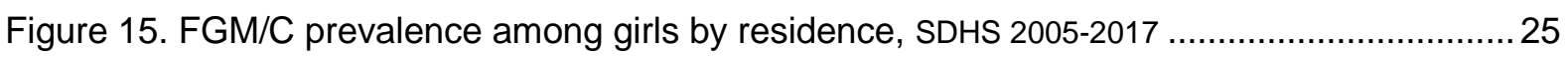

Figure 16. FGM/C prevalence among girls by ethnicity, SDHS 2005-2017 ..................................26

Figure 17. Comparison of age at cutting for women and girls by age group, SDHS 2005-2017 ......31

Figure 18. Kaplan-Meier survival estimates for age at cutting, girls and women, SDHS 2017 .......32

Figure 19. Person who performed FGM/C on women and girls, SDHS 2005-2017 ........................ 33

Figure 20. Types of FGM/C among women and girls, SDHS 2005-2017 ...................................... 33

Table 1. Sample size of women and girls, SDHS 2005-2017 ................................................ 8

Table 2. Categories for the composite indicator of readiness to change among women ............9

Table 3. FGM/C prevalence among women by ethnicity and region, SDHS $2017 \ldots \ldots \ldots \ldots \ldots \ldots \ldots . . . . . . .15$

Table 4. FGM/C prevalence among women by marital status, residence, education, religion

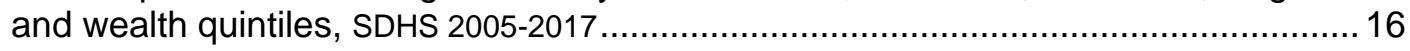

Table 5. FGM/C prevalence among women by beliefs about FGM/C practice, SDHS 2005-2017 17

Table 6. FGM/C prevalence among women by gender norms, decision-making,

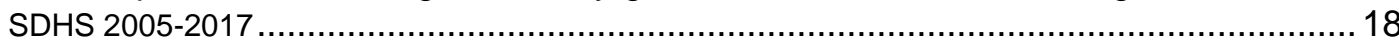

Table 7. FGM/C prevalence among women by employment, earnings, SDHS 2005-2017.......... 19

Table 8. FGM/C prevalence among women by mobility, media exposure, SDHS 2005-2017 .......19

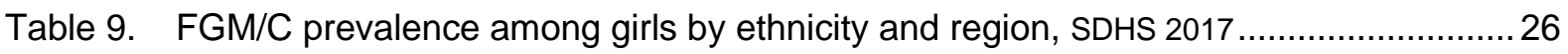

Table 10. FGM/C prevalence among girls by demographic characteristics, SDHS 2005-2017 ......27

Table 11. FGM/C prevalence among girls by mother's FGM/C beliefs, SDHS 2005-2017 ............28

Table 12. FGM/C prevalence among girls by mother's gender norms, SDHS 2005-2017 .............29

Table 13. FGM/C prevalence among girls by mother's employment, earnings, SDHS 2005-2017 .. 30

Table 14. FGM/C prevalence among girls by mother's mobility, media, SDHS 2005-2017 ............30

Table 15. Median age at cutting for women and girls, SDHS 2005-2017 .................................... 31

Table A1. FGM/C questions administered in SDHS 2005-2017 .............................................. 43

Table A2. Trends in FGM/C prevalence among women by demographic data, SDHS 2005-2017.. 45

Table A3. Trends in FGM/C prevalence among girls by demographic data, SDHS 2005-2017 ......47

Table A4. Person who performed cutting on women and girls, SDHS 2005-2017........................ 49

Table A5. Comparison of age at cutting between women and girls, SDHS 2005-2017. ................. 49

Table A6. Type of FGM/C among women and girls, SDHS 2005-2017....................................... 49

Table A7. Regional FGM/C prevalence among women and girls, SDHS 2005-2017.....................50 


\section{Acronyms}

$\begin{array}{ll}\text { DHS } & \text { Demographic and Health Survey } \\ \text { FGM/C } & \text { Female Genital Mutilation/Cutting } \\ \text { FP } & \text { Family Planning } \\ \text { GBV } & \text { Gender-based Violence } \\ \text { IAC } & \text { Inter-African Committee } \\ \text { MICS } & \text { Multiple Indicator Cluster Surveys } \\ \text { NGO } & \text { Non-Governmental Organisations } \\ \text { SDG } & \text { Sustainable Development Goals } \\ \text { SDHS } & \text { Senegal Demographic and Health Survey } \\ \text { UN } & \text { United Nations } \\ \text { UNFPA } & \text { United Nations Population Fund } \\ \text { UNICEF } & \text { United Nations Children's Fund } \\ \text { WHO } & \text { World Health Organisation }\end{array}$




\section{Acknowledgments}

We are grateful to Caroline W. Kabiru, Bettina Shell-Duncan, Cheikh Mbacke Faye, and Jacinta Muteshi for their insightful reviews and comments that enriched this report. Special thanks to ICF Macro for making the Demographic and Health Survey datasets available to us and for always responding to our queries. We are indebted to women and men who voluntarily offered information during implementation of the 2005, 2010-11, 2015, and 2017 Senegal Demographic and Health Surveys. We also wish to thank Robert Pursely for his editorial support. 


\section{Executive Summary}

\section{Background}

To achieve the Sustainable Development Goals, female genital mutilation/cutting (FGM/C) is one of the most prominent issues world leaders and governments must address. In Senegal, the most recent estimates from the 2017 Senegal Demographic and Health Survey (SDHS) show that almost a quarter of women ages 15 to 49 have undergone FGM/C, while 14 percent of girls ages 0 to 14 years are cut. Given the many interventions that have been implemented in Senegal with the intention of scaling down FGM/C rates, the key question is: To what extent has the practice declined? The aim of this study was to generate evidence on where, when, and how FGM/C has been practised in Senegal over the past 13 years.

\section{Methods}

SDHS data from 2005, 2010-11, 2015, and 2017 were used to conduct a detailed analysis on changes in FGM/C prevalence, both nationally and sub-nationally. These surveys are nationally representative and employ a cross-sectional design with two-stage stratified random sampling. This study drew on data on women ages 15 to 49 and mothers' reports for girls ages 0 to 10 years (2010-11 survey) and 0 to 14 years (2005, 2015, and 2017 surveys). The main dependent variable for the analyses was the FGM/C status of women and girls. Demographic and socio-economic factors were the primary independent variables. For each dataset, we applied the DHS standard survey weights to allow for reporting of national estimates. Descriptive survey findings are reported with corresponding weighted denominators for each categorical variable. For average age at cutting, we report the median estimates along with the inter-quartile ranges. All other independent variables are defined as categorical, and findings are reported as frequencies and percentages.

\section{Findings}

Nationally, FGM/C prevalence for both women and girls declined between 2005 and 2010-11, but stagnated from 2010-11 until 2017. Within-country analysis showed significant variations in FGM/C prevalence by geography and socio-demographic characteristics, with some regions of high FGM/C prevalence in early survey years, such as Kolda, experiencing a general decline among both women and girls, while trends in other regions such as Kedougou showed an increase in $\mathrm{FGM} / \mathrm{C}$ rates for both women and girls. The proportion of women and girls who were cut was substantially higher in rural areas in all surveys.

Changes in FGM/C prevalence by ethnicity showed that between 2005 and 2017 the proportion of cut women reduced among the Poular, Soninke, and non-Senegalese, with minimal changes in prevalence among Mandingue and Diola women. Among Poular girls ages 0 to 14, the proportion of girls cut reduced from 2005 to 2010-11, then stagnated from 2010-11 to 2017. Girls of Mandingue ethnicity experienced a decrease in prevalence between 2005 and 2010-11, but it subsequently increased in 2011 and 2017. Notably, in 2017 women and girls from communities traditionally known not to practise FGM/C, such as Wolof and Serer, reported to have been cut in regions of high FGM/C prevalence (Matam, Kedougou, Zuguinchor, and Sedhiou). Other findings indicate a clear association of high FGM/C rates with low levels of education among women and their husbands and partners, Islam adherence, and lower socio-economic status.

Key findings in relation to social norms and beliefs including woman's decision-making power, economic opportunities, mobility, and exposure to mass media show that higher FGM/C prevalence is consistently associated with a woman's belief that $F G M / C$ should continue and that it is required by religion. In all SDHs, higher FGM/C rates are associated with a woman's justification of genderbased violence (GBV), her limited decision-making power, and work in the informal sector, or seasonally, with no compensation. 
The proportion of women in Senegal who want FGM/C to continue reduced only minimally, from 18 percent in 2005 to 15 percent in 2017. Results on readiness to change among cut women show that the percentage of women who support FGM/C's continuation and who had, or planned to, have their daughters cut (willing adherents) reduced from 2005 to 2017. On the other hand, the proportion of women supporting FGM/C's continuation but who would not have it performed on their own daughters (reluctant abandoners), along with women who favour abandonment and who would not have FGM/C performed on their daughters (willing abandoners), increased over the years.

Persons providing FGM/C services are mostly traditional circumcisers, and the majority of mothers and daughters experience forms of FGM/C other than infibulation. Results also reveal intergenerational changes in FGM/C: Most women and girls in Senegal who were cut experienced the procedure before their first birthday, but daughters are now cut at a much younger age than their mothers were.

These findings suggest that FGM/C interventions implemented in the early years (2005 to 201011) may have been more effective for national change than those implemented in later years (from 2011 to 2017). Significant variations in FGM/C prevalence-by geographic zone, sociodemographic characteristics, social norms, and beliefs-demonstrate the need for targeted interventions that are sensitive to the background characteristics of the target population.

\section{Next Steps}

A broader understanding of trends over time, as well as the specific factors responsible for observed changes in FGM/C, especially among girls 0 to 14 years of age, is necessary. We recommend a multivariate regression modelling approach that considers censoring, especially for survey data of girls ages 0 to 14 , and controls for effects of time and geographic location. The next phase of this study will use multivariate geo-additive and survival analysis techniques to develop spatio-temporal models. 


\section{Introduction}

\section{Background}

The World Health Organisation (WHO) defines female genital mutilation/cutting (FGM/C) as all practices that involve the partial or total removal of the external genitalia or other injury to the female organs for non-medical reasons (OHCHR et al 2008, WHO 2016). Globally, communities perform a broad range of practices related to FGM/C. In 1995 and later in 2007, WHO categorised the different types of FGM/C based on more precise anatomical descriptions that include: Type Ialso called clitoridectomy-involves partial or total removal of the clitoris and/or the prepuce; Type II-also called excision-involves partial or total removal of the clitoris and labia minora, with or without excision of the labia majora; Type III-also called infibulation-involves narrowing of the vaginal orifice with the creation of a covering seal by cutting and adhesion of the labia minora or the labia majora, with or without excision of the clitoris; in most instances adhesion is completed by stitching together the cut edges of the labia; and Type IV includes all other harmful procedures to the female genitalia for non-medical purposes, such as pricking, piercing, incising, scraping, and cauterization (OHCHR et al 2008, WHO 2016).

In order to achieve the Sustainable Development Goals (SDGs), FGM/C is included among one of the most prominent issues that world leaders and governments must address. The practice of FGM/C is included in the 2030 SDGs as a form of gender-based violence (GBV), which curtails efforts to achieve gender equality and the empowerment of girls and women-Target 5.3 under SDG 5 focuses on the elimination of all harmful practices, such as child, early and forced marriage as well as FGM/C, by the year 2030 (UN 2015). The impetus for ending this practice was provided by a United Nations (UN) Resolution, when member states agreed to impose a ban on FGM/C in 2012. This global action was informed by growing evidence that the number of women and girls affected by the practice was increasing and that a substantial number of girls were at risk of being cut in many parts of the world (UNICEF 2016).

\section{FGM/C: Global Concern, Statistics, and Practice in Senegal}

An accurate estimate of FGM/C's global prevalence is constrained by a lack of nationallyrepresentative data for all affected countries. National population-based surveys such as Demographic and Health Surveys (DHS) and Multiple Indicator Cluster Surveys (MICS) are not conducted in all countries known to practise FGM/C: There are no data from countries such as Indonesia, India, Pakistan, Oman, Malaysia, Iran, and Colombia, which have traditionally practised FGM/C. In addition, where data exist, and the practice has become illegal, under-reporting is likely (Shell-Duncan et al 2016).

Despite these challenges in estimating FGM/C's global prevalence, analyses of DHS and MICS data show that at least 200 million women and girls in 30 countries have undergone FGM/C (UNICEF 2016). Of these 200 million persons, about 70 million girls age 14 or younger have been cut, or are at risk of being cut (Shell-Duncan et al 2016). Although available data suggest that $\mathrm{FGM} / \mathrm{C}$ is predominantly practised in Africa and the Middle East, FGM/C does not only affect girls and women in these regions, but those in immigrant communities in industrialised countries (Kandala and Komba 2018, Shell-Duncan and Hernlund 2000). FGM/C is a global public health concern.

In 2018, it was estimated that the Republic of Senegal was home to over 16 million people of various ethnic groups, each with its own language, culture, and history (World Population Review 2018). In Senegal, the practice of FGM/C has various names and is commonly referred to as excision in French. FGM/C is generally understood to be practised by certain ethnic groups, with some exceptions, due in part to increasingly common inter-ethnic marriages that are $\mathrm{FGM} / \mathrm{C}$ - 
incongruent. The assumption here is that if one of the partners in the inter-ethnic marriage comes from an ethnic group that does not practise $\mathrm{FGM} / \mathrm{C}$, then there is a possibility of dialogue and contestation of the practice which may lead to abandonment. Ethnic groups that are generally thought not to practise FGM/C include the Wolof and Serer (Mottin-Sylla 1990) who comprise more than half $(58 \%)$ of the total population. FGM/C is most prevalent among the Mandingue/Soce (with $75 \%$ of their female populations cut), followed by the Soninke (63\%), Diola (59\%), and the Poular (49\%) (ANSD/Sénégal and ICF 2018).

The most recent Senegal DHS data (2017) shows that almost one quarter (24\%) of women ages 15 to 49 in the country have undergone FGM/C, while 14 percent of girls 0 to 14 years of age have been subjected to FGM/C (ANSD/Sénégal and ICF 2018). National estimates, however, mask intra-national, or regional, variations. FGM/C varies significantly by region, with southeast Senegal producing the highest rates of women who have been cut, in Kedougou region (where $91 \%$ of women are cut), Sedhiou (76\%), Tambacounda (72\%), Ziguinchor (68\%), and Kolda (64\%). The 2017 SDHS results also indicates that FGM/C is performed upon girls at younger ages-92 percent of women stated that they were cut before age 10, and 80 percent were cut before their fifth birthday.

The practice of $\mathrm{FGM} / \mathrm{C}$ is passed to younger generations as a form of obligation for acceptance and social integration. This inter-generational link and transfer is described by Shell-Duncan and colleagues (2011) as an inter-generational peer convention. FGM/C facilitates entry of younger women into the social network of elder women, guaranteeing access to social support and resources for the younger initiates. Through special networks contacts may be used to access job and business opportunities, families may be relied upon for childcare, and both familial and social contacts relied on for public and social support. These social networks play a critical role in the daily life of the Senegalese, especially in rural areas, for resolving disputes, child-rearing, emergency resources, or employment opportunities.

Older women, established in a community and often wealthier, are crucial in forming networks. To gain entry into these powerful women's networks, young women must offer their deference to older women, which consequently enhances the elders' powers and standing in the community. In the past, when $\mathrm{FGM} / \mathrm{C}$ was frequently performed as a rite of passage to adulthood, FGM/C signalled younger women's readiness to join a network, with the expectation that young inductees would be well-mannered and obedient, subordinate members of the network, upholding a female hierarchy of power (Shell-Duncan et al 2011). Studies show that in the past FGM/C was commonly performed on adolescent girls with lengthy seclusion in the bush, where initiates were trained in moral etiquette and other matters considered important in women's way of life (Shell-Duncan and Hernlund 2000, Shell-Duncan et al 2018). This trend has changed, and now girls are cut individually, at home, with little or no training or celebration involved. In addition, there is a tendency to cut girls at younger ages (Shell-Duncan et al., 2018).

Ethnographic studies have pointed to a multitude of reasons for the practice, related to constructs such as gender ideology, religion, and proper childbearing. Some groups practise FGM/C as a rite of passage that marks transition from childhood to adulthood, but recent trends of performing the procedure at younger ages negate the rationale that the cut signifies a transition to womanhood (Hernlund and Shell-Duncan 2007, Shell-Duncan et al 2010). Several local practising communities have abandoned the ritual celebrations associated with $\mathrm{FGM} / \mathrm{C}$. In contemporary times, it is believed that $\mathrm{FGM} / \mathrm{C}$ is typically conducted to train girls for moral virtues and respect for elders (Shell-Duncan et al 2010). Shell-Duncan et al. (2010) refer to the teaching of girls as "knowing the eye" meaning that they are able to communicate with respect to elders through non-verbal signs; different from uncut girls who are believed to behave in a socially unrefined manner. Apart from the training, elements of the physical cutting are also viewed as essential to the development of 
womanhood. There are myths justifying FGM/C - the clitoris, which is often removed, is considered a "male" tissue that can grow into a penis. The cutting procedure is painful and serves a transformative purpose-pain is viewed as a lesson that prepares initiates to endure suffering and demonstrates strength and maturity to withstand future adversity. Among certain groups, FGM/C is a pre-requisite for legitimate childbearing (Dellenborg 2007).

Across different countries, FGM/C has been associated with religion, especially Islam. Although the Quran does not prescribe FGM/C, and not all Muslims practise FGM/C, Muslims in countries of $F G M / C$ prevalence often link FGM/C with Islam. In Senegal and other similar countries, FGM/C is associated with cleanliness and purification required for religious participation and prayer (ShellDuncan et al 2013). Powerful religious leaders have debated whether FGM/C is a religious requirement. These debates are characterised by divided opinions, resulting in lack of a clear Islamic position on FGM/C. Nevertheless, more Imams are denouncing the link between Islam and $\mathrm{FGM} / \mathrm{C}$, and are being encouraged to declare their stance publicly and lend support to interventions for ending the practice (UNICEF 2010).

Communities that practise $\mathrm{FGM} / \mathrm{C}$ have always associated the practice with their culture. It is crucial to remember that in different communities the cultural meanings of $F G M / C$ are diverse, fluid, and increasingly contested. Cultural meanings are negotiated by various groups in a community who are influenced by local, social, and political movements, as well as national and international interventions, including those encouraging $\mathrm{FGM} / \mathrm{C}$ abandonment. Despite the strong cultural significance attributed to $\mathrm{FGM} / \mathrm{C}$, intense debates on whether $\mathrm{FGM} / \mathrm{C}$ is an outdated custom that should be altered or discarded are common. In Senegal, these debates tend to happen more often among elites in urban areas, but to some extent do occur among relatively poor rural communities (Dellenborg 2007).

\section{Efforts to Accelerate FGM/C Abandonment in Senegal}

Efforts to end FGM/C in Senegal started many years ago, among activists leading both local and international campaigns. The legal context for FGM/C in Senegal has been reviewed by Kandala and Komba (2015) and 28 Too Many (2018). In February 1984, Senegal hosted the first important meeting on FGM/C-a UN-sponsored conference that re-appraised anti-FGM/C policies. The 1984 conference brought together delegates from 20 African nations, and culminated in the formation of the "Inter-African Committee (IAC) on Traditional Practices Affecting the Health of Women and Children." This was a significant step, as one of IAC's primary mandates was to call for governments to actually implement existing national laws that criminalised FGM/C. Despite these developments, only in 1999 did Senegal adopted a criminal law that prohibited FGM/C, by framing it as violation of integrity of the genital organs of women (28 Too Many 2018, Kandala and Komba 2015). This criminal law features a penalty of six months to five years in prison, and when cutting results in death, hard labour for life (Kandala and Komba 2015).

Implementation of Senegal's 1999 anti-FGM/C law resulted in challenges, especially during the first year. In the first year of implementation, only three arrests were reported, and those charges were eventually dropped after emotional public outcries, resulting in no convictions. Implementation proved difficult, forcing the government to make deliberate efforts to promote public acceptance. The government supported a two year awareness and education programme that disseminated information about both the existence and content of the anti-FGM/C legislation. The main challenge with the law as an intervention has always been its limited effects because of the poor rate of prosecution and loopholes in the law itself, especially in terms of failure by the law to address extraterritorial effects. The implementation of the law against FGM/C in Senegal has therefore remained limited and has resulted in instigating a climate of fear of criminal sanctions and allowing the practice to be undertaken secretly. Nevertheless, the law is necessary because it creates a 
structural framework within which the government can officially sanction matters related to $F G M / C$, and legitimises anti-FGM/C campaigns and interventions (Kandala and Komba 2015).

Research related to the anti-FGM/C law reveals that most people are unaware of its specific contents and legal provisions, but the law is widely seen as legitimate and potentially enforceable (Shell-Duncan et al., 2013). It is important to note that respondents' readiness for change plays a significant role in determining whether people think that the law is powerful and enforceable. For those in support of the continuation of $\mathrm{FGM} / \mathrm{C}$, local norms supporting the practice are more powerful than the legal restriction. For those who are actively questioning or opposed to the continuation of $\mathrm{FGM} / \mathrm{C}$, the legal ban emboldens them to oppose the practice. Research also shows that legal reform efforts work in a complementary fashion with ongoing programmes aimed at accelerating the abandonment of FGM/C in Senegal (Shell-Duncan et al., 2010; Shell-Duncan et al., 2013).

In addition to enacting and implementing the anti-FGM/C law, the Senegalese government has ratified all international instruments requiring governments to work for the abandonment of FGM/C. The National Action Plan 2001-2005 articulated how the Senegalese government intended to achieve total FGM/C abandonment by 2015 , with key objectives including improved networking and coordination among stakeholders, awareness campaigns for the law, and integrating FGM/C issues within formal and non-formal education efforts. An evaluation of this action plan in 2008 revealed that its key objectives were partially achieved (Diop-Diagne 2008). Achievements included successful non-formal education efforts that raised awareness about FGM/C and enforcement of the law. The evaluation also revealed deficiencies, particularly in coordinated measures by the state, civil society, and other FGM/C stakeholders (Diop-Diagne 2008). The second National Action Plan 2010-2015, adopted in 2010, continued the government's commitment to ending FGM/C by devising a multi-faceted approach for accelerating change within communities, encouraging community-led and human rights-based approaches (UNICEF 2010). Media reports in 2016 indicated that the United Nations Population Fund (UNFPA) had announced plans for the creation of a common plan of action for Senegal and The Gambia.

Various media campaigns and interventions sponsored by non-governmental organisations (NGOs) have been implemented in Senegal. The Community Empowerment Program developed by the NGO Tostan received substantial coverage, attention, and evaluation. Tostan's focus corresponds with key aspects of social convention theory (Diop and Askew 2009, UNICEF 2010). Tostan began its work in Senegal in 1991 with its activities originally anchored on a literacy-based curriculum that focused on problem solving, health, and management. This approach was later reviewed in 1995 by Tostan's education team and consequently, modules on democracy and human rights were added. The rationale for the review and subsequent addition of these modules was to enable participants to link their new knowledge to social action (Tostan, 1999). The updated approach bore results and led to the first public declaration to abandon FGM/C in 1997 (UNICEF 2008). Revisions in the curriculum between 1995 and 2003 eventually resulted in a 30 month, nonformal education programme with modules on democracy and human rights, problem solving, hygiene and health, literacy, math, and management skills. Programme implementation targeted both adolescents and adults, with activities grounded in the theory of social norms (Tostan 1999). A 2008 evaluation of the Tostan programme in Kolda, Thiès, and Fatick regions revealed decreases in FGM/C prevalence in both Tostan programme communities, in addition to those that participated in the declaration but did not receive training. FGM/C prevalence among girls nine years of age and younger was 15 percent in Tostan programme communities, and eight percent in communities that only took part in a declaration, but was 47 percent in control villages (UNICEF 2008). 
Other small scale projects in Senegal use non-formal education to encourage community abandonment of FGM/C. The Girls' Holistic Development Project (Développement Holistiques des Filles Project) worked with World Vision (Musoko et al 2012) from 2008 to 2011 in Kolda's Velingara area to adopt the methodology of the Grandmother Project, which actively involves grandmothers as resource persons for changing social norms. This is done through strengthening intergenerational communications and using communication methods that foster critical reflection on cultural practices that influence the well-being of girls. The project used community dialogues and intergenerational communication networks to promote positive cultural values and traditions. The approach was also used to discourage harmful practices such as early marriage, corporal punishment, teen pregnancy, and FGM/C. A project evaluation showed positive changes in reported ideal marriage age, parents preferring for daughters to marry later, strengthened familial cohesion, and reduced teen pregnancy risk (Musoko et al 2012).

A recent situation analysis of FGM/C stakeholders and interventions in Senegal by Kandala and colleagues (unpublished report) provides insights into current interventions and stakeholders focused on ending $\mathrm{FGM} / \mathrm{C}$. The analysis found that Senegal has an enabling legal and policy environment conducive to ending all forms of $\mathrm{FGM} / \mathrm{C}$ but is limited by enforcement challenges. Notable organisations leading FGM/C interventions in Senegal include not only Tostan but those supported by the United Nations Children's Fund (UNICEF) and UNFPA. Besides Tostan, no other NGOs have been independently assessed. The situational analysis concluded that there was no significant evidence of whether the approaches of the various organisations have been effective towards FGM/C abandonment in Senegal (Kandala et al unpublished report).

\section{Study Rationale}

Evaluations of some of the interventions by the Senegalese government and NGOs to accelerate FGM/C abandonment reveal progress as well as deficiencies that need to be addressed to ensure total abandonment (Diop and Askew 2009, UNICEF 2008). Since the passage of the UN Resolution banning FGM/C, efforts have been accelerated in Senegal, and given the human and financial resources mobilised, the key question is: To what extent has the practice been declining? Studies have examined the socio-demographic factors of FGM/C prevalence in Senegal (Hernlund and Shell-Duncan 2007, Kandala and Komba 2015, Shell-Duncan et al 2011), but there is a paucity of detailed examination of the successive surveys featuring data on $\mathrm{FGM} / \mathrm{C}$ prevalence and trends in Senegal. Such detailed analyses are important for policy and FGM/C programming, as they generate evidence of the locations, times, and manners in which FGM/C is performed. Importantly, analyses that consider social norms, women's decision-making power, and women's mobility are rare and yet understanding these factors in the context of FGM/C is key in designing effective interventions to facilitate total abandonment.

In 2015, the Population Council began a large research programme, Evidence to End Female Genital Mutilation/Cutting: Research to Help Girls and Women Thrive, analysing contextual data to address FGM/C evidence needs, and the fragmented nature of existing evidence. National surveys such as DHS and MICS provide valuable information on the circumstances of FGM/C, including age at which a girl or woman undergoes it, FGM/C type, and individual performing it. This Descriptive Analysis of Senegal Demographic and Health Surveys, 2005-2017, employs data from four surveys over a decade to investigate changes in FGM/C prevalence, both nationally and subnationally within Senegal, and important socio-demographic factors.

\section{Study Aims and Objectives}

The aim of this study was to generate evidence on where, when, and how FGM/C is practised in Senegal. To achieve this aim, we conducted a detailed analysis on changes in FGM/C prevalence both at national and sub-national levels with a keen interest in trends across the different socio- 
demographic segments as well as exposure to social norms. The specific objectives of the study included the following:

1) Examine changes over time in the national prevalence of $F G M / C$ among women aged 1549 years and girls aged $0-14$ years;

2) Consider variation in prevalence by geopolitical zones (regions, urban-rural residence) and socio-demographic segments (age, religion, ethnicity, education, wealth);

3) Investigate differences in prevalence by social norms and beliefs, decision-making power within the household, women's opportunities, mobility, and exposure to mass media; and

4) Explore intergenerational patterns in the age at cutting, types of $F G M / C$, and persons performing $\mathrm{FGM} / \mathrm{C}$ for women aged 15-49 years and girls aged 0-14 years.

\section{Methods}

\section{Data}

This study utilises secondary data from 2005, 2010-11, 2015, and 2017 Senegal Demographic and Health Surveys (SDHS), which are accessible through ICF Macro. These nationally representative surveys feature a cross-sectional design with two stage stratified random sampling. Each survey's design, organisation, sampling design and size, questionnaires, and implementation procedures are described in their respective reports (ANSD/Sénégal and ICF 2016, 2018, ANSD/Sénégal and International 2012, Ndiaye and Ayad 2006). SDHS provide information on population health with specific interest in fertility, childhood mortality, family planning (FP) use, and maternal and child health $(\mathrm{MCH})$ indicators, including HIV/AIDS and GBV. This study utilised data on women ages 15 to 49 and mothers' reports of girls ages 0 to 10 (2010-11 survey) and 0 to $14(2005,2015,2017)$.

Table 1. Sample sizes of women and girls*, Senegal DHS 2005-2017

\begin{tabular}{|l|cc|}
\hline Year & Women Ages $\mathbf{1 5}$ to $\mathbf{4 9}$ & Girls Ages $\mathbf{0}$ to $\mathbf{1 4}$ \\
2005 DHS & 14,602 & 11,878 \\
$2010-11$ DHS & 15,688 & 9,740 \\
2015 DHS & 8,851 & 7,529 \\
2017 DHS & 16,787 & 14,008 \\
\hline
\end{tabular}

*In the 2005 SDHS, FGM/C questions were asked about most recently cut daughters of any age; for this analysis, sample size is limited to most recently cut girls ages 0-14. In the 2010-11 SDHS, FGM/C questions were asked of all daughters ages 0-10. In the 2015 and 2017 SDHS, FGM/C questions were asked for all daughters ages 0-14.

To examine changes in FGM/C prevalence in Senegal, we focused on two age cohorts: women ages 15 to 49 years and girls ages 0 to 14. All surveys included modules on FGM/C questions (see Appendix Table A1 for details). Data on FGM/C prevalence were obtained via self-reports of women of reproductive age (15 to 49 years). Data about girls ages 0 to 14 were obtained by asking mothers about the FGM/C status of their living daughters. In calculating prevalence, the inclusion criteria were all female respondents ages 15 to 49 and their daughters ages 0 to 14 .

\section{FGM/C Modules and Variables in Senegal Demographic and Health Surveys}

There have been changes in the FGM/C module administered in the various SDHS. Following standardisation of the FGM/C module, the 2010-11, 2015, and 2017 surveys contain more data and variables relevant to FGM/C compared to earlier surveys (see Appendix Table A1). The main 
dependent variable for this analysis relates to the FGM/C status of women and girls. Demographic and socio-economic factors are the independent variables and were selected based on their availability in the four datasets.

The main independent variables considered are women's age, marital status, ethnicity, education, region of residence, urban or rural residence, religion, and wealth index. Given the importance of social norms, power dynamics, mobility, and media exposure with FGM/C (Cislaghi et al 2016, Mackie and LeJeune 2009, Shell-Duncan et al 2018, 2011), proxy variables measured a woman's exposure to social norms and beliefs about FGM/C, her employment and earning status, mobility, and mass media exposure. Other secondary outcome variables considered were: those who perform FGM/C, type of FGM/C, age at cutting for both a woman and her daughters, and woman's attitude about continuation or discontinuation of FGM/C. To assess the FGM/C statuses of girls ages 0 to 14 , information from the daughter's birth history was used, with analysis restricted to daughters whose mothers responded to the $\mathrm{FGM} / \mathrm{C}$ module questions in the datasets of women.

Acknowledging that people often do not make decisions in isolation, and that FGM/C decisions are influenced by social norms (Gruenbaum 2001), Shell-Duncan and Hernlund's (2006) approach was used to compute a composite indicator of readiness to change among women ages 15 to 49 . The categories of change are charted in Table 2.

Table 2. Categories of composite indicator of readiness to change among women ages 15 to 49

\begin{tabular}{|c|c|c|c|c|}
\hline & \multicolumn{3}{|c|}{ FUTURE ACTION PLAN FOR THEIR DAUGHTERS } \\
\hline & & $\begin{array}{c}\text { DAUGHTERS CUTI } \\
\text { WILL PERFORM FGM } \\
\text { ON THEIR } \\
\text { DAUGHTERS } \\
\end{array}$ & $\begin{array}{l}\text { UNDECIDED } \\
\text { ON THEIR PLAN }\end{array}$ & $\begin{array}{l}\text { DAUGHTERS NOT CUT/ } \\
\text { WILL NOT PERFORM } \\
\text { FGM/C ON THEIR } \\
\text { DAUGHTERS } \\
\end{array}$ \\
\hline \multirow{3}{*}{$\begin{array}{l}\text { 岂 } \\
\text { 岃 } \\
\text { 岃 } \\
\text { 㟧 }\end{array}$} & $\begin{array}{l}\text { CONTINUATION } \\
\text { OF FGM/C }\end{array}$ & $\begin{array}{c}\text { Willing } \\
\text { Adherents }\end{array}$ & \multirow{3}{*}{ Contemplators } & \multirow[t]{2}{*}{ Reluctant Abandoners } \\
\hline & $\begin{array}{l}\text { UNDECIDED/ } \\
\text { NO PREFERENCE }\end{array}$ & & & \\
\hline & $\begin{array}{l}\text { DISCONTINUE/ } \\
\text { STOP FGM }\end{array}$ & $\begin{array}{l}\text { Reluctant } \\
\text { Adherents }\end{array}$ & & $\begin{array}{c}\text { Willing } \\
\text { Abandoners }\end{array}$ \\
\hline
\end{tabular}

As depicted in Table 2, "Willing Adherents are women who support FGM/C's continuation and have had, or will have, their daughters cut; Contemplators are undecided about their preferences and future of their daughters in relation to FGM/C; Reluctant Adherents who oppose FGM/C's continuation but who have had, or will have, FGM/C performed on their daughters; Reluctant Abandoners are women who prefer FGM/C to continue but who will not have it performed on their daughters; and Willing Abandoners are women who favour stopping FGM/C and will not have it performed on their daughters.

\section{Considerations}

It is important to note that there are differences in the way $F G M / C$ data for daughters were collected. During the 2005 survey, women were asked to provide information about the most recently cut daughter of any age, in the 2010-11 survey the FGM/C questions were asked for all daughters 0 to 10 years old, while in the 2015 and 2017 surveys women were asked about the $\mathrm{FGM} / \mathrm{C}$ status of all daughters 0 to 14 years of age. The observed differences in the way FGM/C data for daughters were collected have implications especially in interpreting changes in $\mathrm{FGM} / \mathrm{C}$ prevalence across surveys. Therefore, our study findings should be interpreted considering the 
changes in the FGM/C modules over the years and their subsequent impact on the size of extracted data for daughters and consistency of variables across surveys.

The underlying assumption in the pre-2010 survey data has always been that the sample of eldest or most recently cut daughter is an underestimation of prevalence of all the girls. This assumption implies that the selected woman's eldest or most recently cut daughters are not representative of all the daughters. Mothers are assumed to have had several daughters, but data were collected only on the eldest or the most recently cut daughter, not all of her daughters. To our knowledge, this assumption has not been examined empirically using DHS data. If justified, the assumption would mean that all surveys prior to 2010 would have underestimated the true FGM/C prevalence among girls. However, after close analysis of the pre-2010 surveys in Senegal, we found FGM/C prevalence before 2010 to be higher than subsequent surveys (see Figure 11 below) suggesting that there is no underestimation of $\mathrm{FGM} / \mathrm{C}$ prevalence before the 2010 harmonisation of the module in Senegal. Since the DHS uses multi-stage cluster sampling, it may well be that the selected sample of eldest daughter/most recently cut daughter was a representative sample of the study population. That said, it must be observed that the changes in the FGM/C module overtime have improved in detail and clarity in the way questions are asked and therefore provide more reliable estimates in the recent surveys. Notably, where there are data, and the practice has become illegal, there may be underreporting.

Kaffrine, Kedougou, and Sedhiou regions were created in 2008 and therefore the 2005 DHS does not have specific data for these regions. These regions were part of larger regions prior to 2008 (e.g. Kaffrine region was originally part of Kaolack region, Kedougou region was part of Tambacounda, and Sedhiou region was historically part of Kolda).

Another consideration relates to girls' current and future FGM/C status. SDHS collects information on current FGM/C status of daughters, which could be different from final FGM/C status: A girl who is not cut at the time of the survey may still be cut in the future. Consequently, caution needs to be exercised when comparing FGM/C prevalence for girls ages 0 to 14 among the different surveys. This limitation can be addressed statistically through censoring-an approach used in this study by adopting survival analysis methods. Kaplan-Meier survival curves allow for censoring of daughter data (right censored), as daughters may still be at risk of FGM/C after the interview.

\section{Computation and Analysis}

Demographic and Health Surveys are hierarchal, with a two-stage stratified random sampling design. This descriptive analysis used the survey weights to ensure estimates reflect the actual population size captured in the various surveys. For each dataset, we applied the DHS standard survey weights to allow for reporting national estimates using the svy command in STATA. Descriptive survey findings are reported with corresponding weighted denominators for each categorical variable. For average age at cutting, for women ages 15 to 49 and girls ages 0 to 14 , we report the median estimates along with inter-quartile ranges. All other independent variables are defined as categorical, and findings are reported as frequencies and percentages.

This study also reports the statistical significance of observed variations in FGM/C prevalence in both mothers and girls, using all indicators considered. Significance testing of association between different socio-demographic factors and FGM/C status in women and girls was assessed using the Chi-Square Test for independence at five percent level of significance ( $P$-value $<0.05$ indicates a significant test). All analyses used STATA version 13. 


\section{Results}

Findings on where, when, and how FGM/C is practised in Senegal are presented in this section. National changes in prevalence of FGM/C among women ages 15 to 49 are presented first followed by findings for girls ages 0 to 14. This section highlights variations in FGM/C prevalence by region, urban and rural residence, and socio-demographic characteristics. Differences in $\mathrm{FGM} / \mathrm{C}$ prevalence by social norms and beliefs, woman's opportunities, decision-making power, women's mobility, and exposure to mass media are also presented. The results section also covers intergenerational changes in $\mathrm{FGM} / \mathrm{C}$ practice by comparing data for women ages 15 to 49 and girls ages 0 to 14 with reference to the age at cutting, types of $F G M / C$, and persons performing $F G M / C$. Detailed results of the various analyses are presented in the Appendix (see Tables A2-A7).

\section{FGM/C Among Women 15 to 49 Years of Age}

\section{National prevalence among women}

To understand trends in FGM/C prevalence among women ages 15 to 49, national prevalence rates were compared for successive surveys, and used the age-cohort approach to examine prevalence rates across the different age groups. As shown in Figure 1, the first approach compares national rates of FGM/C in women across four successive surveys from 2005 to 2017. The latest DHS data shows that FGM/C prevalence among women at national level was 24 percent in 2017. There was a four-percentage point decline in prevalence between 2005 (28\%) and 2017 (24\%). Looking at declines between surveys shows that the biggest drop is between 2005 and 2010-11 (2.5 percentage points), and then smaller declines between successive rounds (1.5\%, and $0.2 \%)$.

Figure 1. National FGM/C prevalence among women ages 15 to 49, SDHS 2005-2017

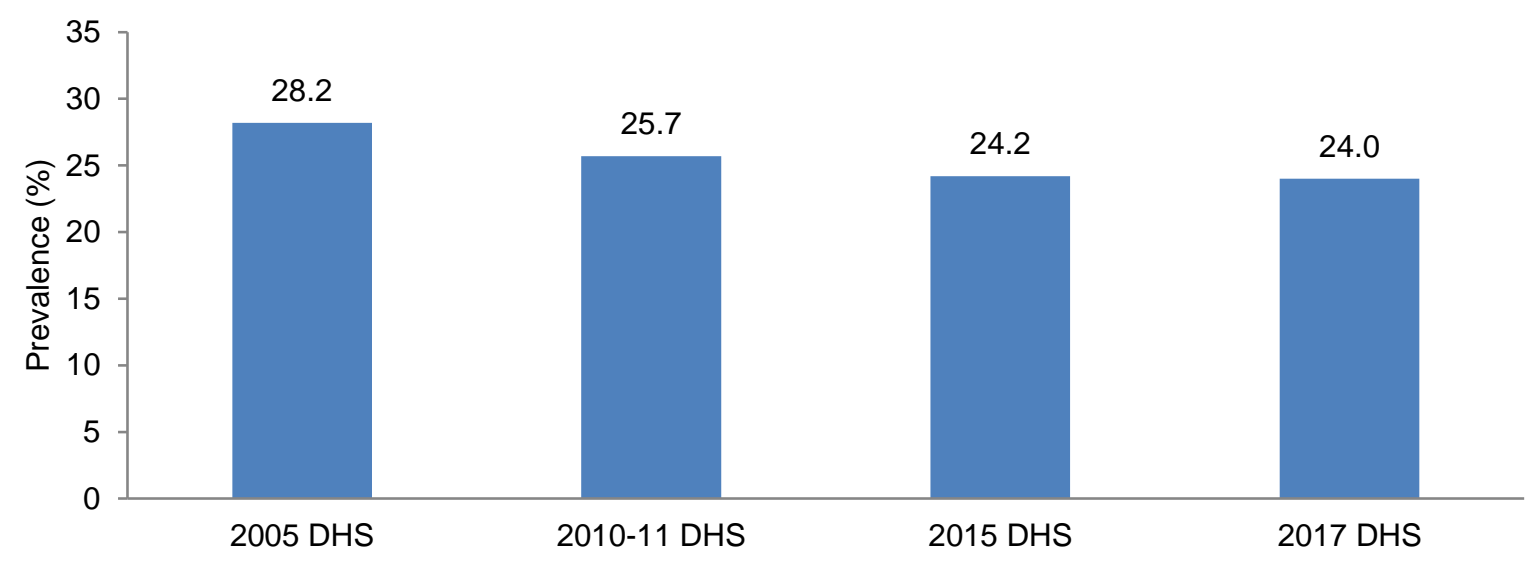

Comparing national prevalence across survey years is the simplest method of tracking change in FGM/C but this approach masks important variability along lines of age, geographical regions, urban-rural, and socio-demographic characteristics. It is therefore critical that more refined approaches that offer detailed analysis are used in tracking changes over time. The age-cohort approach offers more insight especially on the timing of change. This approach involves categorising surveyed women into 5-year age cohorts, and calculating prevalence for each cohort (Shell-Duncan et al., 2017). It is then possible to spot where a decline in the prevalence of FGM/C first began. As shown in Figure 2, in the 2005 and 2017 surveys FGM/C prevalence appears steady in the eldest age cohorts, with a general minimal decline in prevalence among the younger age cohorts. To estimate when the minimal decline in the prevalence of FGM/C first began, it is important to consider age at time of cutting. If the median age at cutting in Senegal is before one 
year of age, the changes that first appeared in the 25 to 29 year old cohort in 2005 occurred 24 to 28 years before the survey was conducted, in the late 1970 s or early 1980 s.

Figure 2. FGM/C prevalence among women, by age group, SDHS 2005-2017

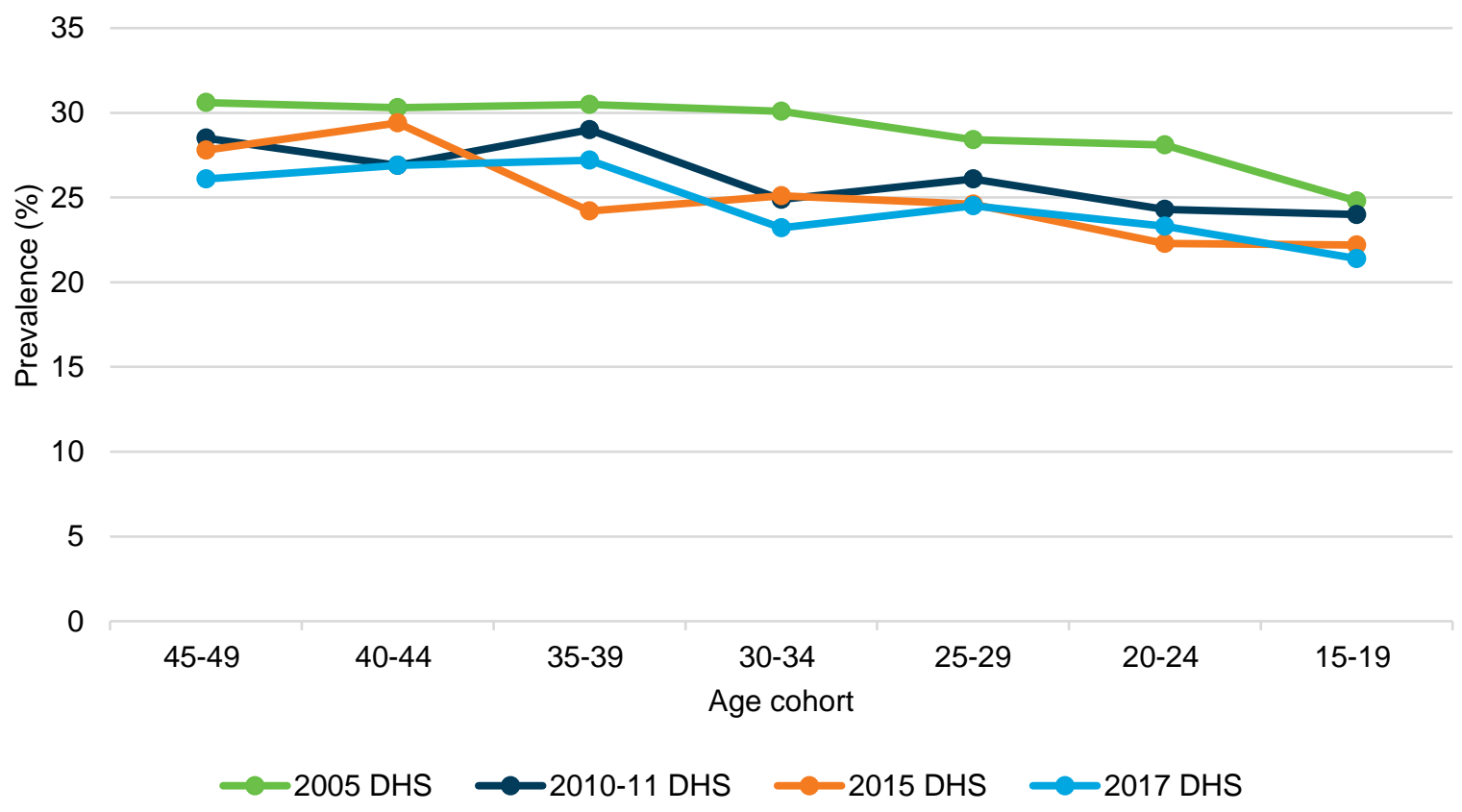

\section{Regional prevalence}

Findings show significant regional differences in FGM/C prevalence within Senegal. In 2005, regions with the highest prevalence were Kolda (94\%), Matam (93\%), and Tambacounda (86\%), while Diourbel and Lounga each had an FGM/C prevalence of less than five percent.

Figure 3. FGM/C prevalence among women, by region, SDHS 2005-2017

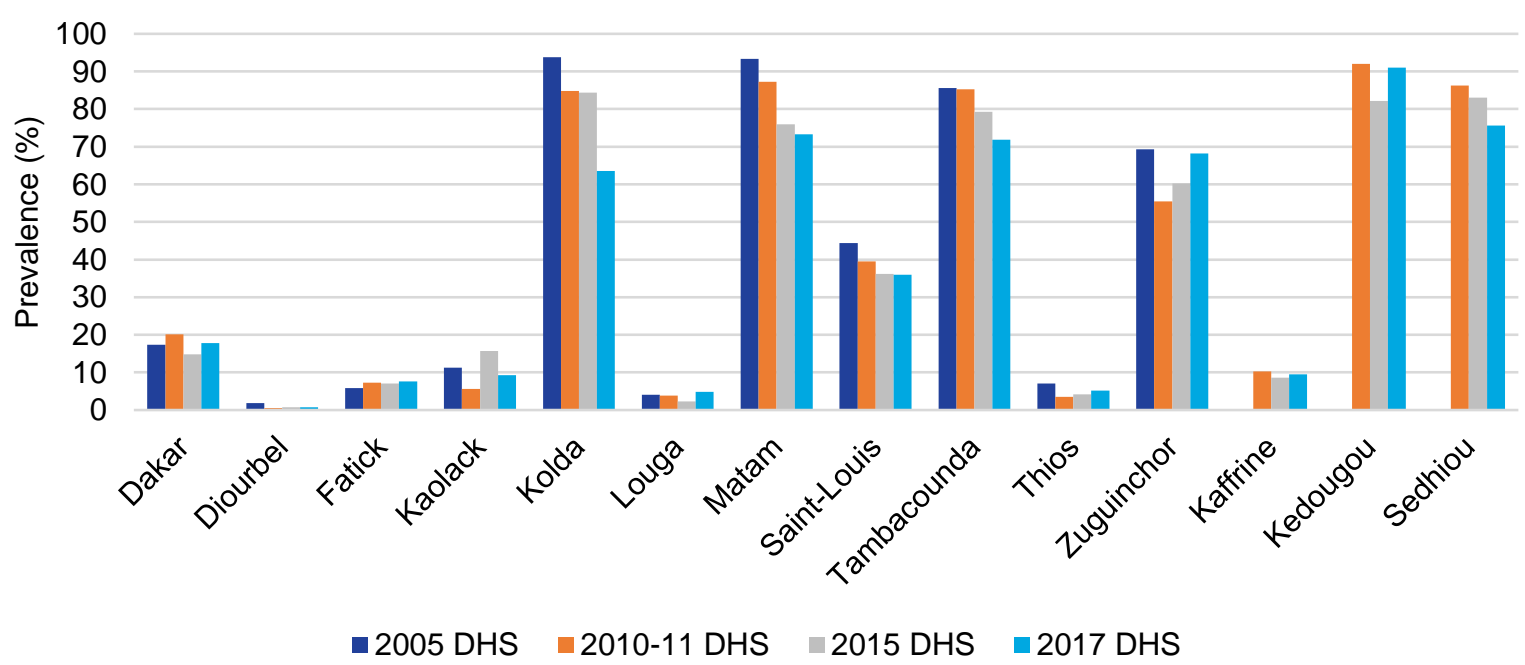

In 2005, Kaffrine region was part of Kaolack region, Kedougou was in Tambacounda region, and Sedhiou was in Kolda.

From 2005 to 2017, there were notable regional changes in proportions of women who were cut. Data show clear declines in prevalence in four regions: Kolda (94\% in 2005 to $64 \%$ in 2017), Matam (93\% in 2005 to $73 \%$ in 2017), Tambacounda (86\% in 2005 to $72 \%$ in 2017 ), and Sedhiou (86\% in 2010-11 to 75\% in 2017). In Zuguinchor region, prevalence declined from 69 percent in 2005 to 56 
percent in 2010-11, then increased to 60 percent in 2015 and 69 percent in 2017; and in Kedougou, prevalence fell from 92 percent in 2010-11 to 82 percent in 2015 but rose to 91 percent in 2017.

\section{Figure 4. Regional evolution of FGM/C prevalence among women, SDHS 2005-2017}
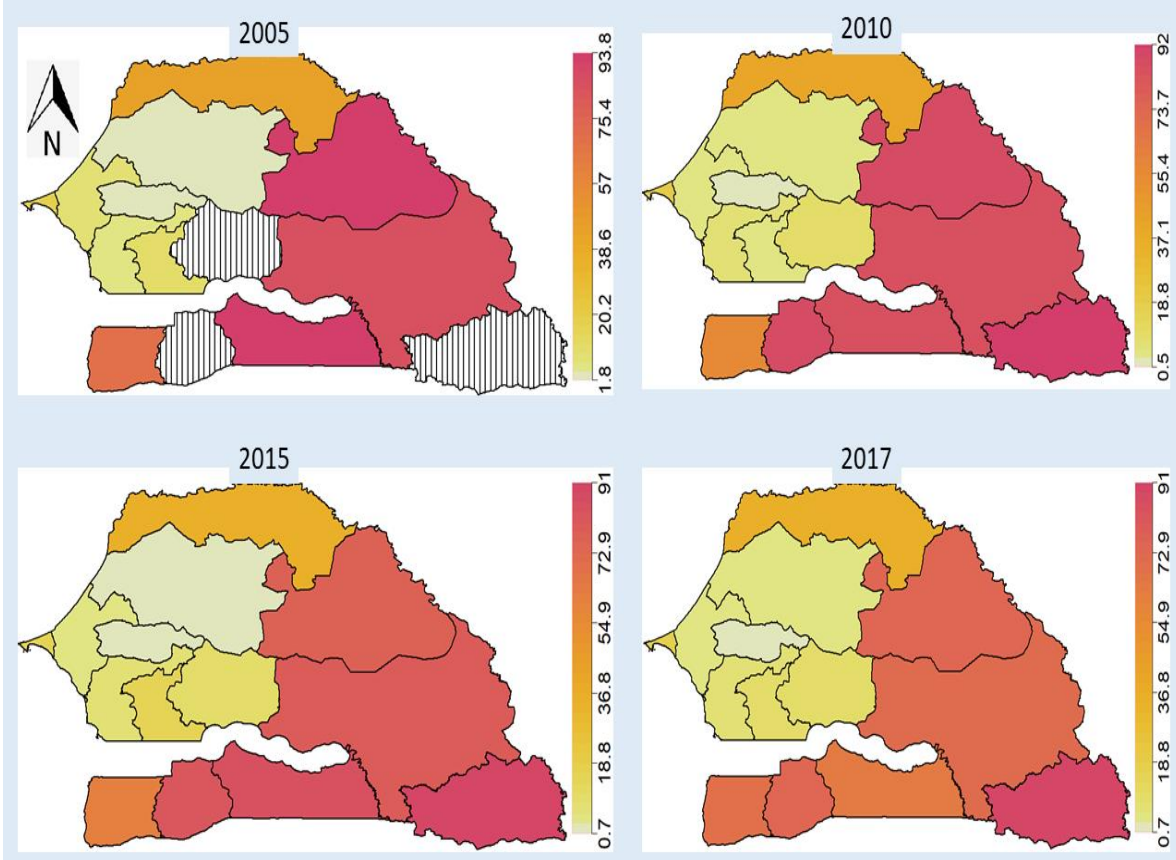

Darker red indicates higher prevalence. In 2005, Kaffrine region was in Kaolack region, Kedougou was in Tambacounda, and Sedhiou was in Kolda. In the 2005 map the three regions are presented in black and white stripes.

\section{Prevalence according to urban or rural residence}

Women living in rural areas are at a significantly higher risk of FGM/C. From 2005 through 2017, the proportion of women who were cut is substantially higher in rural areas.

Figure 5. FGM/C prevalence among women, by residence, SDHS 2005-2017

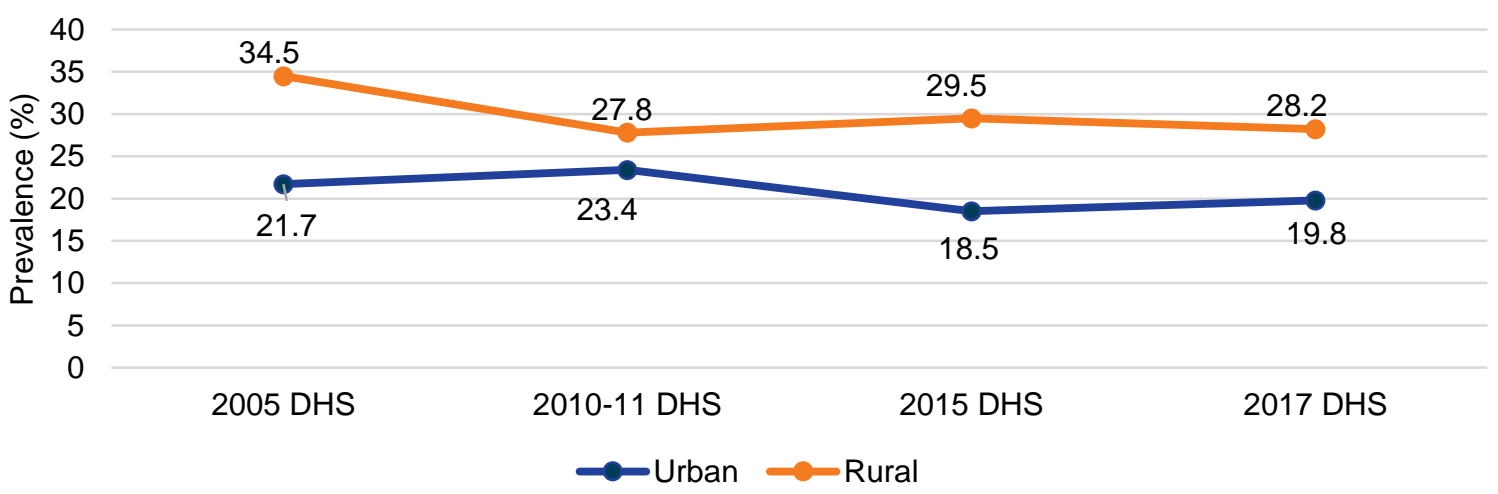

\section{Prevalence by ethnic group}

The practice of $\mathrm{FGM} / \mathrm{C}$ has long been associated with ethnic identity, signalling mutual expectations among community members. Ethnicity represents shared norms within a reference group for various aspects of shared values such as marriageability, sexual restraint, initiation into adulthood, among others (Gruenbaum 2001). SDHS findings show substantial FGM/C prevalence variance by ethnicity (Figure 6). In 2005 prevalence ranged from less than two percent among women of Wolof and Serer ethnic groups to as high as 78 percent among Soninke women. Over 
the years, there has been notable variations in FGM/C prevalence within ethnic groups. Between 2005 and 2017, the proportion of cut women reduced among the Poular (62\% in 2005 to $49 \%$ in 2017), Soninke (78\% in 2005 to $63 \%$ in 2017), and non-Senegalese (71\% in 2005 to $29 \%$ in 2017). There were minimal changes in FGM/C prevalence among women of Mandingue and Diola ethnic groups. Interestingly, minimal decreases in prevalence were experienced between 2005-2015 among other Senegalese women, but the proportion almost doubled from 31 percent in 2015 to 60 percent in 2017.

Figure 6. FGM/C prevalence among women, by ethnicity, SDHS 2005-2017

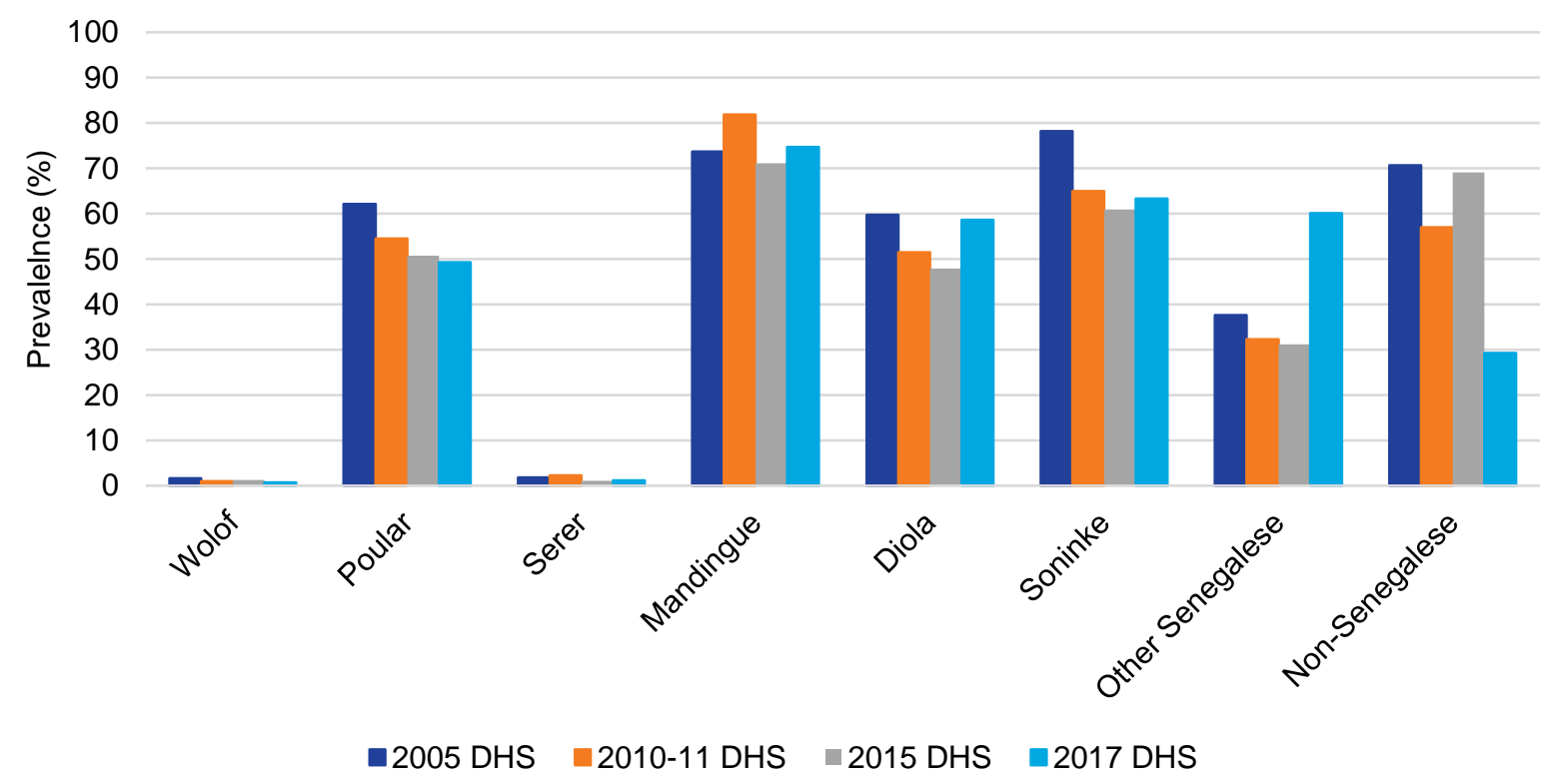

Dis-aggregating FGM/C prevalence by ethnicity for women ages 15 to 49, in five year age cohorts using data from the most recent survey (SDHS 2017), offers more insight on the timing of observed changes, specifically variations in FGM/C rates among different age cohorts of women. Age cohorts were plotted beginning with the oldest cohort of 45 to 49 (who experienced FGM/C earlier than the youngest cohort), to see any changes in prevalence over the years. Figure 7 shows variations in FGM/C declines among different age cohorts of various ethnic groups in Senegal. FGM/C prevalence remains high among ethnic Mandingue women, but may have just begun to drop among the youngest, 15 to 19 year old, cohort. FGM/C prevalence is high in older cohorts of Soninke and Poular women but appears to have declined among the middle age cohort (age 30 to 34), and stagnated among younger age cohorts. Remarkably, there was a steady increase in $\mathrm{FGM} / \mathrm{C}$ prevalence in the older cohorts of non-Senegalese women, from 56 percent (age 45 to 49) to 75 percent (age 25 to 29), which then declined in the youngest age cohorts. FGM/C prevalence among Other Senegalese ethnic groups appear to have declined in the middle age cohort (age 30 to 34) and stagnated among the younger age cohorts. 
Figure 7. FGM/C prevalence among women, by age cohort and ethnicity, SDHS 2017

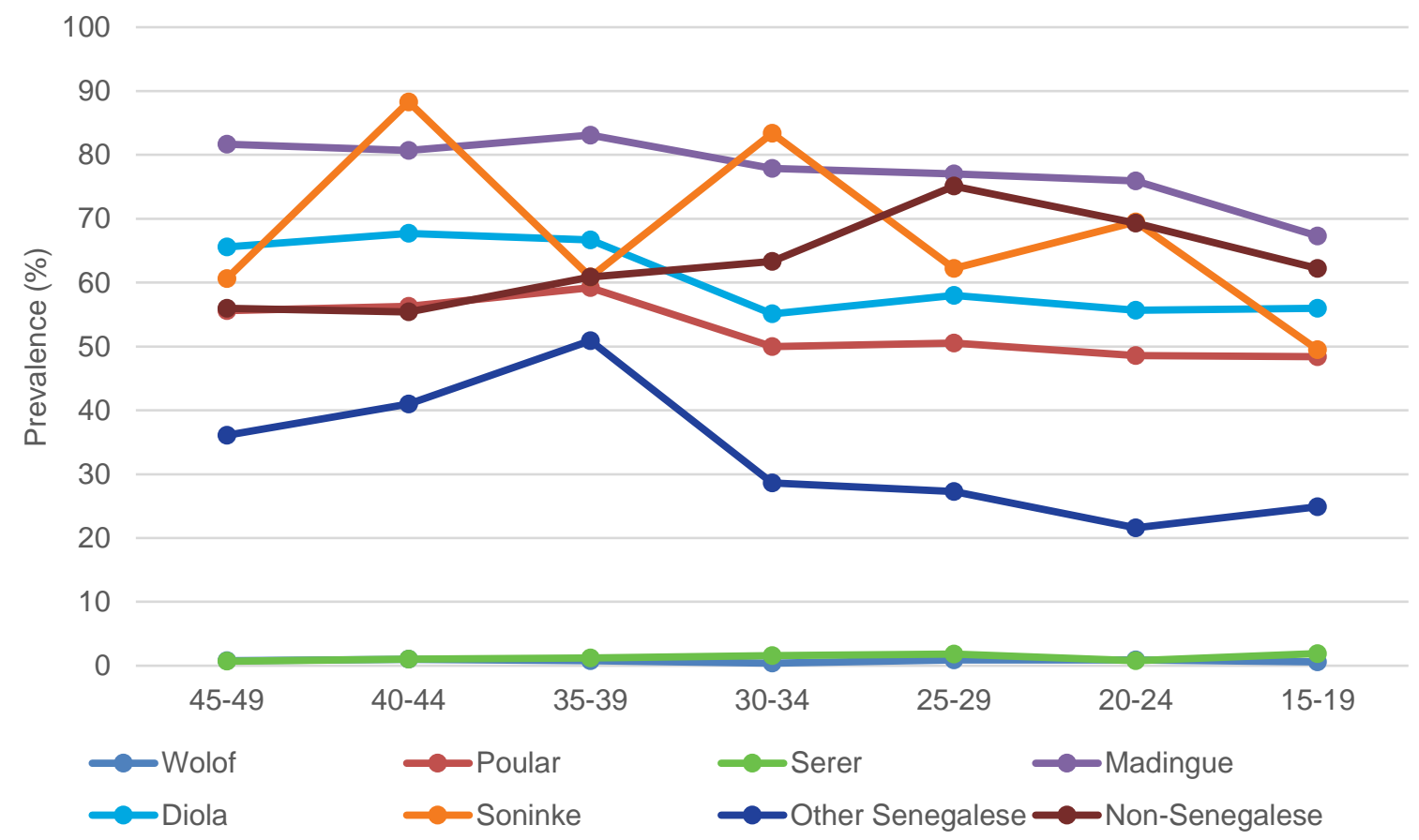

Sub-dividing FGM/C prevalence data by ethnicity and region for women ages 15 to 49 reveals important information on the geographic locations and ethnic identities of women who practise FGM/C. Table 3 shows that in 2017, the highest proportion of women cut were from the Mandingue ethnic group (76\%) mainly inhabiting Louga, Matam, Sedhiou, Kedougou, and Zuguinchor regions, where $\mathrm{FGM} / \mathrm{C}$ is almost universally practised. Other ethnic groups with high $\mathrm{FGM} / \mathrm{C}$ prevalence include other Senegalese (65\%), who live mainly in Kedougou and Tambacounda regions, Soninke (65\%) inhabiting Zuguinchor, Sedhiou, and Tambacounda regions, Diola (60\%) inhabiting Kedougou and Sedhiou regions, and the Poular (52\%) of Kedougou, Sedhiou, Zuguinchor, and Tambacounda regions. Notably, regions of high FGM/C prevalence also have high prevalences of FGM/C among women from communities traditionally known not to practise FGM/C, such as the Wolof and Serer. FGM/C prevalence among Wolof women was high in Matam (38\%), Kedougou (33\%), and Zuguinchor (23\%) regions compared to national prevalence of 0.8 percent for Wolof women. National FGM/C prevalence for women of Serer ethnicity was 1.4 percent, but prevalences were higher among Serer women living in Zuguinchor (52\%) and Kolda (41\%) regions.

Table 3. FGM/C prevalence among women, by ethnicity and region, SDHS 2017

\begin{tabular}{|c|c|c|c|c|c|c|c|c|c|}
\hline \multirow[b]{2}{*}{ Region } & \multicolumn{8}{|c|}{ Mother's Ethnicity } & \multirow{2}{*}{$\begin{array}{c}\text { Total } \\
\text { FGM/C } \\
\text { Prevalence }\end{array}$} \\
\hline & Wolof & Poular & Serer & Mandingue & Diola & Soninke & \begin{tabular}{|c|} 
Non- \\
Senegalese
\end{tabular} & $\begin{array}{c}\text { Other } \\
\text { Senegalese }\end{array}$ & \\
\hline Dakar & 0.3 & 32.7 & 1.5 & 58.2 & 54.5 & 41.5 & 21.7 & 69.0 & 18.2 \\
\hline Diourbel & 0.1 & 3.7 & 0.0 & 26.8 & 16.6 & 0.0 & 5.0 & - & 0.7 \\
\hline Fatick & 0.0 & 22.4 & 1.8 & 79.4 & 46.5 & 24.4 & 20.9 & 47.5 & 8.5 \\
\hline Kaolack & 1.0 & 20.1 & 0.0 & 55.3 & 33.3 & 33.5 & 39.2 & 62.0 & 10.5 \\
\hline Kolda & 7.9 & 78.5 & 40.5 & 76.3 & 45.2 & 88.6 & 56.0 & 48.0 & 64.9 \\
\hline Louga & 0.6 & 16.7 & 0.0 & 100.0 & 0.0 & & 0.0 & 27.4 & 5.3 \\
\hline Matam & 38.3 & 79.4 & 16.4 & 100.0 & - & 55.2 & 58.2 & 61.5 & 76.6 \\
\hline Saint-Louis & 0.2 & 64.2 & 6.8 & 14.2 & 62.7 & 19.6 & 17.0 & 54.6 & 37.1 \\
\hline Tambacounda & 4.3 & 80.8 & 9.7 & 83.9 & 47.5 & 90.7 & 64.8 & 88.8 & 72.9 \\
\hline Thios & 0.6 & 11.9 & 0.2 & 55.3 & 31.6 & 28.4 & 16.7 & 43.7 & 5.6 \\
\hline Zuguinchor & 22.9 & 82.3 & 51.6 & 92.8 & 69.5 & 100.0 & 51.6 & 65.5 & 70.1 \\
\hline Kaffrine & 0.4 & 34.8 & 0.0 & 78.7 & 0.0 & 27.7 & 43.7 & 56.1 & 11.2 \\
\hline Sedhiou & 4.4 & 83.0 & 9.4 & 97.8 & 81.3 & 93.0 & 71.7 & 78.7 & 78.3 \\
\hline
\end{tabular}




\begin{tabular}{|c|c|c|c|c|c|c|c|c|c|}
\hline \multirow[b]{2}{*}{ Region } & \multicolumn{8}{|c|}{ Mother's Ethnicity } & \multirow{2}{*}{$\begin{array}{c}\text { Total } \\
\text { FGM/C } \\
\text { Prevalence }\end{array}$} \\
\hline & Wolof & Poular & Serer & Mandingue & Diola & Soninke & $\begin{array}{c}\text { Non- } \\
\text { Senegalese }\end{array}$ & $\begin{array}{c}\text { Other } \\
\text { Senegalese }\end{array}$ & \\
\hline Kedougou & 33.2 & 90.9 & 0.0 & 95.2 & 100.0 & 88.5 & 81.7 & 94.0 & 91.6 \\
\hline $\begin{array}{l}\text { Total FGM/C } \\
\text { Prevalence }\end{array}$ & 0.8 & 51.5 & 1.4 & 76.0 & 59.6 & 64.8 & 30.1 & 65.2 & 25.5 \\
\hline
\end{tabular}

\section{Prevalence by socio-demographic characteristics}

All four surveys show significant differences in proportions of cut women in relation to marital status, education, religion, and household wealth (see Appendix Table A2 for detailed findings). Women who were currently or formerly married consistently had higher prevalences than those who were never married. Differences in prevalence in relation to education-of either the woman or her husband or partner-showed similar patterns. FGM/C prevalence was remarkably higher among women with no education and whose husbands or partners had no education. FGM/C prevalence tends to decrease with increased education, but it is important not to confer a causal relationship between women's education and cutting prevalence, as women may their education many years after being cut. Prevalence according to women's religious affiliation was also significant. The proportion of Muslim women who were cut was significantly higher than those of Christian women, in all surveys. In all survey years, there was a general inverse relationship between $F G M / C$ prevalence and wealth, with women in the lower wealth quintiles revealing greater prevalence.

Table 4. FGM/C prevalence among women, by socio-demographic characteristics, SDHS

\begin{tabular}{|c|c|c|c|c|c|c|c|c|}
\hline \multirow{2}{*}{ Background Characteristics } & \multicolumn{2}{|c|}{2005 DHS } & \multicolumn{2}{|c|}{ 2010-11 DHS } & \multicolumn{2}{|c|}{2015 DHS } & \multicolumn{2}{|c|}{2017 DHS } \\
\hline & $\%$ & $\mathbf{n}$ & $\%$ & $\mathbf{n}$ & $\%$ & $\mathbf{n}$ & $\%$ & $\mathbf{n}$ \\
\hline \multicolumn{9}{|l|}{ Marital status } \\
\hline Never married & 17.0 & 3941 & 19.4 & 4585 & 16.5 & 2709 & 17.1 & 5079 \\
\hline Currently married & 32.7 & 9866 & 28.2 & 10347 & 27.8 & 5731 & 26.8 & 10895 \\
\hline Formerly married & 28.7 & 795 & 29.0 & 757 & 25.4 & 412 & 29.1 & 813 \\
\hline \multicolumn{9}{|l|}{ Woman's education } \\
\hline No education & 31.8 & 8699 & 28.4 & 9079 & 27.6 & 4505 & 26.2 & 7749 \\
\hline Primary & 25.3 & 3677 & 24.1 & 3414 & 22.9 & 1927 & 25.0 & 3861 \\
\hline Secondary & 19.0 & 2074 & 20.2 & 2871 & 20.1 & 2136 & 20.6 & 4431 \\
\hline Higher & 20.3 & 152 & 14.3 & 323 & 11.5 & 283 & 16.2 & 745 \\
\hline \multicolumn{9}{|l|}{ Husband, partner education } \\
\hline No education & 34.5 & 6693 & 29.2 & 7702 & 29.8 & 4012 & 28.8 & 6578 \\
\hline Primary & 31.0 & 1196 & 28.7 & 1211 & 24.7 & 648 & 20.7 & 1484 \\
\hline Secondary & 27.8 & 1225 & 28.1 & 940 & 24.1 & 536 & 23.9 & 1252 \\
\hline Higher & 22.6 & 411 & 21.3 & 354 & 16.8 & 240 & 28.2 & 580 \\
\hline \multicolumn{9}{|l|}{ Religion } \\
\hline Christian & 10.9 & 647 & 6.5 & 656 & 7.8 & 429 & 7.0 & 619 \\
\hline Muslim & 29.1 & 13931 & 26.5 & 14997 & 25.0 & 8380 & 24.7 & 16160 \\
\hline \multicolumn{9}{|l|}{ Wealth quintile } \\
\hline Lowest & 38.6 & 2433 & 42.6 & 2585 & 42.4 & 1509 & 40.8 & 2768 \\
\hline Second & 42.6 & 2565 & 30.4 & 2805 & 32.0 & 1579 & 30.0 & 2984 \\
\hline Middle & 32.2 & 2839 & 26.1 & 3114 & 25.4 & 1757 & 25.0 & 3310 \\
\hline Higher & 22.5 & 3154 & 20.5 & 3494 & 15.6 & 1886 & 17.1 & 3581 \\
\hline Highest & 13.0 & 3610 & 14.7 & 3689 & 12.3 & 2121 & 13.7 & 4144 \\
\hline
\end{tabular}

Bivariate association tests between FGM/C status and background characteristics are statistically significant $(p<0.05)$ 


\section{FGM/C prevalence by social norms associated with FGM/C continuation}

Social norms theory posits that FGM/C may be entrenched in communities with interdependent expectations and beliefs often linked to marriageability, ethnic identity, rites of passage, religion, honour and modesty codes, sexual restraint, and aesthetics and/or hygiene (Mackie and LeJeune 2009). In the DHS, the FGM/C module includes questions that were used as proxy indicators of social norms that can hold the practice in place. Of specific importance is the question on the respondent's opinion on the continuation or discontinuation of FGM/C. Responses to this question, which are pre-coded as "continued," "discontinued," "it depends," or "not sure", represent ongoing positioning in relation to "fluctuating needs and realities, representing contingencies that affect decision making on FGM/C" (Hernlund and Shell-Duncan 2007, p 44).

Data (Table 5) showe that FGM/C prevalence is consistently higher among women who believe $\mathrm{FGM} / \mathrm{C}$ should continue than among those who believe it should be discontinued, or who are ambivalent. In $2005 \mathrm{FGM} / \mathrm{C}$ prevalence among women who believed that FGM/C should continue was significantly higher, at 91 percent, than the rate of 16 percent among those who believed it should be discontinued, and was 29 percent for those who were ambivalent. This trend is observed in other survey years.

Evidence provided in Table 5 also shows that FGM/C prevalence tends to be significantly higher among women who believe $\mathrm{FGM} / \mathrm{C}$ is required by their religion than among women who believe otherwise. In all survey years, $\mathrm{FGM} / \mathrm{C}$ prevalence is over 80 percent among women who believe $\mathrm{FGM} / \mathrm{C}$ is required by religion, and is at less than 20 percent among those who believe $\mathrm{FGM} / \mathrm{C}$ is not a religious requirement.

Table 5. FGM/C prevalence among women, by beliefs about FGM/C practice, SDHS 2005-2017

\begin{tabular}{|c|c|c|c|c|c|c|c|c|}
\hline & \multicolumn{2}{|c|}{2005 DHS } & \multicolumn{2}{|c|}{ 2010-11 DHS } & \multicolumn{2}{|c|}{2015 DHS } & \multicolumn{2}{|c|}{2017 DHS } \\
\hline & $\%$ & $\mathbf{n}$ & $\%$ & $\mathbf{n}$ & $\%$ & $\mathbf{n}$ & $\%$ & $\mathbf{n}$ \\
\hline \multicolumn{9}{|l|}{ Women's attitudes toward FGM/C } \\
\hline Should be continued & 90.6 & 2417 & 88.8 & 2378 & 90.9 & 765 & 88.5 & 2412 \\
\hline Should be discontinued & 16.0 & 10263 & 14.8 & 11268 & 15.8 & 3089 & 13.1 & 12764 \\
\hline Depends/Don't know & 28.6 & 1006 & 36.5 & 674 & 35.5 & 107 & 36.4 & 608 \\
\hline \multicolumn{9}{|l|}{ Women's beliefs about FGM/C } \\
\hline $\mathrm{FGM} / \mathrm{C}$ is required by religion & 88.7 & 2322 & 82.9 & 2456 & 87.2 & 572 & 84.9 & 2023 \\
\hline $\mathrm{FGM} / \mathrm{C}$ is not required by religion & 16.4 & 9976 & 15.3 & 10877 & 20.5 & 3198 & 15.4 & 12684 \\
\hline
\end{tabular}

Bivariate association tests between FGM/C status and the background characteristics are statistically significant $(p<0.05))$ 
The social status of a woman within her household and community may influence her adherence to the community's social norms (Shell-Duncan et al 2018). Whether women condone GBV, in addition to their decision-making power for both household purchases and their own health care, along with their economic empowerment opportunities, may play a vital role in shaping social norms. Table 6 highlights findings on FGM/C prevalence among women ages 15 to 49, disaggregated by a woman's stance on GBV (gender norm) and her decision-making ability for her own health care.

Findings show that in all four surveys, FGM/C prevalence is significantly higher among women who justify violence for any reason than those who opposed violence. Prevalence was equally higher among women whose own health care decisions were made either in concert with her husband, or by someone else, rather than those who made such decisions themselves.

Table 6. FGM/C prevalence among women, by gender norms and decision-making, SDHS 2005-2017

\begin{tabular}{|c|c|c|c|c|c|c|c|c|}
\hline & \multicolumn{2}{|c|}{2005 DHS } & \multicolumn{2}{|c|}{ 2010-11 DHS } & \multicolumn{2}{|c|}{2015 DHS } & \multicolumn{2}{|c|}{2017 DHS } \\
\hline & $\%$ & $\mathbf{n}$ & $\%$ & $\mathbf{n}$ & $\%$ & $\mathbf{n}$ & $\%$ & $\mathbf{n}$ \\
\hline \multicolumn{9}{|l|}{$\begin{array}{l}\text { Husband is justified in hitting } \\
\text { or beating his wife if she: }\end{array}$} \\
\hline \multicolumn{9}{|l|}{ Burns the food } \\
\hline Yes & 29.5 & 3411 & 33.6 & 3835 & 28.9 & 1999 & 32.8 & 3708 \\
\hline No & 28.0 & 10880 & 23.1 & 11772 & 22.9 & 6832 & 21.5 & 12965 \\
\hline \multicolumn{9}{|l|}{ Neglects children } \\
\hline Yes & 29.1 & 7096 & 32.7 & 6288 & 29.5 & 3885 & 30.4 & 5935 \\
\hline No & 27.6 & 7258 & 21.0 & 9316 & 20.1 & 4943 & 20.5 & 10732 \\
\hline \multicolumn{9}{|l|}{ Argues with him } \\
\hline Yes & 29.4 & 7104 & 31.0 & 6979 & 28.9 & 3989 & 31.6 & 5945 \\
\hline No & 27.5 & 7175 & 21.3 & 8612 & 20.4 & 4841 & 19.8 & 10710 \\
\hline \multicolumn{9}{|l|}{ Goes out without telling him } \\
\hline Yes & 31.4 & 7254 & 32.9 & 6258 & 31.1 & 3774 & 32.1 & 5574 \\
\hline No & 25.2 & 7074 & 20.8 & 9342 & 19.1 & 5059 & 19.9 & 11132 \\
\hline \multicolumn{9}{|l|}{ Refuses to have sex with him } \\
\hline Yes & 29.7 & 6569 & 29.8 & 7212 & 28.1 & 3862 & 31.6 & 5901 \\
\hline No & 27.5 & 7509 & 21.8 & 8216 & 21.0 & 4931 & 19.9 & 10557 \\
\hline \multicolumn{9}{|l|}{$\begin{array}{l}\text { Final say in making decisions } \\
\text { on women's own health care }\end{array}$} \\
\hline Self only & 28.4 & 2109 & 26.8 & 1311 & 18.9 & 333 & 15.1 & 819 \\
\hline Jointly with husband/someone else & 35.5 & 773 & 25.0 & 1853 & 38.5 & 795 & 20.0 & 2048 \\
\hline Husband/someone else only & 27.8 & 11673 & 29.3 & 7137 & 26.6 & 4571 & 29.8 & 7986 \\
\hline
\end{tabular}

Bivariate association tests between FGM/C status and the background characteristics are statistically significant $(p<0.05))$

Findings of FGM/C prevalence specifically in relation to women's economic opportunities are shown in Table 7. Women working in the informal sector, those who work seasonally, and who work but are not compensated either in cash or in kind, show significantly higher prevalence of $\mathrm{FGM} / \mathrm{C}$ than women working in the formal sector, who are employed all year, and who are remunerated either in cash or in kind. 
Table 7. FGM/C prevalence among women, by employment and earnings, SDHS 2005-2017

\begin{tabular}{|c|c|c|c|c|c|c|c|c|}
\hline & \multicolumn{2}{|c|}{2005 DHS } & \multicolumn{2}{|c|}{ 2010-11 DHS } & \multicolumn{2}{|c|}{2015 DHS } & \multicolumn{2}{|c|}{2017 DHS } \\
\hline & $\%$ & $\mathbf{n}$ & $\%$ & $\mathbf{n}$ & $\%$ & $\mathbf{n}$ & $\%$ & $\mathbf{n}$ \\
\hline \multicolumn{9}{|l|}{ Woman's occupation } \\
\hline Formal & 21.6 & 4413 & 23.4 & 5065 & 22.3 & 1977 & 19.6 & 4784 \\
\hline Informal & 42.9 & 2155 & 34.1 & 2164 & 29.6 & 2835 & 25.1 & 4826 \\
\hline Not working & 28.1 & 7995 & 24.8 & 8450 & 21.7 & 3957 & 26.4 & 7012 \\
\hline \multicolumn{9}{|l|}{ Woman's employment } \\
\hline All year & 21.9 & 3414 & 23.6 & 4169 & 20.1 & 2831 & 19.0 & 5808 \\
\hline Seasonal/occasionally & 35.5 & 3180 & 30.6 & 3126 & 34.9 & 2064 & 27.1 & 3985 \\
\hline \multicolumn{9}{|c|}{ Payment (cash only, cash and in kind) } \\
\hline Yes & 25.0 & 5192 & 24.4 & 6135 & 22.3 & 3682 & 20.5 & 7496 \\
\hline No & 41.0 & 1417 & 38.4 & 1160 & 38.7 & 1213 & 28.1 & 2297 \\
\hline
\end{tabular}

A woman's mobility away from her community may offer her an opportunity to interact with other people who may hold differing opinions on some of the social norms observed in her reference group. Her exposure to mass media may act as a source to new information about the harms of some of the practices in the community. In contexts where women have authority to raise questions, mobility and exposure to mass media can stimulate dialogue that questions harmful traditional practices such as FGM/C that are valued by the community and observed as a social rule. Table 8 shows that during the 2010-11 and 2015 surveys (mobility data were not collected in 2005 and 2017), the proportion of cut women was substantially higher among those who had not made any trip away from their communities compared to those who made at least one trip away from their communities in the last 12 months. For instance, FGM/C prevalence among those who had not made any trip away from their communities was 30 percent in 2010-11 and 33 percent in 2015 while the prevalence for those who had made between 1-25 trips outside their community was 23 percent in 2010-11 and 19 percent in 2015. Very few women had made more than 25 trips away from their communities in the last 12 months. Data on exposure to mass media showed that across all the surveys, women who as a matter of routine did not read a newspaper/magazine, listen to radio, and watch television experienced $\mathrm{FGM} / \mathrm{C}$ in significantly higher proportions than those who had been exposed to mass media (Table 8).

Table 8. FGM/C prevalence among women, by mobility and media exposure, SDHS 2005-2017

\begin{tabular}{|c|c|c|c|c|c|c|c|c|}
\hline & \multicolumn{2}{|c|}{2005 DHS } & \multicolumn{2}{|c|}{ 2010-11 DHS } & \multicolumn{2}{|c|}{2015 DHS } & \multicolumn{2}{|c|}{2017 DHS } \\
\hline & $\%$ & $\mathbf{n}$ & $\%$ & $\mathbf{n}$ & $\%$ & $\mathbf{n}$ & $\%$ & $\mathbf{n}$ \\
\hline \multicolumn{9}{|c|}{ Number of trips (overnight) in last year } \\
\hline 0 & & & 30.1 & 6692 & 33.0 & 3318 & & \\
\hline $1-25$ & & & 22.5 & 8762 & 18.8 & 5406 & & \\
\hline $26-50$ & & & 20.7 & 111 & 29.5 & 85 & & \\
\hline 51 or more & & & 10.9 & 123 & 29.2 & 41 & & \\
\hline \multicolumn{9}{|c|}{ Newspaper or magazine reading } \\
\hline Not at all & 30.6 & 11741 & 27.5 & 12195 & 26.4 & 7113 & 26.5 & 12620 \\
\hline Less than once a week & 18.7 & 1346 & 23.1 & 1543 & 19.9 & 805 & 19.2 & 2344 \\
\hline At least once a week & 18.2 & 1441 & 16.0 & 1950 & 11.6 & 933 & 12.8 & 1823 \\
\hline \multicolumn{9}{|c|}{ Radio listening frequency } \\
\hline Not at all & 42.5 & 1246 & 31.8 & 2475 & 32.3 & 1437 & 32.4 & 2815 \\
\hline Less than once a week & 26.0 & 1522 & 29.8 & 3344 & 23.6 & 2453 & 25.9 & 5559 \\
\hline
\end{tabular}




\begin{tabular}{|l|cccccccc|}
\hline $\begin{array}{l}\text { At least once a week } \\
\text { Television viewing frequency }\end{array}$ & 27.1 & 2755 & 22.7 & 9869 & 22.2 & 4961 & 20.0 & 8413 \\
Not at all & & & & & & & & \\
Less than once a week & 39.8 & 3708 & 35.7 & 3857 & 35.1 & 2258 & 39.0 & 3245 \\
At least once a week & 29.0 & 1726 & 32.0 & 2061 & 30.3 & 1333 & 31.4 & 2930 \\
\hline Bivariate association tests between FGM/C status and the background characteristics are statistically significant (p<0.05) & \\
\hline
\end{tabular}

\section{Trends in FGM/C attitudes}

Examining trends of support for FGM/C's continuation is helpful in understanding prevailing social norms. Although a person's attitude and behaviours may differ, especially in terms of social norms, increased support for FGM/C could be an indicator of increased risk for its perpetuation (ShellDuncan and Hernlund 2006). Trends in support for FGM/C continuation show that the proportion of women who support FGM/C has declined only slightly, from 18 percent in 2005 to 15 percent in 2017 (Figure 8). Conspicuously, support for FGM/C's continuation increased in 2015 (by 2.7 percentage points). 2015 SDHS data on support for FGM/C's continuation show a substantial increase in missing cases (49\%), which could have skewed the 2015 estimates.

Figure 8. Opinion about the continuation of FGM/C among women ages 15 to 49, SDHS 2005-2017

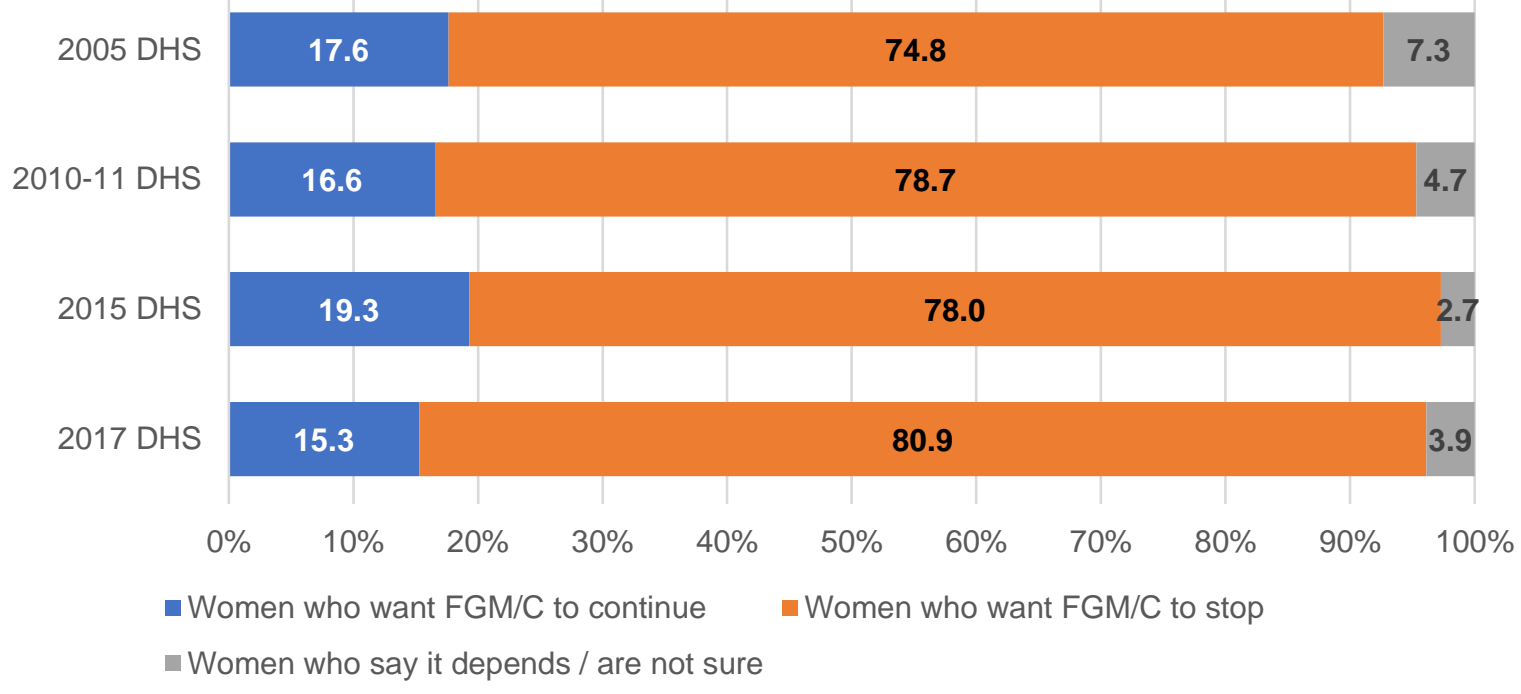

Data show that support for $\mathrm{FGM} / \mathrm{C}$ is consistently lower than its national prevalence from 2005 to 2017 among women age 15 to 49 in Senegal. Notably, both support for FGM/C and its prevalence (except in 2015) reduced minimally from 2005 to 2017 (support for FGM/C 18\% to 15\%; FGM/C prevalence $28 \%$ to $24 \%$ ). Despite the four percentage-point drop in support for $F G M / C$ 's continuation between 2015 and 2017, its prevalence remained the same, at 24 percent. 
Figure 9. Trends in prevalence of and support for FGM/C, SDHS 2005-2017

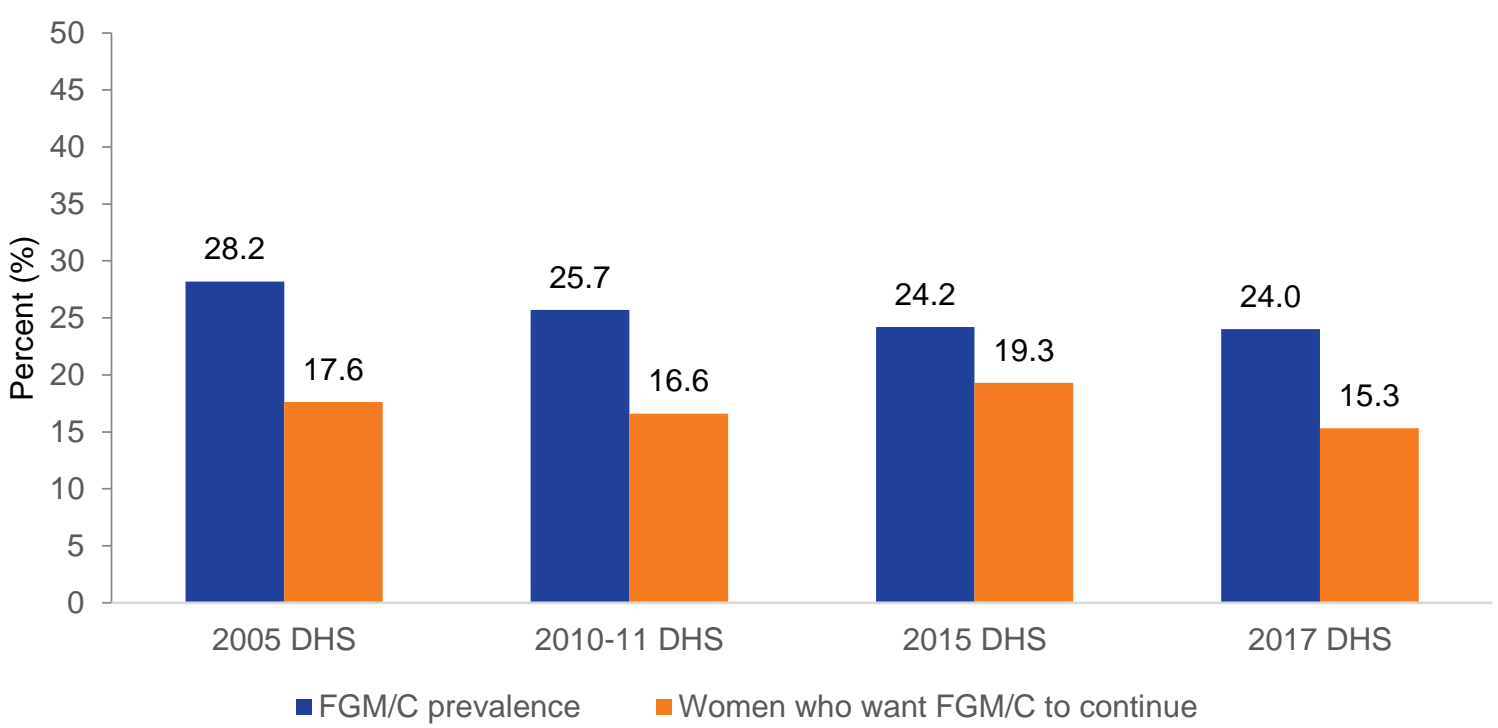

\section{Readiness to change among cut women}

While interviewees' responses on support for continuation of FGM/C may not capture information on normative expectations, a respondent's opinion of FGM/C's continuation can be helpful in understanding its social dynamics. The concept of readiness to change examines an individual's opinion of FGM/C in conjunction with their actual or intended behaviour. Figure 10 shows that in successive surveys, the proportions of willing adherents (women who support the continuation of FGM/C and have had, or will have, their daughters cut) reduced from 40 percent in 2005 to 22 percent in 2017. Meanwhile, the proportion of reluctant abandoners (women who prefer to continue $\mathrm{FGM} / \mathrm{C}$ but who will not have $\mathrm{FGM} / \mathrm{C}$ performed on their daughters) and willing abandoners (women who favour stopping FGM/C and will not have $\mathrm{FGM} / \mathrm{C}$ performed on their daughters) increased between 2005 and 2017.

Figure 10. Among cut women ages 15 to 49, percentage in each of the assigned stages of readiness to change based on at least one cut daughter, SDHS 2005-2017

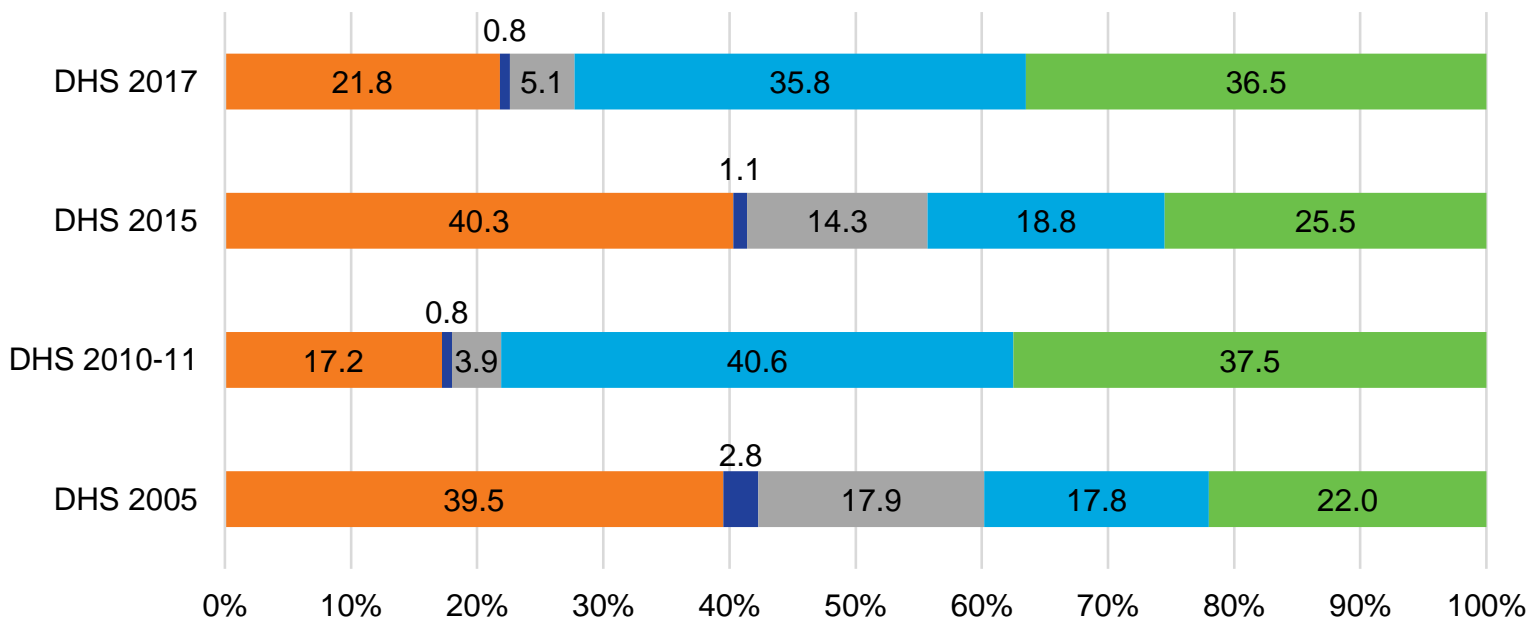

Willing Adherent $\quad$ Contemplator $\quad$ Reluctant Adherent $\quad$ Reluctant Abandoner $\square$ Willing Abandoner 


\section{FGM/C Among Girls Age 14 and Younger}

\section{Collection of data on girls' FGM/C status}

Over the years, there have been notable changes in how data on the FGM/C statuses of daughters of women ages 15 to 49 are collected. In the 2005 SDHS, FGM/C questions were asked about most recently cut daughters, of any age; in the 2010-11 SDHS, FGM/C questions were asked for all daughters ages 10 and younger; and in both the 2015 and 2017 SDHS, FGM/C questions were asked of all daughters ages 14 and younger. These changes in how information on daughters' FGM/C status was collected have implications for calculations of prevalence, as some of the surveys (2005 and 2010-11) have limitations that affect calculation of FGM/C prevalence in the 14 and younger age groups.

Information on the FGM/C status of one daughter (either eldest or most recently cut) can calculate the proportion of women with at least one living daughter who has undergone $\mathrm{FGM} / \mathrm{C}$, but only considering the $\mathrm{FGM} / \mathrm{C}$ status of one daughter limits estimation of $\mathrm{FGM} / \mathrm{C}$ prevalence among girls because it does not provide the needed denominator: all girls younger than 15. This limitation applies to surveys conducted before 2010 (2005 survey), after which FGM/C modules were standardised, with information on FGM/C collected for all of a respondent's living daughters.

Complete data on age at cutting among all daughters, rather than the eldest or most recently cut, is advantageous in two ways. First, it allows for estimation of FGM/C prevalence at the youngest ages, where effects of recent changes will be detected; and it allows for analysis of trends in age at cutting across generations.

\section{Considerations for analysis of complete daughter data: understanding the difference between current and final FGM/C status}

The fact that not all girls who are younger than 15 have reached their final cutting status requires caution during data analysis and interpretation for all daughters ages 14 and younger. Not only are there are girls who are currently cut, but girls who are currently uncut but who will be cut in the future, as well as girls who are currently uncut and will never be cut. (In 2005 there were also girls who were likely to have been cut but whose data were not collected because data were only collected for the eldest or most recently cut daughter.) Since not all daughters have attained their final cutting status, distinguishing whether the prevalence is declining, or if a substantial proportion of girls are simply not yet old enough to undergo FGM/C, is challenging.

It is nonetheless possible to address these limitations statistically using specialised statistical analyses. In statistical terms, cases in which a girl may still be at risk of being cut in the future are described as "censored" observations. Since age at which FGM/C is conducted varies by setting, amount of censoring also varies. Where most girls are cut in infancy, the effects of censoring on daughter prevalence data are minimal. Evidence in this study shows that in Senegal, FGM/C often occurs early in life (see findings on age at cutting in Table 13) and therefore censoring is likely not be of significant concern. Regardless, failure to adjust for the effects of censoring results in underestimation of prevalence rates.

\section{National FGM/C prevalence among girls}

Considering the restrictions in the denominator-daughters-FGM/C prevalence among most recently cut daughters ages 0 to 14 was 20 percent in 2005; prevalence among all daughters ages 0 to 10 was 12 percent in 2010-11; and in 2015 and in 2017, prevalences among all daughters ages 0 to 14 were 15 percent and 14 percent, respectively (Figure 11). These observed rates suggest that FGM/C prevalence among girls in Senegal declined between 2005 and 2010-11, followed by a slight increase in 2015, and stagnation between 2015 and 2017. As noted, these 
changes need to be interpreted, considering the different methodologies used to generate the estimates from the four surveys.

\section{Figure 11. National FGM/C prevalence among girls ages 0 to 14, SDHS 2005-2017}

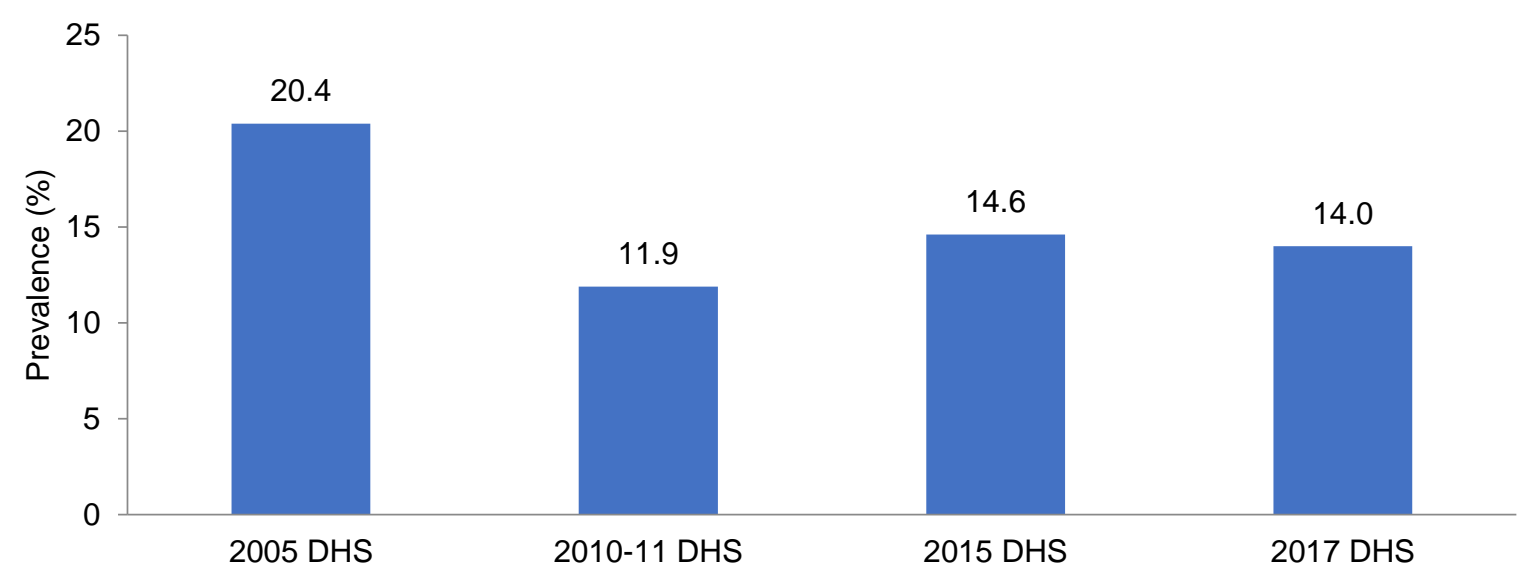

In the 2005 SDHS, FGM/C questions were asked about most recently cut daughters of any age; for this analysis, sample size is limited to most recently cut girls ages 0-14. In the 2010-11 SDHS, FGM/C questions were asked for all daughters ages 0-10. In the 2015 and 2017 SDHS, FGM/C questions were asked for all daughters ages 0-14.

Changes in national FGM/C prevalence among girls can also be observed by examining prevalence rates within girls' age groups in the four surveys, as shown in Figure 12. Similar to changes observed for the combined 0 to 14 age category, changes for the five year interval age groups showed a general decline between 2005 and 2010-11, but then stagnating in subsequent years.

Figure 12. FGM/C prevalence among girls by age group, SDHS 2005-2017

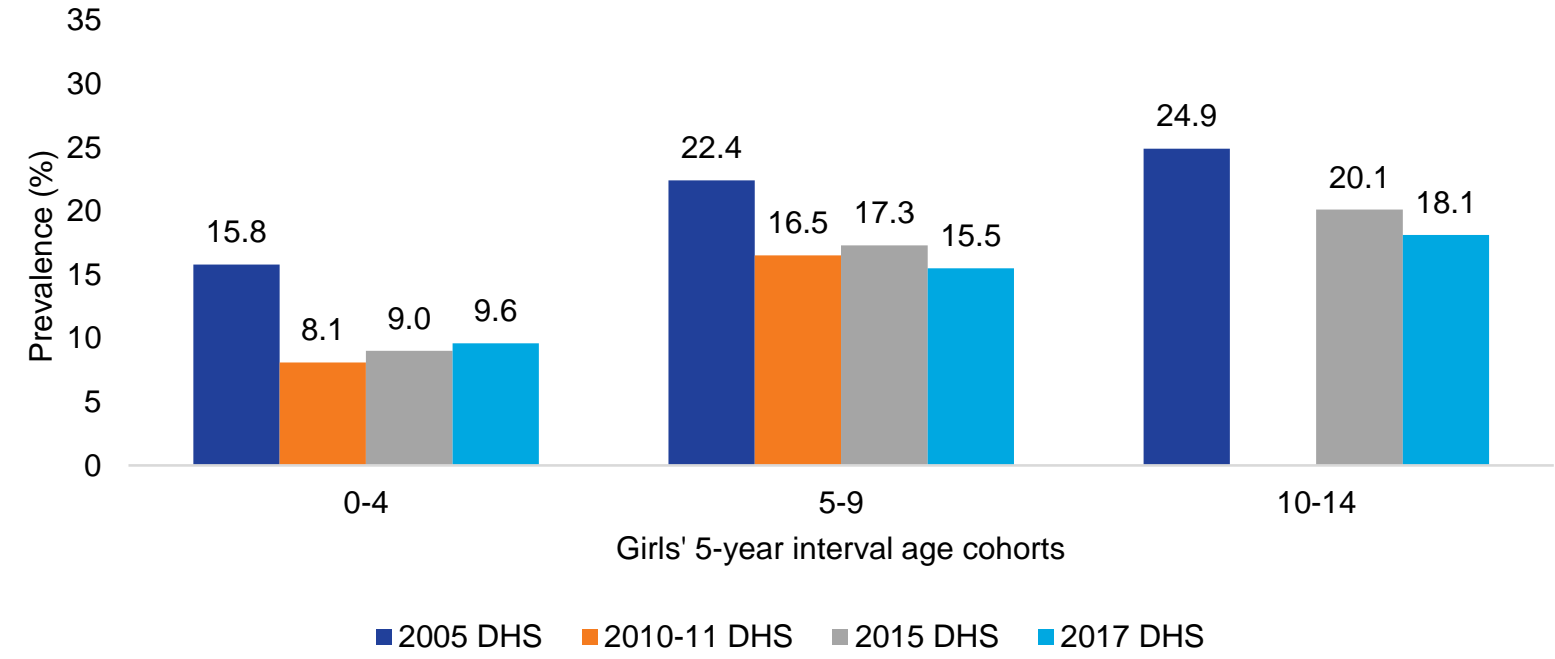

In the 2005 SDHS, FGM/C questions were asked about most recently cut daughters of any age; for this analysis, sample size is limited to most recently cut girls ages 0-14. In the 2010-11 SDHS, FGM/C questions were asked for all daughters ages 0-10. In the 2015 and 2017 SDHS, FGM/C questions were asked for all daughters ages 0-14.

\section{Regional prevalences among girls}

In Senegal, there are substantial regional differences in the proportion of cut girls across regions. Prevalence ranged from as high as 78 percent in 2005 and 61 percent in 2017 among girls in Matam region to as low as less than one percent in 2005 and 2017 among girls in Diourbel region. Other regions with generally higher prevalence rates included Kolda, Saint Louis, Tambacounda, 
Zuguinchor, Kedougou, and Sedhiou, while regions such as Dakar, Fatick, Kaolack, Lounga, Thios, and Kaffrine showed lower prevalences.

From 2005 to 2017 there were notable changes in proportions of girls who were cut in various regions. Regional changes in FGM/C prevalence among girls in the four surveys are shown in graphs in Figure 13 and in maps in Figure 14 on the following page.

Prevalence in Kolda region dropped from 69 percent in 2005 to 35 percent in 2017. In Matam region, prevalence declined from 78 percent in 2005 to 41 percent in 2010-11, but then started to increase in subsequent surveys (57\% in 2015 and 61\% in 2017). In Tambacounda region, there was an 11 percentage point decline in the proportion of girls cut between 2005 (55\%) and 2010$11(44 \%)$, following which the region experienced a stagnation in prevalence. The trend was different in Kedougou, where a steady increase in prevalence was observed (17\% in $2010-11,36 \%$ in 2015 , and $45 \%$ in 2017).

Figure 13. FGM/C prevalence among girls, by region, SDHS 2005-2017

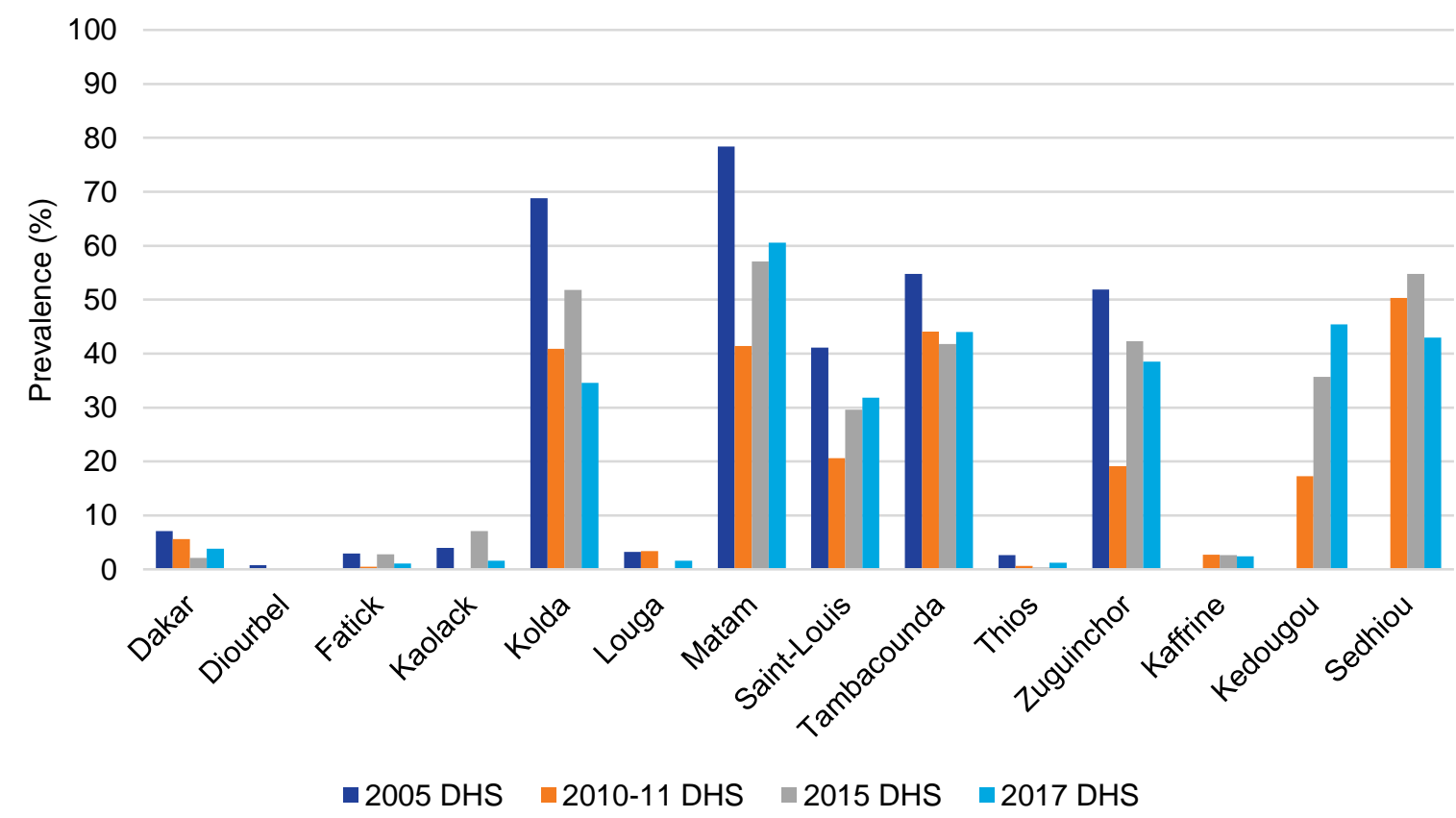

In 2005, Kaffrine region was part of Kaolack region, Kedougou was in Tambacounda region, and Sedhiou was in Kolda. 
Figure 14. Evolution within regions of FGM/C prevalence among girls, Senegal DHS 2005-2017
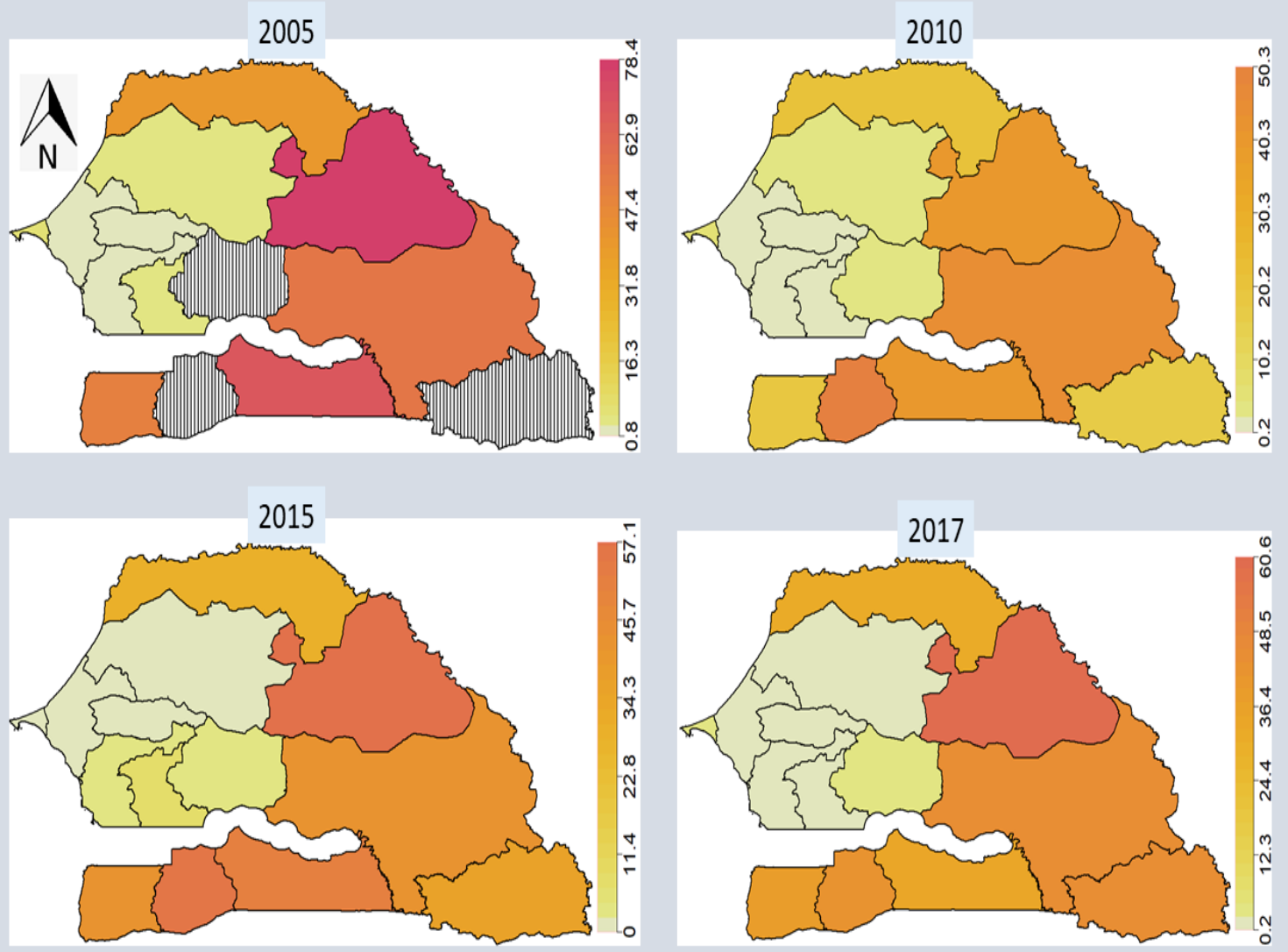

Darker red indicates regions with higher prevalence. In 2005, Kaffrine region was part of Kaolack region, Kedougou was in Tambacounda region, and Sedhiou was in Kolda. The three regions are presented in black and white stripes in the 2005 map.

\section{Prevalence among girls by urban and rural residence}

Figure 15 shows differences in FGM/C prevalence in urban and rural areas among girls ages 0 to 14. Consistently over the years, girls in rural areas are at a significantly higher risk of being cut than those in urban areas. From 2005 through 2017, the proportion of girls who underwent FGM/C was substantially higher in rural areas than in urban areas. Interestingly, while there seems to be a declining trend in the proportion of girls undergoing FGM/C in urban areas, the proportion of cut girls in rural areas seem to have stagnated between the last two surveys.

Figure 15. FGM/C prevalence among girls, by residence, SDHS 2005-2017

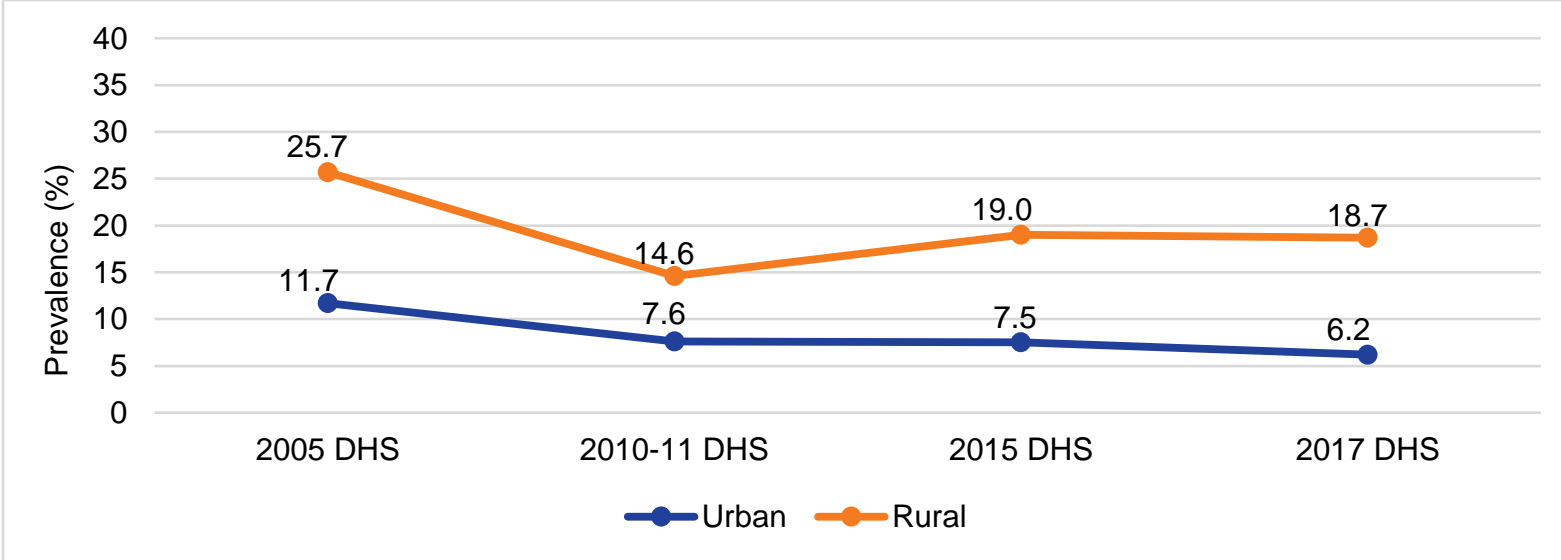




\section{Prevalence among girls by ethnic group}

Figure 16 highlights changes in FGM/C prevalence among girls, dis-aggregated by ethnic background, showing that $\mathrm{FGM} / \mathrm{C}$ prevalence varies greatly according to ethnic background. In 2005, over half of Mandingue and Soninke girls ages 0 to 14 were cut, compared to less than one percent of Wolof and Serer girls. From 2005 to 2017, there were notable changes in FGM/C prevalence among various ethnic groups. The proportion of cut Poular girls reduced from 46 percent in 2005 to 28 percent in 2010-11, increased slightly between 2010-11 and 2015, then stagnated at 31 percent in 2015 and 2017. Among the Mandingue, prevalence dropped from 50 percent in 2005 to 32 percent in 2010-11, but then increased to 37 percent in 2015 and 39 percent in 2017. A similar trend was observed among girls from other Senegalese ethnic groups, where prevalence reduced from 27 percent in 2005 to 14 percent in 2010-11 and 2015, but then rose to 31 percent in 2017.

Figure 16. FGM/C prevalence among girls, by ethnicity, SDHS 2005-2017

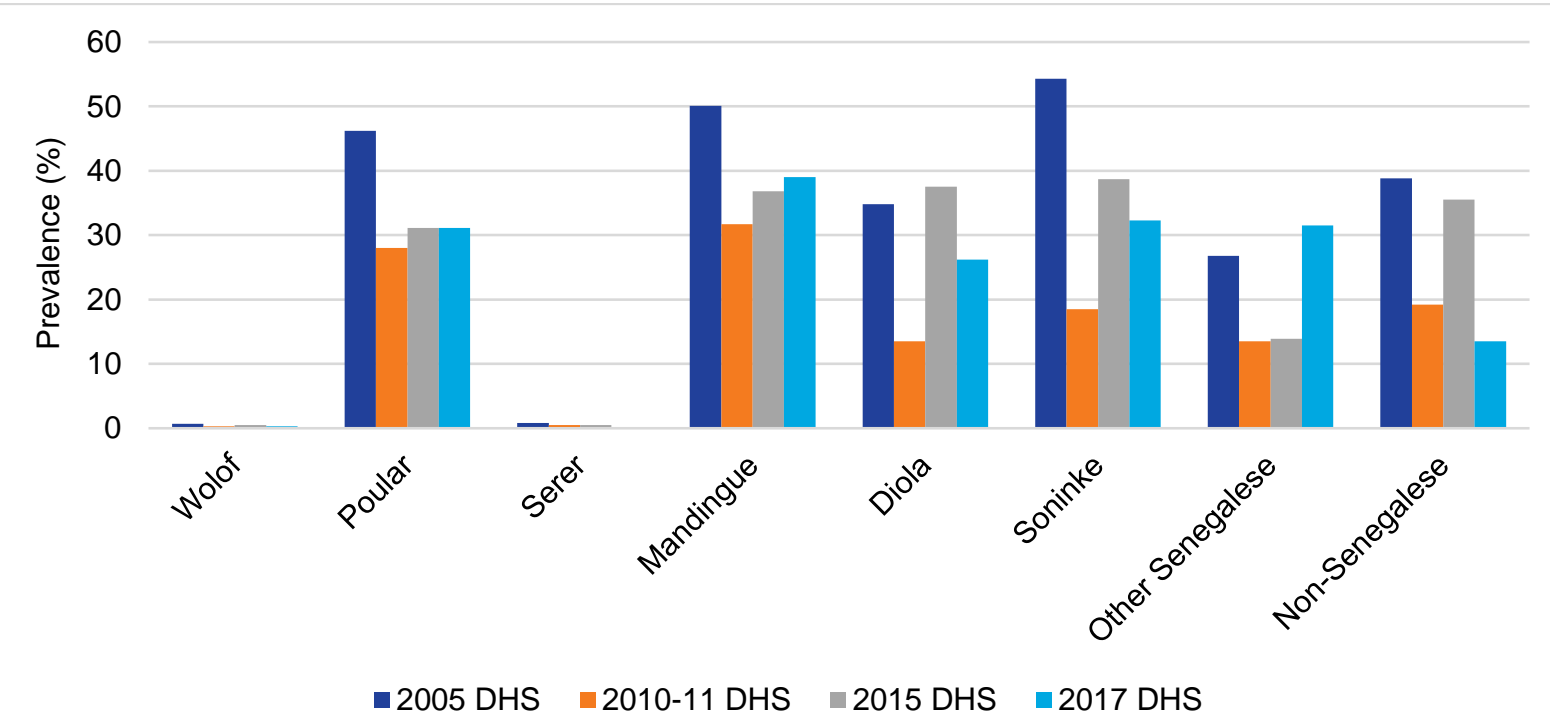

Findings show that in 2017 ethnic FGM/C prevalence among girls ages 0 to 14 varied significantly by region. The highest proportion of girls cut were from the Mandingue ethnic group (40\%) inhabiting mainly the Zuguinchor (61\%), Kedougou (60\%) and Sedhiou (60\%) regions. Girls from the Soninke ethnic group showed somewhat lower prevalence (33\%), inhabiting mainly the Tambacounda region (67\%), followed by girls from the Poular ethnic group (32\%), mainly in Matam $(66 \%)$, Tambacounda (53\%), and Saint-Luis (51\%) regions.

Interestingly, there was a high proportion of cut girls from communities that are traditionally known not to practise FGM/C (Wolof and Serer) inhabiting regions of high $\mathrm{FGM} / \mathrm{C}$ prevalence. FGM/C prevalence among Wolof girls living in Matam region was 26 percent, compared to the Wolof's 0.3 percent national FGM/C prevalence. National FGM/C prevalence for girls of Serer ethnic background is 0.1 percent, but their prevalence was higher when living in the Sedhiou region (6.3\%).

Table 9. FGM/C prevalence among girls ages 0 to 14 by ethnicity and region, SDHS 2017

\begin{tabular}{|c|c|c|c|c|c|c|c|c|c|}
\hline \multirow[b]{2}{*}{ Region } & \multicolumn{8}{|c|}{ Mother's Ethnicity } & \multirow{2}{*}{$\begin{array}{l}\text { Total } \\
\text { FGM/C } \\
\text { Prevalence }\end{array}$} \\
\hline & Wolof & Poular & Serer & Mandingue & Diola & Soninke & $\begin{array}{c}\text { Non- } \\
\text { Senegalese }\end{array}$ & $\begin{array}{c}\text { Other } \\
\text { Senegalese }\end{array}$ & \\
\hline Dakar & 0.0 & 4.6 & 0.0 & 11.7 & 11.1 & 0.0 & 5.2 & 29.8 & 3.8 \\
\hline Diourbel & 0.0 & 0.7 & 0.0 & 15.1 & 0.0 & - & 0.0 & - & 0.3 \\
\hline Fatick & 0.0 & 1.7 & 0.1 & 10.6 & 0.0 & 0.0 & 17.7 & 0.0 & 1.2 \\
\hline Kaolack & 0.7 & 2.9 & 0.0 & 7.2 & - & 16.1 & 9.1 & 0.0 & 1.8 \\
\hline Kolda & 3.1 & 46.3 & 0.0 & 32.2 & 8.3 & 27.5 & 13.2 & 32.9 & 34.8 \\
\hline
\end{tabular}




\begin{tabular}{|c|c|c|c|c|c|c|c|c|c|}
\hline \multirow[b]{2}{*}{ Region } & \multicolumn{8}{|c|}{ Mother's Ethnicity } & \multirow{2}{*}{$\begin{array}{l}\text { Total } \\
\text { FGM/C } \\
\text { Prevalence }\end{array}$} \\
\hline & Wolof & Poular & Serer & Mandingue & Diola & Soninke & $\begin{array}{c}\text { Non- } \\
\text { Senegalese }\end{array}$ & $\begin{array}{c}\text { Other } \\
\text { Senegalese }\end{array}$ & \\
\hline Louga & 0.0 & 5.1 & 0.0 & 0.0 & - & 0.0 & 0.0 & 7.0 & 1.8 \\
\hline Matam & 26.0 & 66.0 & 0.0 & 0.0 & - & 33.2 & 0.0 & 54.4 & 62.8 \\
\hline Saint-Louis & 0.0 & 51.1 & 0.0 & 5.1 & 0.0 & 0.0 & 11.0 & 67.3 & 32.2 \\
\hline Tambacounda & 2.3 & 52.6 & 1.1 & 46.8 & 9.6 & 66.8 & 10.6 & 39.2 & 44.3 \\
\hline Thios & 0.0 & 3.7 & 0.0 & 22.2 & 0.0 & 0.0 & 3.8 & 0.0 & 1.3 \\
\hline Zuguinchor & 5.7 & 31.0 & 0.0 & 61.3 & 41.8 & 0.0 & 69.3 & 87.9 & 39.0 \\
\hline Kaffrine & 0.0 & 7.4 & 0.0 & 33.3 & 0.0 & 0.0 & 13.9 & 18.9 & 2.8 \\
\hline Sedhiou & 0.0 & 36.5 & 6.3 & 59.7 & 34.2 & 23.1 & 44.7 & 53.8 & 43.6 \\
\hline Kedougou & 0.0 & 36.3 & 0.0 & 60.1 & - & 10.3 & 28.7 & 46.0 & 45.6 \\
\hline $\begin{array}{l}\text { Total FGM/C } \\
\text { Prevalence }\end{array}$ & 0.3 & 32.1 & 0.1 & 39.7 & 26.5 & 32.5 & 13.7 & 32.4 & 14.7 \\
\hline
\end{tabular}

\section{Prevalence among girls according to socio-demographic characteristics}

Results from 2005 to 2017 show significant differences in the proportions of girls who had been cut according to socio-demographic characteristics including mother's type of union, mother's and her partner's education, mother's religion, and household wealth. Differences in FGM/C prevalence according to mother's type of union indicate that girls whose mothers are in a polygamous union consistently show higher $\mathrm{FGM} / \mathrm{C}$ prevalence than those whose mothers are in a monogamous union. FGM/C prevalence is remarkably higher among daughters of women and husbands or partners with no education than among those whose parents have some education. The proportion of girls cut tends to decrease as parents' educations increase, in all survey years.

Variations in FGM/C prevalence among girls according to mother's religion are equally worth noting. Like trends observed among women ages 15 to 49, the proportion of girls who were cut was significantly higher among those whose mothers are Muslim than among those whose mothers are Christian-in 2005, 2010-11, and 2017. Another important socio-demographic factor revealing showed significant variations in girls' FGM/C prevalence is household wealth. In all four surveys, girls from households in the lower wealth quintiles had a higher prevalence than those in the upper wealth quintiles. Table 10 on the following page summarises major findings in FGM/C prevalence among girls according to key socio-demographic characteristics. Detailed findings on $\mathrm{FGM} / \mathrm{C}$ prevalence by all the socio-demographic factors considered are presented in Appendix Table A3.

Table 10. FGM/C prevalence among girls*, by demographic characteristics, SDHS 2005-2017

\begin{tabular}{|c|c|c|c|c|c|c|c|c|}
\hline \multirow{2}{*}{ Background Characteristics } & \multicolumn{2}{|c|}{2005 DHS } & \multicolumn{2}{|c|}{ 2010-11 DHS } & \multicolumn{2}{|c|}{2015 DHS } & \multicolumn{2}{|c|}{2017 DHS } \\
\hline & $\%$ & $\mathbf{n}$ & $\%$ & $\mathbf{n}$ & $\%$ & $\mathbf{n}$ & $\%$ & $\mathbf{n}$ \\
\hline \multicolumn{9}{|l|}{ Mother's type of union } \\
\hline Monogamous & 19.5 & 6251 & 10.9 & 5818 & 13.6 & 4507 & 13.2 & 8219 \\
\hline Polygamous & 22.5 & 4821 & 14.2 & 3367 & 16.8 & 2612 & 15.5 & 4919 \\
\hline \multicolumn{9}{|l|}{ Mother's education } \\
\hline No education & 23.7 & 8796 & 14.0 & 7134 & 17.4 & 5270 & 16.3 & 9313 \\
\hline Primary & 13.5 & 2215 & 7.1 & 1905 & 9.8 & 1574 & 11.0 & 3053 \\
\hline Secondary & 5.0 & 801 & 3.5 & 654 & 5.6 & 601 & 7.0 & 1400 \\
\hline Higher & 1.4 & 66 & 0.0 & 47 & 0.8 & 83 & 0.9 & 241 \\
\hline \multicolumn{9}{|c|}{ Current husband or partner education } \\
\hline No education & 23.3 & 8111 & 13.7 & 6848 & 17.9 & 5164 & 17.2 & 8630 \\
\hline Primary & 16.5 & 1275 & 9.0 & 1068 & 7.1 & 767 & 8.0 & 1715 \\
\hline Secondary & 12.0 & 1121 & 7.8 & 699 & 5.2 & 501 & 7.2 & 1185 \\
\hline Higher & 7.0 & 319 & 5.7 & 223 & 4.5 & 241 & 4.8 & 521 \\
\hline Mother's religion & & & & & & & & \\
\hline
\end{tabular}




\begin{tabular}{|c|c|c|c|c|c|c|c|c|}
\hline \multirow{2}{*}{ Background Characteristics } & \multicolumn{2}{|c|}{2005 DHS } & \multicolumn{2}{|c|}{ 2010-11 DHS } & \multicolumn{2}{|c|}{2015 DHS } & \multicolumn{2}{|c|}{2017 DHS } \\
\hline & $\%$ & $\mathbf{n}$ & $\%$ & $\mathbf{n}$ & $\%$ & $\mathbf{n}$ & $\%$ & $\mathbf{n}$ \\
\hline Christian & 8.1 & 389 & 2.2 & 302 & 7.2 & 237 & 3.1 & 394 \\
\hline Muslim & 20.8 & 11467 & 12.2 & 9385 & 14.8 & 7236 & 14.3 & 13605 \\
\hline \multicolumn{9}{|l|}{ Wealth quintile } \\
\hline Lowest & 26.8 & 2639 & 21.2 & 2292 & 25.4 & 1777 & 25.8 & 3291 \\
\hline Second & 31.6 & 2669 & 13.7 & 2125 & 19.2 & 1636 & 18.3 & 3122 \\
\hline Middle & 21.2 & 2492 & 11.3 & 1898 & 15.3 & 1531 & 11.5 & 2821 \\
\hline Higher & 12.6 & 2201 & 6.8 & 1909 & 5.0 & 1359 & 5.3 & 2564 \\
\hline Highest & 3.5 & 1877 & 2.4 & 1516 & 2.8 & 1225 & 3.5 & 2211 \\
\hline
\end{tabular}

*In SDHS 2005, FGM/C questions were asked about most recently cut daughters of any age; in this analysis, sample size is limited to most recently cut girls ages 0-14. In SDHS 2010-11 SDHS, FGM/C questions were asked for all daughters ages 0-10. In SDHS 2015 and 2017, FGM/C questions were asked for all daughters ages 0-14. Bivariate association tests of FGM/C status and background characteristics are statistically significant $(p<0.05)$.

\section{Prevalence among girls according to social norms associated with FGM/C continuation}

A mother's opinion of FGM/C's continuation or discontinuation represents likelihoods of FGM/C decisions, especially for girls under her care (Hernlund and Shell-Duncan 2007, Shell-Duncan and Hernlund 2006). Cut daughters are more frequent, in all years, among mothers who want FGM/C to continue than they are among mothers want it discontinued, or who are ambivalent. In 2017 only three percent of girls whose mothers opposed FGM/C were cut, compared to 62 percent of girls whose mothers supported FGM/C. Prevalence tends to be significantly higher among daughters of mothers who believe $\mathrm{FGM} / \mathrm{C}$ is required by religion than among those who do not.

Table 11. FGM/C prevalence among girls*, by mother's FGM/C beliefs, SDHS 2005-2017

\begin{tabular}{|c|c|c|c|c|c|c|c|c|}
\hline & \multicolumn{2}{|c|}{2005 DHS } & \multicolumn{2}{|c|}{ 2010-11 DHS } & \multicolumn{2}{|c|}{2015 DHS } & \multicolumn{2}{|c|}{2017 DHS } \\
\hline & $\%$ & $\mathbf{n}$ & $\%$ & $\mathbf{n}$ & $\%$ & $\mathbf{n}$ & $\%$ & $\mathbf{n}$ \\
\hline \multicolumn{9}{|l|}{ Women's FGM/C Attitudes } \\
\hline Should be continued & 69.8 & 2299 & 53.6 & 1740 & 57.3 & 1412 & 62.3 & 2522 \\
\hline Should be discontinued & 8.6 & 8175 & 2.7 & 6775 & 5.2 & 5194 & 3.3 & 10324 \\
\hline Depends/Don't know & 12.8 & 885 & 8.4 & 469 & 11.3 & 211 & 9.0 & 482 \\
\hline \multicolumn{9}{|l|}{ Women's FGM/C Beliefs } \\
\hline $\mathrm{FGM} / \mathrm{C}$ required by religion & 67.4 & 2220 & 46.6 & 1719 & 54.1 & 1010 & 59.2 & 2052 \\
\hline $\mathrm{FGM} / \mathrm{C}$ is not required by religion & 9.2 & 8151 & 4.5 & 6707 & 9.3 & 5465 & 6.3 & 10553 \\
\hline
\end{tabular}

Another example of social norms are gender norms that define women's social status both within households and surrounding communities. A mother's personal opinion of GBV perpetrated by men, as well as her decision-making power and economic empowerment, may play a significant role in shaping social norms such as practising FGM/C among daughters.

Findings of FGM/C prevalence among girls according to a mother's justification of GBV and her decision-making power for her own health care are shown in Table 12. FGM/C prevalence is significantly higher among daughters whose mothers justify violence perpetuated by men, for whatever reason, compared to girls whose mothers are against GBV. The proportion of cut daughters was equally higher among girls whose mothers either made decisions for their own health care either jointly with their husband or if the decision was made by someone else, compared to girls whose mothers made such decisions themselves. 
Table 12. FGM/C prevalence among girls*, by mother's gender norms, SDHS 2005-2017

\begin{tabular}{|c|c|c|c|c|c|c|c|c|}
\hline & \multicolumn{2}{|c|}{2005 DHS } & \multicolumn{2}{|c|}{ 2010-11 DHS } & \multicolumn{2}{|c|}{2015 DHS } & \multicolumn{2}{|c|}{2017 DHS } \\
\hline & $\%$ & $\mathbf{n}$ & $\%$ & $\mathbf{n}$ & $\%$ & $\mathbf{n}$ & $\%$ & $\mathbf{n}$ \\
\hline \multicolumn{9}{|c|}{$\begin{array}{l}\text { Husband is justified in hitting or beating } \\
\text { his wife if she: }\end{array}$} \\
\hline \multicolumn{9}{|l|}{ Burns the food } \\
\hline Yes & 19.8 & 3012 & 16.3 & 2717 & 17.0 & 2025 & 18.9 & 3883 \\
\hline No & 20.8 & 8729 & 10.2 & 6994 & 13.8 & 5500 & 12.1 & 10101 \\
\hline \multicolumn{9}{|l|}{ Neglects children } \\
\hline Yes & 20.3 & 6269 & 15.3 & 4462 & 18.2 & 3899 & 18.4 & 5940 \\
\hline No & 20.7 & 5504 & 9.0 & 5254 & 11.0 & 3627 & 10.7 & 8044 \\
\hline \multicolumn{9}{|l|}{ Argues with him } \\
\hline Yes & 21.5 & 6312 & 14.9 & 4869 & 17.4 & 3940 & 19.2 & 6098 \\
\hline No & 19.6 & 5381 & 8.9 & 4818 & 11.6 & 3584 & 9.9 & 7879 \\
\hline \multicolumn{9}{|l|}{ Goes out without telling him } \\
\hline Yes & 21.8 & 6588 & 15.8 & 4554 & 19.1 & 3826 & 18.7 & 5834 \\
\hline No & 18.7 & 5138 & 8.4 & 5142 & 10.0 & 3698 & 10.5 & 8147 \\
\hline \multicolumn{9}{|l|}{ Refuses to have sex with him } \\
\hline Yes & 20.7 & 6156 & 14.5 & 5221 & 17.2 & 3955 & 18.3 & 6424 \\
\hline No & 20.6 & 5532 & 8.6 & 4452 & 11.8 & 3568 & 10.2 & 7553 \\
\hline \multicolumn{9}{|l|}{$\begin{array}{l}\text { Final say in making decisions on } \\
\text { women's own health care }\end{array}$} \\
\hline Self only & 25.2 & 1784 & 23.3 & 1053 & 20.1 & 405 & 14.6 & 1015 \\
\hline Jointly with husband/someone else & 22.0 & 804 & 26.9 & 1696 & 38.3 & 1071 & 22.2 & 2527 \\
\hline Husband/someone else only & 19.4 & 9261 & 30.2 & 6407 & 27.8 & 5618 & 30.7 & 9567 \\
\hline
\end{tabular}

*In the 2005 SDHS, FGM/C questions were asked about most recently cut daughters of any age; in this analysis, sample size is limited to most recently cut girls ages 0-14. In the 2010-11 SDHS, FGM/C questions were asked for all daughters ages 0-10. In the 2015 and 2017 SDHS, FGM/C questions were asked for all daughters ages 0-14. Bivariate association tests of FGM/C status and background characteristics are statistically significant $(p<0.05)$.

Table 13 shows findings on FGM/C prevalence among girls by mother's economic opportunities. Similar to trends observed among women aged 15-49 years, the prevalence of FGM/C was significantly higher among daughters of women working in the informal sector, working on a seasonal basis, and those who worked but were not compensated either in cash or kind or both. Daughters of women working in the formal sector, employed all year, and paid in cash or kind or both experienced fewer cases of FGM/C. 
Table 13. Girls' FGM/C prevalence*, by mother's employment and earnings, SDHS 2005-2017

\begin{tabular}{|c|c|c|c|c|c|c|c|c|}
\hline & \multicolumn{2}{|c|}{2005 DHS } & \multicolumn{2}{|c|}{ 2010-11 DHS } & \multicolumn{2}{|c|}{2015 DHS } & \multicolumn{2}{|c|}{2017 DHS } \\
\hline & $\%$ & $\mathbf{n}$ & $\%$ & $\mathbf{n}$ & $\%$ & $\mathbf{n}$ & $\%$ & $\mathbf{n}$ \\
\hline \multicolumn{9}{|l|}{ Mother's occupation } \\
\hline Formal & 15.6 & 3932 & 8.5 & 3366 & 9.8 & 2169 & 8.0 & 4881 \\
\hline Informal & 31.3 & 2301 & 19.2 & 1444 & 20.9 & 2787 & 17.3 & 4579 \\
\hline Not working & 19.5 & 5606 & 12.1 & 4919 & 12.0 & 2517 & 17.0 & 4426 \\
\hline \multicolumn{9}{|l|}{ Mother's employment } \\
\hline All year & 15.9 & 2936 & 9.2 & 2521 & 10.1 & 2696 & 8.0 & 5489 \\
\hline Seasonal/occasional & 26.1 & 3312 & 14.3 & 2316 & 22.8 & 2316 & 18.5 & 4112 \\
\hline \multicolumn{9}{|c|}{ Mother works for cash (only/and in kind) } \\
\hline Yes & 18.6 & 4845 & 9.5 & 4124 & 12.2 & 3909 & 9.9 & 7568 \\
\hline No & 30.5 & 1413 & 23.8 & 712 & 29.2 & 1102 & 22.4 & 2033 \\
\hline
\end{tabular}

*In the 2005 SDHS, FGM/C questions were asked about most recently cut daughters of any age; in this analysis, sample size is limited to most recently cut girls ages 0-14. In the 2010-11 SDHS, FGM/C questions were asked for all daughters ages 0-10. In the 2015 and 2017 SDHS, FGM/C questions were asked for all daughters ages 0-14. Bivariate association tests for FGM/C status and background characteristics are statistically significant $(p<0.05)$.

The proportion of girls who were cut was higher among daughters of women who made no significant trips than it was among those who made at least one trip in the last 12 months. From 2005 to 2017, girls whose mothers had never been exposed to newspapers, magazines, radio, or television experienced significantly higher rates of $\mathrm{FGM} / \mathrm{C}$ than those whose mothers were exposed to mass media.

Table 14. Girls' FGM/C prevalence*, by mother's mobility and media exposure, SDHS 2005-2017

\begin{tabular}{|c|c|c|c|c|c|c|c|c|}
\hline & \multicolumn{2}{|c|}{2005 DHS } & \multicolumn{2}{|c|}{ 2010-11 DHS } & \multicolumn{2}{|c|}{2015 DHS } & \multicolumn{2}{|c|}{2017 DHS } \\
\hline & $\%$ & $\mathbf{n}$ & $\%$ & $\mathbf{n}$ & $\%$ & $\mathbf{n}$ & $\%$ & $\mathbf{n}$ \\
\hline \multicolumn{9}{|c|}{ Mother's trips (overnight) in last 12 months } \\
\hline 0 & & & 14.7 & 4350 & 21.1 & 2752 & & \\
\hline $1-25$ & & & 9.7 & 5281 & 10.7 & 4673 & & \\
\hline $26-50$ & & & 11.5 & 58 & 20.5 & 69 & & \\
\hline 51 or more & & & 0.7 & 52 & 20.0 & 34 & & \\
\hline \multicolumn{9}{|c|}{ Mother's newspaper or magazine reading } \\
\hline Not at all & 22.2 & 10500 & 12.9 & 8644 & 15.6 & 6915 & 15.4 & 12240 \\
\hline Less than once a week & 6.6 & 705 & 6.1 & 567 & 5.0 & 283 & 5.2 & 1097 \\
\hline At least once a week & 6.5 & 631 & 2.2 & 529 & 3.9 & 331 & 2.7 & 671 \\
\hline \multicolumn{9}{|c|}{ Mother's radio listening frequency } \\
\hline Not at all & 33.1 & 1104 & 12.5 & 1874 & 18.0 & 1344 & 19.2 & 2173 \\
\hline Less than once a week & 13.9 & 1365 & 15.5 & 2223 & 15.5 & 2065 & 16.3 & 4618 \\
\hline At least once a week & 17.9 & 2397 & 10.3 & 5644 & 13.1 & 4120 & 10.9 & 7217 \\
\hline \multicolumn{9}{|c|}{ Mother's television viewing frequency } \\
\hline Not at all & 29.0 & 4083 & 17.0 & 3399 & 21.3 & 2670 & 23.7 & 3957 \\
\hline Less than once a week & 17.7 & 1750 & 15.6 & 1382 & 19.3 & 1203 & 19.3 & 2798 \\
\hline At least once a week & 19.3 & 1708 & 7.3 & 4959 & 8.2 & 3655 & 6.6 & 7253 \\
\hline
\end{tabular}

*In the 2005 SDHS, FGM/C questions were asked about most recently cut daughters of any age; in this analysis, sample size is limited to most recently cut girls ages 0-14. In the 2010-11 SDHS, FGM/C questions were asked for all daughters ages 0-10. In the 2015 and 2017 SDHS, FGM/C questions were asked for all daughters ages 0-14. Bivariate association tests for FGM/C status and background characteristics are statistically significant $(p<0.05)$. 


\section{Inter-Generational Changes: Mother and Daughter Comparisons}

In many places, $\mathrm{FGM} / \mathrm{C}$ is considered a tradition passed from one generation to another, so mother and daughter comparisons of FGM/C over time were conducted to see whether the practice is being passed from mothers to daughters, and conducted in similar ways, or whether there are intergenerational shifts (Shell-Duncan et al 2017). Because currently uncut daughters may still be cut in the future, direct comparisons of FGM/C prevalence among daughters ages 0 to 14 to mothers ages 15 to 49 may not provide a completely accurate picture of inter-generational changes. Such comparisons must consider the issue of censoring during data analysis.

\section{Age at cutting for women and girls}

A simple approach for mother and daughter comparisons with greater validity (although still affected by censoring) is comparing age-specific cutting rates of women and girls of different ages. This method allows comparison of the proportion of girls already cut by their present age to the proportion of women who reported having been cut at a certain age. In all four surveys, about seven in 10 of cut women were cut at age four or younger (ranging from $68 \%$ to $80 \%$ ). An even higher percentage of girls were cut at age four or younger (ranging from $77 \%$ to $94 \%$ ). For both women and girls, the proportion of those cut before age five has been increasing.

Figure 17. Comparison of age at cutting between women ages 15 to 49 and girls ages 0 to $14^{\star}$ by age group, SDHS 2005-2017

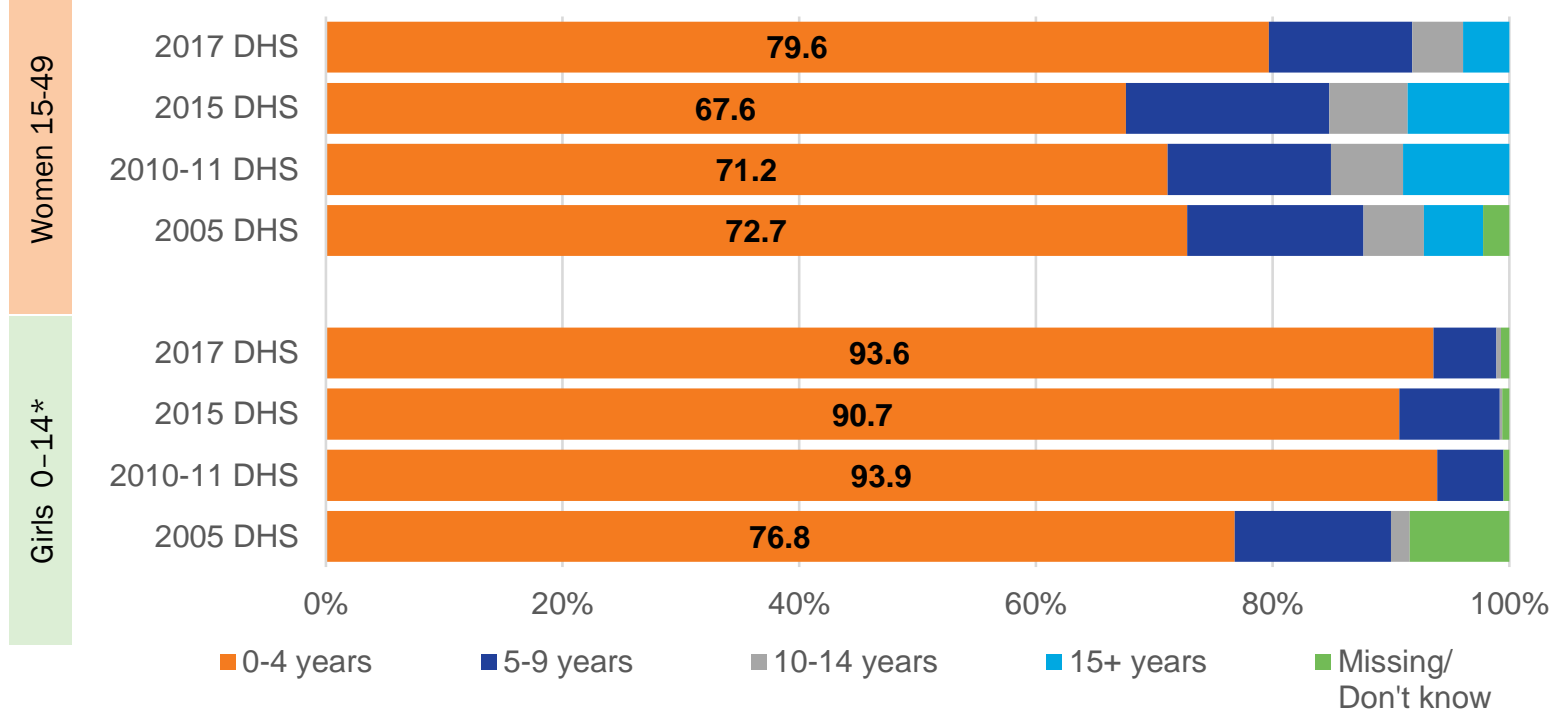

*In the 2010-11 SDHS, FGM/C questions were asked for all daughters ages 0-10. In the 2015 and 2017 SDHS, FGM/C questions were asked for all daughters ages 0-14.

Table 15 presents a more detailed picture on the specific age at cutting by comparing the median age at cutting between mothers and daughters across surveys. Although direct comparison of median ages at cutting among women and girls is subject to censoring, as a portion of currently uncut girls may be cut in the future, findings show that most women and girls in Senegal were cut before their first birthday.

Table 15. Median age at cutting for women ages 15 to 49 and girls ages 0 to 14, SDHS 2005-2017

\begin{tabular}{|lcccccccc|} 
& \multicolumn{2}{c}{ 2005 SDHS } & \multicolumn{2}{c}{ 2010 SDHS } & \multicolumn{2}{c|}{ 2015 SDHS } & \multicolumn{2}{c|}{ 2017 SDHS } \\
& Women & Girls & Women & Girls & Women & Girls & Women & Girls \\
Median Age (years) & 0 & 1 & 0 & 1 & 0 & 1 & 0 & 0 \\
Range (min-max) & $0-27$ & $0-14$ & $0-29$ & $0-8$ & $0-27$ & $0-10$ & $0-25$ & $0-14$ \\
Total cut (unweighted) & 4,954 & 2,993 & 5,280 & 1,720 & 2,981 & 1,772 & 5,569 & 3,046 \\
\hline
\end{tabular}

In 2005, only 15 women were cut at age 16 or older, 2 from ages 25 to 27; 3 girls were cut between age 11 and 14 in 2017. 
A special statistical analytical technique, survival analysis, helped account for censoringsystematic under-representation of girls cut at later ages resulting in under-estimation of median age at cutting. Survival analysis can handle censored data, for more accurate comparisons of estimates between mothers and daughters. Findings show that in 2017 daughters had been cut at a much younger age than their mothers, suggesting that the trend of decreasing age at cutting detected among cohorts of adult women is continuing into the next generation. Analysis stratified by ethnicity reveals that women belonging to the Poular, Mandingue, and Soninke ethnic groups are cut at much younger ages than women from other ethnic groups.

Figure 18. Kaplan-Meier survival estimate curves of age at cutting for girls ages 0 to 14 and women ages 15 to 49, SDHS 2017

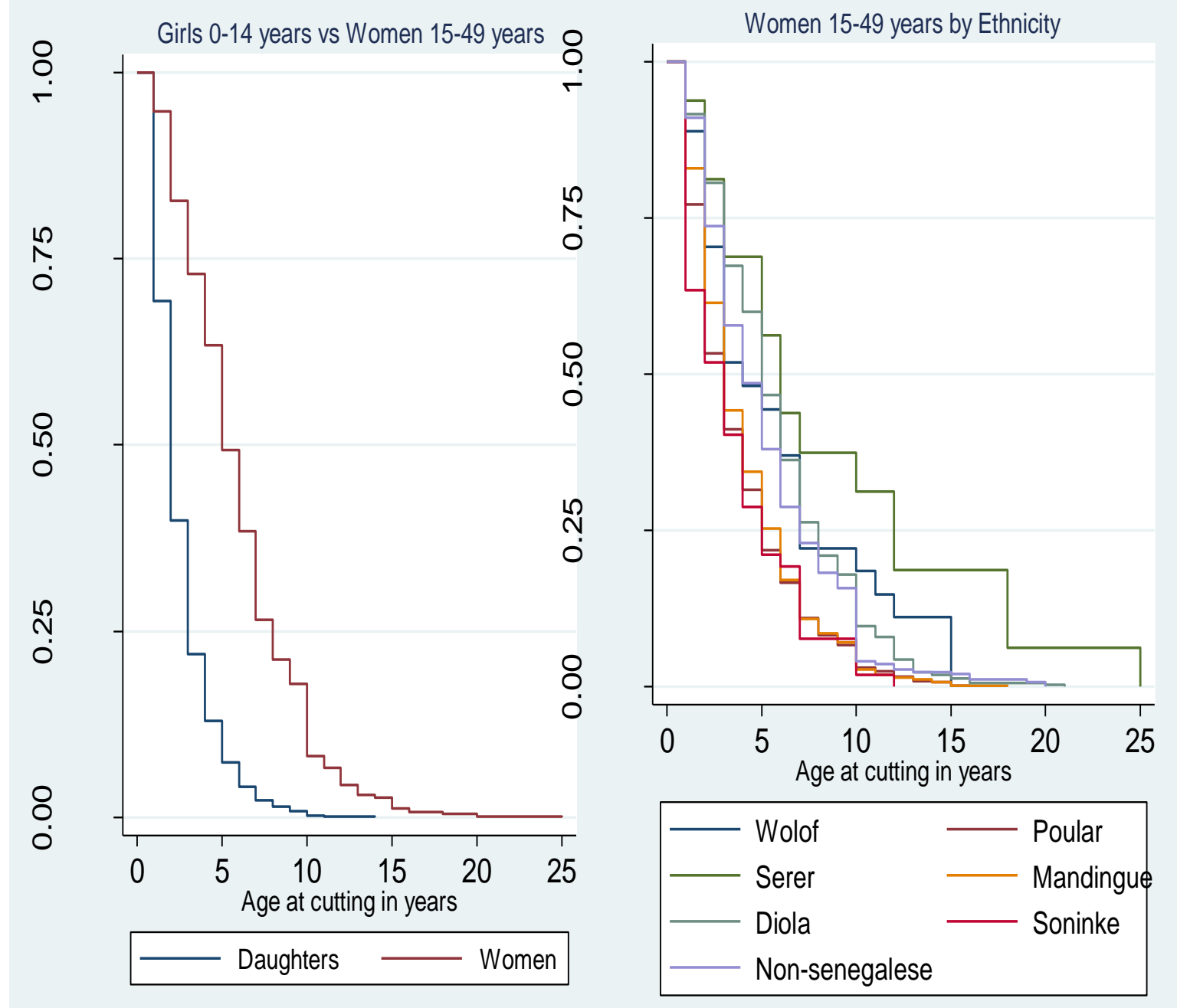

\section{Those who cut women and girls}

$\mathrm{FGM} / \mathrm{C}$ is illegal in Senegal, so those who perform it commit a criminal offense, which makes investigating cutters of particular interest, especially whether they have changed over the years. A large majority of women and girls in Senegal (more than 9 in 10) were cut by traditional circumcisers. This trend has been stable over years and generations. 
Figure 19. Who performed FGM/C on women ages 15 to 49 and girls ages 0 to 14, SDHS 2005-2017

Women 15 - 49

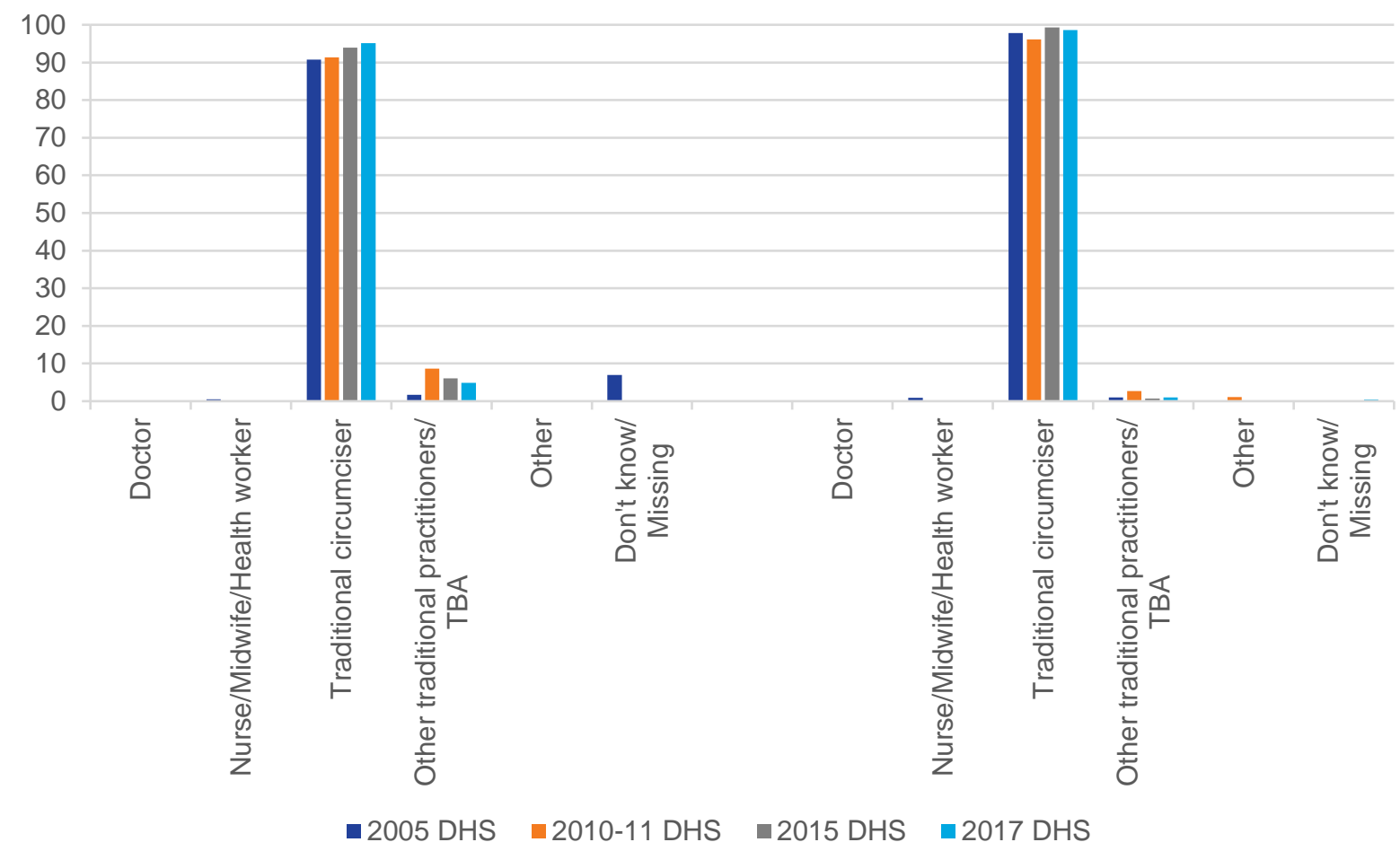

\section{Types of FGM/C among women and girls}

Comparing types of FGM/C among mothers and daughters makes it possible to examine potential changes in type of cutting across generations. Figure 20 shows that between three percent and 21 percent of cut women and girls reportedly had the most invasive form of FGM/C, in which the labia are removed, and vaginal opening narrowed by creating a covering seal (infibulation). In all survey years, data indicate a great deal of inter-generational stability in cutting types for mothers and daughters, with a majority experiencing forms of FGM/C other than infibulation. In Senegal there is a form of FGM/C called "sealing"-cut labia are allowed to adhere, but there is not sewing, and it still forms a tissue connection that covers the vagina (Shell-Duncan et al 2018). How DHS questions are worded may make it difficult to capture this type of FGM/C.

Figure 20. Type III (sewn closed) and other forms (not sewn closed) of FGM/C among women ages 15 to 49 and girls ages 0 to 14, SDHS 2005-2017

$$
\text { Women 15-49 }
$$

Girls $0-14$

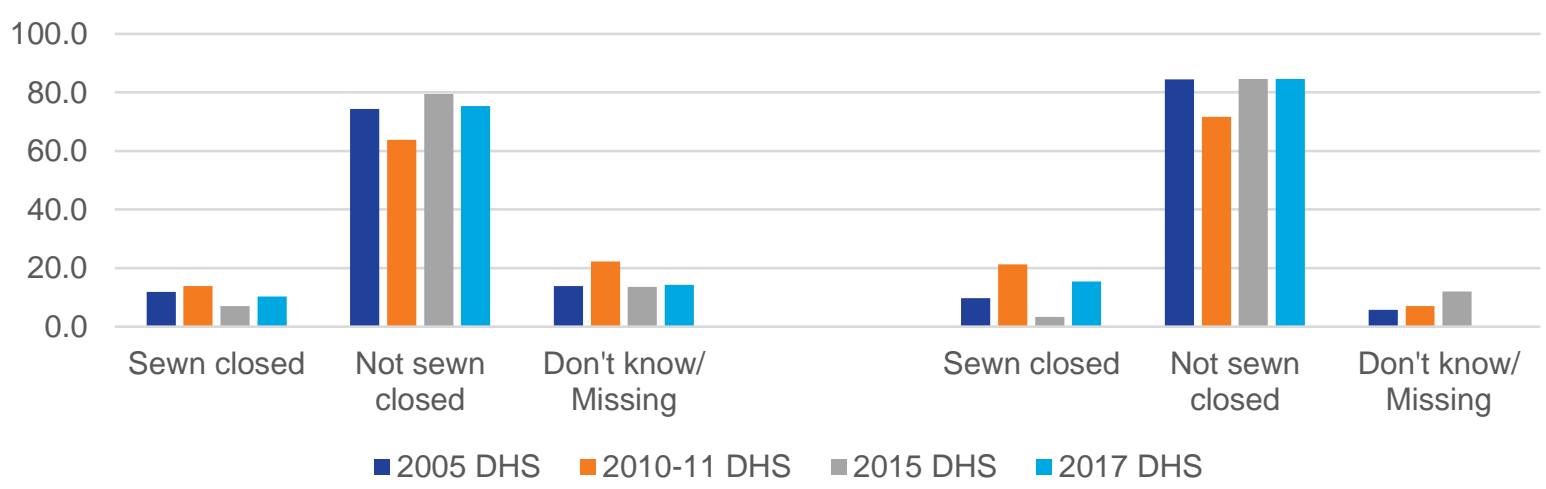




\section{Discussion}

This study set out to investigate where, when, and how FGM/C is practised in Senegal, with the first objective of examining changes in national prevalence of $\mathrm{FGM} / \mathrm{C}$ over time among women ages 15 to 49 and girls ages 0 to 14 . Given the many interventions that have been undertaken in Senegal, the key question was: To what extent has the practice been declining? Study findings show, for women ages 15 to 49, that FGM/C prevalence declined from 2005 to 2017 by four percentage points, but prevalence was stagnant at 24 percent in 2015 and 2017. Categorising women into five year age cohorts revealed that between 2005 and $2017 \mathrm{FGM} / \mathrm{C}$ prevalence was steady in the older cohorts, with a general minimal decline in prevalence among the younger cohorts. Among girls 0 to 14 years of age, prevalence declined from 2005 and 2010-11, followed by a slight increase in 2015, followed by stagnation between 2015 and 2017 .

These national changes for women and girls point to general decline in $\mathrm{FGM} / \mathrm{C}$ prevalence from 2005 to $2010-11$ followed by stagnation between $2010-11$ and 2017. It is possible that intervention efforts to reduce FGM/C in Senegal were effective in earlier years (2005 to 2010-11) but had limited effects in reducing $\mathrm{FGM} / \mathrm{C}$ rates, especially among younger cohorts in subsequent years. A recent situation analysis of $\mathrm{FGM} / \mathrm{C}$ interventions in Senegal found that evaluations of interventions are limited, with no evidence on whether approaches by various organisations led to actual FGM/C abandonment across the country (Kandala et al, Unpublished report).

National estimates can obscure regional variations, and so the second objective of this study was to investigate variations in $\mathrm{FGM} / \mathrm{C}$ prevalence by geographic zones as well as socio-demographic characteristics. There are significant differences in FGM/C prevalence among regions of Senegal. Regions in 2005 with the highest FGM/C prevalences for women ages 15 to 49 included Kolda, Matam, and Tambacounda, and there have been clear declines in prevalence among women in Kolda, Matam, Tambacounda, as well as Sedhiou. For girls ages 0 to 14, prevalence in 2005 was highest in Matam region and lowest in Diourbel region, with trends over time showing a general decline in $\mathrm{FGM} / \mathrm{C}$ prevalence in Kolda region. In Matam region, prevalence among girls declined in early surveys but then increased. In Tambacounda region, prevalence among girls declined between 2005 and 2010-11, followed by stagnation, while in Kedougou region the proportion of cut girls from steadily rose from 2010-11 through 2017.

Regional variations in $\mathrm{FGM} / \mathrm{C}$ prevalence need to be interpreted in relation to $\mathrm{FGM} / \mathrm{C}$ interventions taking place in specific regions. The well-known Tostan programme has been implementing interventions for decades in various regions of Senegal. A 2008 evaluation of Tostan in Kolda, Thiès, and Fatick regions revealed that $F G M / C$ was still practised in the villages surveyed, but the frequency of $\mathrm{FGM} / \mathrm{C}$ practice had significantly decreased in intervention sites compared to control sites (Diop and Askew 2009, UNICEF 2008). Inferences from these study findings indicate a possibility that interventions in Kolda region are yielding results, as the region experienced a general decline in FGM/C prevalence among both women and girls; interventions in Kedougou region have not been that successful, as that region saw $\mathrm{FGM} / \mathrm{C}$ rates for both women and girls increase over the years.

Differences in rural or urban residence closely relate to regional variations in FGM/C prevalence. From 2005 through 2017, the proportion of women and girls who were cut was substantially higher in rural areas. Rural settings are more likely to be occupied by homogenous communities with limited cultural diversity compared to urban settings. In a rural setting where most members favour continuation of $F G M / C$, those who challenge it could face sanctions. Urban settings may be more culturally diverse, offering opportunity for interaction among communities that practise $\mathrm{FGM} / \mathrm{C}$ and those that do not. Those in urban contexts who challenge FGM/C may face fewer sanctions (Mackie and LeJeune 2009, Shell-Duncan et al 2017). 
$\mathrm{FGM} / \mathrm{C}$ prevalence among women and girls varies substantially by ethnicity. Few women and girls from Wolof and Serer ethnic groups experience FGM/C compared to higher rates reported among other ethnic groups such as the Soninke. FGM/C is possibly a powerful marker of ethnic identity among communities with higher prevalences (Gruenbaum 2001). Between 2005 and 2017, the proportion of cut women reduced among the Poular, Soninke, and non-Senegalese, but there were minimal changes in FGM/C prevalence among women of Mandingue and Diola ethnicities. Among the Poular, the proportion of cut girls reduced between 2005 and 2010-11, slightly increased between 2010-11 and 2015, then stagnated from 2015 to 2017. Among the Mandingue, prevalence dropped between 2005 and 2010-11 but then increased in subsequent years.

In-depth analysis of FGM/C ethnic and religious prevalence using the most recent SDHS (2017) reveals fascinating results: Women ages 15 to 49 and girls ages 0 to 14 from communities such as the Wolof and Serer, traditionally understood not to practise $F G M / C$, reported having been cut within geographic regions of high FGM/C prevalence (Matam, Kedougou, Zuguinchor, and Sedhiou). These findings show that in communities where there is a strong link between $\mathrm{FGM} / \mathrm{C}$ and ethnicity, there is a possibility that ethnicity signals reciprocal expectations that preserve the practice. The reciprocal expectations affect ethnic communities that traditionally practise $\mathrm{FGM} / \mathrm{C}$ and those that do not but live in areas where the practice is prevalent. In this scenario, ethnicity and region of residence act as proxies for shared FGM/C values (Gruenbaum 2001, Kandala and Komba 2015).

Other key socio-demographic findings show differences in FGM/C prevalence according to education, religion, and household wealth. In every SDHS, for both women and girls, high FGM/C prevalence is associated with less education among women and their husbands or partners, in addition to Islamic religious affiliation and lower socio-economic status. These findings are not unique to Senegal, as similar findings have occurred in other settings (Shell-Duncan et al 2017, UNICEF 2005). A woman's educational attainment may have indirect associations with $F G M / C$ in settings such as Senegal where cutting occurs early in life before educational attainment. Nonetheless, parents with no education and living in poverty are likely to engage in traditional practices and less likely to challenge the status quo (UNICEF 2005). Socio-economic improvements could lead to broader social effects, including weakened traditional family structures, and changing women's social and economic roles, which can herald a decline in support for FGM/C (Hayes 1975, Hayford 2005, Kennedy 1970, Van Der Kwaak 1992, Yount 2002).

$\mathrm{FGM} / \mathrm{C}$ has often been linked to Islam due to its frequency of the practice in many African Muslim groups. It is important to note, however, that not all Islamic groups practise FGM/C, and many nonIslamic groups practise $\mathrm{FGM} / \mathrm{C}$. It has been observed that the primary religious groupsChristianity, Judaism, and Islam—have at one time practised FGM/C (Gruenbaum 2001).

The third objective was to investigate differences in prevalence by social norms and beliefs, including women's decision-making power, economic opportunities, mobility, and exposure to mass media. Trends in support for FGM/C's continuation and readiness to change among women who were cut were also investigated. Study findings show that, among both women and girls, higher FGM/C prevalence is consistently associated with belief by a woman that FGM/C should be continued, and that $F G M / C$ is required by religion. In all four surveys, higher rates of $F G M / C$ among both women and girls are equally associated with women's justification of GBV, their limited decision-making power for their own health care, work in the informal sector, or seasonal work, and lack of formal compensated for work. Women's support for continuation of FGM/C and GBV, their restricted decision-making power, and limited access to economic opportunities are proxy indicators of prevailing social norms that can sustain the practice (Hernlund and Shell-Duncan 2007, Mackie and LeJeune 2009, Shell-Duncan and Hernlund 2006). 
With regards to a woman's mobility and access to mass media, higher FGM/C prevalence among women and girls was synonymous with women's lack of mobility away from their communities and lack of exposure to any form of mass media. A woman's lack of mobility and exposure to mass media denies her the opportunity to interact with people with differing opinions or accessing information that could spur dialogue questioning prevailing practices such as FGM/C. The social norms theory posits that ongoing interactions with members outside the social networks who do not share expectations related to FGM/C may contribute to shifting opinions regarding $\mathrm{FGM} / \mathrm{C}$ (Hernlund \& Shell-Duncan, 2007; Mackie \& LeJeune, 2009; Shell-Duncan \& Hernlund, 2006).

Findings on trends in support for the continuation of FGM/C showed that in Senegal, the proportion of women who want $\mathrm{FGM} / \mathrm{C}$ to continue had minimally reduced. A comparison on the level of support for FGM/C against FGM/C prevalence across successive surveys showed that the level of support for $F G M / C$ among women has been consistently lower than the prevalence of $F G M / C$. Results on readiness to change among cut women in Senegal indicated that across the successive surveys, the proportion of women who support the continuation of FGM/C and have or will cut their daughters in future (willing adherents) has reduced from 40 percent in 2005 to 22 percent in 2017. On the other hand, the proportion of women who prefer to continue FGM/C but will not perform FGM/C on their daughters (reluctant abandoners) and women who favour stopping FGM/C and will not perform FGM/C on their daughters (willing abandoners) has increased over time. A study conducted in Senegal and The Gambia found that there was a broad range of realities inhabited by people who practise FGM/C in the two countries. There were people who strongly supported or opposed $\mathrm{FGM} / \mathrm{C}$ but with the potential movement over time from one category to another, and potentially back again (Shell-Duncan \& Hernlund, 2006).

The fourth objective was to explore inter-generational differences in age at cutting, types of $F G M / C$, and persons performing $\mathrm{FGM} / \mathrm{C}$. In Senegal, most women and girls are cut before they celebrate their first birthday. Daughters are cut at a much younger age than their mothers were, and women from the Poular, Mandingue, and Soninke ethnic groups were cut at much younger ages than women from other ethnic groups. Trends in individuals providing FGM/C show that a large majority of women and girls in Senegal are cut by traditional circumcisers. In every survey, data on types of $\mathrm{FGM} / \mathrm{C}$ experienced by mothers and daughters indicate inter-generational stability, with most mothers and daughters experiencing forms of FGM/C besides the severest type, infibulation.

These findings illustrate both inter-generational shifts and stability in FGM/C practice in Senegal. Shifts include cutting at relatively younger ages for daughters than their mothers experienced, with stability of non-infibulation types performed by traditional circumcisers across generations.

\section{Limitations}

Findings from this study need to be interpreted with caution on the following grounds:

During the 2005 survey, women were asked to provide information about the most recently cut daughter of any age, in the 2010-11 survey the FGM/C questions were asked for all daughters aged 0 to 10 years old, while in the 2015 and 2017 surveys women were asked about the FGM/C status of all daughters 0 to 14 years. These differences in the way FGM/C data for daughters were collected have implications especially in interpreting changes in FGM/C prevalence across surveys. Information on the FGM/C status of one daughter (either eldest or most recently cut) can be used to calculate the proportion of women with at least one living daughter who has undergone FGM/C. However, only considering the FGM/C status of one daughter may limit estimation of the prevalence of $\mathrm{FGM} / \mathrm{C}$ among girls younger than 15 because it does not provide the needed denominator (all girls younger than 15). This limitation applies to surveys prior to 2010 (i.e. the 2005 SDHS), after which FGM/C modules were standardised, with information collected for all 
respondents' living daughters. After close analyses of the pre-2010 surveys in Senegal, FGM/C prevalence was higher than in subsequent surveys (see Figure 11), however, suggesting no underestimation of FGM/C prevalence before the 2010 harmonisation of the module.

It is important to note that not all girls in the age category 0 to 14 years are at a final cutting status. The 14 year age range includes girls who are currently cut, girls who are currently uncut but who will be cut in the future, and girls who are currently uncut and will never be cut. Limitations exist for distinguishing whether the prevalence is declining, or if a substantial proportion of girls are simply not yet old enough to undergo FGM/C. In this study survival analysis adjusted for the effects of censoring when estimating age at cutting.

This study relies upon self-reported data for FGM/C status. Although clinically determined FGM/C status is regarded as the gold standard, studies that have investigated the validity of self-reporting versus clinical examination show that self-reporting is a valid approach, although concurrence between the two approaches varies depending on context (Elmusharaf et al 2006, Morison et al 2001, Odujinrin et al 1989, Population Council 1996, Snow et al 2002). In Sudan, there was a complete agreement (100\%) between what women and girls reported about their FGM/C statuses and what was found in genital inspection (Elmusharaf et al 2006). A community-based study in The Gambia indicated 97 percent concurrence in FGM/C self-reports and clinical examinations (Morison et al 2001). Another Egyptian fertility care study indicated 94 percent concurrence (Population Council 1996), while another study in Nigeria showed 79 percent concurrence (Snow et al 2002). A study in rural Tanzania, however, revealed inconsistencies between self-reported and clinically determined FGM/C statuses, and its authors emphasised that both women and clinicians might incorrectly report a woman's FGM/C status (Klouman et al 2005). It is important to be cognisant of the limitations of self-reported FGM/C status, especially where FGM/C is illegal, conducted early in life, and is less severe (Elmusharaf et al 2006, Klouman et al 2005, Snow et al 2002).

\section{Conclusion}

The four Demographic and Health Surveys in Senegal provide evidence of when, where, and how $\mathrm{FGM} / \mathrm{C}$ is practised among women ages 15 to 49 and girls age 14 and younger. Key national findings reveal that FGM/C prevalence among women and girls declined between 2005 and 201011 , but stagnated in subsequent years, suggesting that FGM/C interventions in Senegal were more effective in their early years but had limited national effects in later years. There is need for further investigations to understand this stagnation.

Analysis indicates significant variations in FGM/C prevalence, according to both geography and socio-demographic characteristics. Regional and residential differences reveal areas of Senegal that have made improvements, while others require attention. Evidence suggests that interventions in Kolda region are successful, as the region experienced a general decline in $\mathrm{FGM} / \mathrm{C}$ prevalence among both women and girls. Rural women and girls in general, however, as well as those in Kedougou region, have experienced increasing FGM/C prevalence. (Kedougou is at the border between Senegal and Guinea, and it is possible that its increases are related to foreign immigration to gold mining areas.) More effort needs to be directed in these areas.

There are significant ethnic differences in FGM/C prevalence, implying that the practice could be linked to ethnic identity. Ethnic trends also reveal variability in changes of FGM/C prevalence over the years among ethnic groups with earlier high prevalences. Proportions of cut women reduced among the Poular, Soninke, and non-Senegalese, but minimal changes were noted among women of Mandingue and Diola ethnicities. The proportion of cut Poular girls reduced between 2005 and 2010-11, slightly increased between 2010-11 and 2015, then stagnated from 2015 to 2017. 
Mandingue girls experienced a decrease in prevalence between 2005 and 2010-11, but prevalence increased in 2015 and 2017.

Importantly, these study findings clearly show that communities traditionally not practising $\mathrm{FGM} / \mathrm{C}$ can experience social pressure to begin the practice if they inhabit areas where $F G M / C$ predominates. Other key socio-demographic findings reveal clear associations between high FGM/C rates and lack of education, among both women and their husbands or partners, along with associations with Muslim women and those of lower socio-economic statuses. There is a need for targeted interventions that are sensitive to the individual characteristics of target populations-in terms of ethnicity, region, women's and their partners' educational attainment, religious affiliation, and socio-economic status.

Findings from this study also show clear associations between $\mathrm{FGM} / \mathrm{C}$ and existing social norms and beliefs, including women's decision-making power, economic opportunities, mobility, and mass media exposure. Greater FGM/C prevalence is consistently associated with belief by women that $\mathrm{FGM} / \mathrm{C}$ should continue and is required by religion, along with justification of GBV, limited decisionmaking power, informal sector and seasonal employment, and lack of formal compensation for work. Programmes should consider these factors when designing and implementing interventions.

The proportion of women in Senegal who want FGM/C to continue has stagnated. Readiness to change questions among cut women reveals that Willing Adherents reduced from 2005 to 2017, while Reluctant Abandoners and Willing Abandoners increased. These findings show the need for concerted efforts targeting women who support FGM/C's continuation and have had, or will have, their daughters cut (willing adherents), and women who prefer to continue FGM/C but will not have FGM/C performed on their daughters (reluctant abandoners), with the intention of transitioning them to become Willing Abandoners - women who favour stopping FGM/C and will have it performed on their daughters.

Inter-generational dynamics create a mixed picture. Over time, daughters are being cut at much younger ages than their mothers. Most women and girls in Senegal were generally cut before their first birthday. Individuals performing FGM/C are generally traditional circumcisers, and most mothers and daughters do experience forms of FGM/C other than infibulation.

\section{Next Steps}

These findings provide useful insights of the changes in $\mathrm{FGM} / \mathrm{C}$ prevalence among women ages 15 to 49 and girls ages 0 to 14 , at national and sub-national levels. This report details changes in FGM/C prevalence from 2005 to 2017, revealing how, where, and in what sub-groups. Although these findings are descriptive, they provide useful information to policy-makers, to guide discussions of policies that can accelerate FGM/C abandonment. This information is equally useful for programme implementers, especially for guidance in where to target their interventions.

The descriptive nature of this study limits a broader understanding of trends over time and the specific factors responsible for observed changes in FGM/C, especially among girls. A multivariate regression modelling approach that accounts for censoring, especially for survey data of girls ages 0 to 14, and controls for effects of time and geographic location, is necessary. Adjusting for censoring, time, and geographic location in a multivariate regression is critical for various reasons. First, as the DHS collects information on current FGM/C status of daughters ages 0 to 14, there is a possibility that a girl who is currently not cut could be cut in the future, or may not ever be cut. Secondly, in settings where FGM/C is a social norm, communities close to one another are more likely to observe the social norm of FGM/C than communities that are farther apart. To address these knowledge deficiencies effectively, the next phase of this study will use multivariate geo- 
additive and survival analysis to develop spatio-temporal models that account for the influence of space. Estimates from such models are precise, as they account for the effects of space, time, and other possible determinants of $\mathrm{FGM} / \mathrm{C}$. 


\section{References}

28 Too Many. 2018. Country Profile: FGM in Senegal. www.28toomany.org/static/media/uploads/Country\%20Research\%20and\%20Resources/Seneg al/senegal country profile v2 (august 2018).pdf

ANSD/Sénégal, A.N. de la S. et de la D. and ICF International. 2016. Senegal Enquête Démographique et de Santé Continue (EDS-Continue) 2015. https://dhsprogram.com/publications/publication-FR320-DHS-Final-Reports.cfm

ANSD/Sénégal, A.N. de la S. et de la D. and ICF International. 2018. Senegal: Enquête Démoggraphique et de Santé Continue (EDS-Continue) 2017. www.dhsprogram.com/publications/publication-FR345-DHS-Final-Reports.cfm

ANSD/Sénégal, A.N. de la S. et de la D. and I.C.F. International. 2012. Enquête Démographique et de Santé à Indicateurs Multiples Sénégal (EDS-MICS) 2010-2011.Calverton, Maryland, USA. http://dhsprogram.com/publications/publication-fr258-dhs-final-reports.cfm

Cislaghi, B., D. Gillespie, G. Mackie. 2016. Analysis: How Values Deliberations Lead to Community Empowerment. In B. Cislaghi, D. Gillespie, \& G. Mackie (eds.), Values Deliberation and Collective Action: Community Empowerment in Rural Senegal (143-186). https://doi.org/10.1007/978-3-319-33756-2 7

Dellenborg, L. 2007. Multiple meanings of female initiation. "Circumcision" among Jola women in Lower Casamance, Senegal (Dissertation). Department of Social Anthropology, School of Global Studies, Göteborg University, Sweden.

Diop, N.J. and I. Askew. 2009. The effectiveness of a community-based education program on abandoning female genital mutilation/cutting in Senegal. Studies in Family Planning 40(4): 307318.

Diop-Diagne, A. 2008. Evaluation of the National Action Plan for the Abandonment of the Practice of Female Genital Mutilation. Dakar: Republic of Senegal, Minister of the Family, National Solidarity, and Feminine Entrepreneurship.

Elmusharaf, S., N. Elhadi, L. Almroth. 2006. Reliability of self-reported form of female genital mutilation and WHO classification: cross sectional study. BMJ 333(7559): 124. https://doi.org/10.1136/bmj.38873.649074.55

Gruenbaum, E. 2001. The female circumcision controversy: an anthropological perspective. University of Pennsylvania Press.

Hayes, R.O. 1975. Female genital mutilation, fertility control, women's roles, and the patrilineage in modern Sudan: a functional analysis1. American Ethnologist 2(4): 617-633. https://doi.org/10.1525/ae.1975.2.4.02a00030

Hayford, S.R. 2005. Conformity and Change: Community Effects on Female Genital Cutting in Kenya. Journal of Health and Social Behavior 46(2): 121-140. https://doi.org/10.1177/002214650504600201

Hernlund, Y. and B. Shell-Duncan. 2007. Contingency, context, and change: Negotiating female genital cutting in the Gambia and Senegal. Africa Today 53(4): 43-57.

Kandala, N.B. and P.N. Komba. 2015. Geographic Variation of Female Genital Mutilation and Legal Enforcement in Sub-Saharan Africa: A Case Study of Senegal. The American Journal of Tropical Medicine and Hygiene 92(4): 838-847. https://doi.org/10.4269/ajtmh.14-0074 
Kandala, N.B. and P.N. Komba. 2018. Female Genital Mutilation around The World:: Analysis of Medical Aspects, Law and Practice. Springer.

Kandala, N.B., P. Komba, C.C. Nnanatu, M. Lubanzadio. (Unpublished report). Situational Analysis of FGM/C Stakeholders and interventions in Senegal.

Kennedy, J.G. 1970. Circumcision and Excision in Egyptian Nubia. Man 5(2): 175-191. https://doi.org/10.2307/2799646

Klouman, E., R. Manongi, K.I. Klepp. 2005. Self-reported and observed female genital cutting in rural Tanzania: associated demographic factors, HIV and sexually transmitted infections. Tropical Medicine \& International Health 10(1): 105-115. https://doi.org/10.1111/j.13653156.2004.01350.x

Mackie, G. and J. LeJeune. 2009. Social Dynamics of Abandonment of Harmful Practices: A new look at the theory. Special Series on Social Norms and Harmful Practices, Innocenti Working Paper 6, 2009-06.

Morison, L., C. Scherf, G. Ekpo, K. Paine, B. West, R. Coleman, G. Walraven. 2001. The longterm reproductive health consequences of female genital cutting in rural Gambia: a communitybased survey. Tropical Medicine and International Health 6(8): 643-653. https://doi.org/10.1046/j.1365-3156.2001.00749.x

Mottin-Sylla, M.H. 1990. L'excision au Sénégal: éléments d'information pour l'action. ENDA, Dakar.

Musoko, A., C. Scoppa, E. Mononcourt. 2012. Girls and Grandmothers Hand-in-Hand: Dialogue between Generations for Community Change. Rome: The Grandmother Project.

Ndiaye, S. and M. Ayad. 2006. Sénégal Enquête Démographique et de Santé 2005. https://dhsprogram.com/publications/publication-FR177-DHS-Final-Reports.cfm

Odujinrin, O.M., C.O. Akitoye, M.A. Oyediran. 1989. A study on female circumcision in Nigeria. West African Journal of Medicine 8(3): 183-192.

OHCHR, UNAIDS, UNDP, UNECA, UNESCO, UNFPA...WHO. 2008. Eliminating female genital mutilation: an interagency statement.

Population Council. 1996. Clinic-based Investigation of the Typology and Self-reporting of FGM in Egypt. www.zohry.com/pubs/egyptFGM.pdf

Shell-Duncan, B. and Y. Hernlund. 2006. Are There "Stages of Change" in the practice of Female Genital Cutting? Qualitative Research Finding from Senegal and the Gambia. African Journal of Reproductive Health 10(2): 57-71.

Shell-Duncan, B., Y. Hernlund, K. Wander, A. Moreau. 2010. Contingency and change in the practice of female genital cutting: Dynamics of decision making in Senegambia. Summary Report 2010.

Shell-Duncan, B., K. Wander, Y. Hernlund, A. Moreau. 2013. Legislating Change? Responses to Criminalizing Female Genital Cutting in Senegal. Law \& Society Review 47(4): 803-835. https://doi.org/10.1111/lasr.12044

Shell-Duncan, B., D. Gathara, Z. Moore. 2017. Female Genital Mutilation/Cutting in Kenya: Is Change Taking Place? Descriptive Statistics from Four Waves of Demographic and Health Surveys. New York: Population Council.

Shell-Duncan, B. and Y. Hernlund. 2000. Female "circumcision" in Africa: culture, controversy, and change. Lynne Rienner Publishers. 
Shell-Duncan, B., A. Moreau, K. Wander, S. Smith. 2018. The role of older women in contesting norms associated with female genital mutilation/cutting in Senegambia: A factorial focus group analysis. PLOS ONE 13(7): e0199217. https://doi.org/10.1371/journal.pone.0199217

Shell-Duncan, B., R. Naik, C. Feldman-Jacobs. 2016. A State-of-Art-Synthesis of Female Genital Mutilation/Cutting: What Do We Know Now? New York: Population Council. www.popcouncil.org/EvidencetoEndFGM-C

Shell-Duncan, B., K. Wander, Y. Hernlund, A. Moreau. 2011. Dynamics of change in the practice of female genital cutting in Senegambia: Testing predictions of social convention theory. Social Science \& Medicine 73(8): 1275-1283. https://doi.org/10.1016/j.socscimed.2011.07.022

Snow, R.C., T.E. Slanger, F.E. Okonofua, F. Oronsaye, J. Wacker. 2002. Female genital cutting in southern urban and peri-urban Nigeria: self-reported validity, social determinants and secular decline. Tropical Medicine and International Health 7(1): 91-100. https://doi.org/10.1046/j.13653156.2002.00829.x

Tostan. 1999. Breakthrough in Senegal: Ending Female Genital Cutting. Population Council Dakar, Senegal.

UN. 2015. The Sustainable Development Goals (SDGs). United Nations. https://sustainabledevelopment.un.org/sdg5

UNICEF. 2005. Female Genital Mutilation/cutting: A Statistical Exploration 2005. UNICEF.

UNICEF. 2008. Long Term Evaluation of the TOSTAN Programme in Senegal: Kolda, Thies and Fatick Region.

UNICEF. 2010. The dynamics of social change towards the abandonment of female genital mutilation/cutting in five African countries. Florence, Italy: UNICEF Innocenti Research Centre.

UNICEF. 2016. Female genital mutilation/cutting: a global concern. UNICEF1-4.

Van Der Kwaak, A. 1992. Female circumcision and gender identity: A questionable alliance? Social Science \& Medicine 35(6): 777-787. https://doi.org/10.1016/0277-9536(92)90077-4

WHO. 2016. Female genital mutilation. Fact Sheet 241, Updated February 2016. www.who.int/mediacentre/factsheets/fs241/en

World Population Review. 2018. Senegal Population 2019 (Demographics, Maps, Graphs). http://worldpopulationreview.com/countries/senegal-population

Yount, K.M. 2002. Like Mother, like Daughter? Female Genital Cutting in Minia, Egypt. Journal of Health and Social Behavior 43(3): 336-358. https://doi.org/10.2307/3090208 


\section{Appendix}

Table A1. Female genital mutilation/cutting (FGM/C) questions administered in the Senegal DHS 2005-2017

\begin{tabular}{|c|c|c|c|c|}
\hline Questions & 2005 DHS & 2010-11 DHS & 2015 DHS & 2017 DHS \\
\hline \multicolumn{5}{|c|}{ WOMAN'S QUESTIONNAIRE } \\
\hline Have you ever heard about female circumcision? & $\sqrt{ }$ & $\sqrt{ }$ & $\sqrt{ }$ & $\sqrt{ }$ \\
\hline $\begin{array}{l}\text { In some countries, there is a practice in which a } \\
\text { girl may have part of her genitals cut. Have you } \\
\text { heard about this practice? }\end{array}$ & $\sqrt{ }$ & $\sqrt{ }$ & $\sqrt{ }$ & $\sqrt{ }$ \\
\hline $\begin{array}{l}\text { Has your genital area been cut? (2005) } \\
\text { Are you circumcised? }(2010-11 ; 2017)\end{array}$ & $\sqrt{ }$ & $\sqrt{ }$ & $\sqrt{ }$ & $\sqrt{ }$ \\
\hline Was any flesh removed from the genital area? & $\sqrt{ }$ & $\sqrt{ }$ & $\sqrt{ }$ & $\sqrt{ }$ \\
\hline $\begin{array}{l}\text { Was the genital area just nicked without } \\
\text { removing any flesh? }\end{array}$ & $\sqrt{ }$ & $\sqrt{ }$ & $\sqrt{ }$ & $\sqrt{ }$ \\
\hline Was your vaginal area sewn closed? & $\sqrt{ }$ & $\sqrt{ }$ & $\sqrt{ }$ & $\sqrt{ }$ \\
\hline How old were you when you were cut? & $\sqrt{ }$ & $\sqrt{ }$ & $\sqrt{ }$ & $\sqrt{ }$ \\
\hline Who performed the circumcision? & $\sqrt{ }$ & $\sqrt{ }$ & $\sqrt{ }$ & $\sqrt{ }$ \\
\hline $\begin{array}{l}\text { Do you think circumcision should be continued, } \\
\text { or should it be discontinued? }\end{array}$ & $\sqrt{ }$ & $\sqrt{ }$ & $\sqrt{ }$ & $\sqrt{ }$ \\
\hline $\begin{array}{l}\text { Do you think that men want this practice to be } \\
\text { continued or abandoned (discontinued)? }\end{array}$ & $\sqrt{ }$ & & & \\
\hline $\begin{array}{l}\text { Do you believe that this practice is required by } \\
\text { your religion? }\end{array}$ & $\sqrt{ }$ & $\sqrt{ }$ & $\sqrt{ }$ & $\sqrt{ }$ \\
\hline $\begin{array}{l}\text { Do you think this practice is required by your } \\
\text { tradition or customs? }\end{array}$ & $\sqrt{ }$ & & & \\
\hline \multicolumn{5}{|c|}{ Questions about female respondent's daughters ${ }^{\star \star}$} \\
\hline $\begin{array}{l}\text { Have any of your daughters been cut? If so, how } \\
\text { many girls were cut? (2005) }\end{array}$ & $\sqrt{ }$ & & $\sqrt{ }$ & $\sqrt{ }$ \\
\hline $\begin{array}{l}\text { To which of your daughters did this happen to } \\
\text { most recently? (2005) }\end{array}$ & $\sqrt{ }$ & & & $\sqrt{ }$ \\
\hline $\begin{array}{l}\text { Has (NAME OF EACH DAUGHTER } \underline{0-10} \\
\text { YEARS) been circumcised? }(2010-11)\end{array}$ & & $\sqrt{ }$ & & \\
\hline $\begin{array}{l}\text { Has (NAME OF EACH DAUGHTER } \underline{0-14} \\
\text { YEARS) been circumcised? }\end{array}$ & & & & $\sqrt{ }$ \\
\hline Was any flesh removed from the genital area? & $\sqrt{ }$ & & & $\sqrt{ }$ \\
\hline $\begin{array}{l}\text { Was her genital area just nicked without } \\
\text { removing any flesh? }\end{array}$ & $\sqrt{ }$ & & & \\
\hline Was her genital area sewn closed? & $\sqrt{ }$ & $\sqrt{ }$ & & $\sqrt{ }$ \\
\hline $\begin{array}{l}\text { How old was (NAME OF DAUGHTER) when she } \\
\text { was circumcised? }\end{array}$ & $\sqrt{ }$ & $\sqrt{ }$ & $\sqrt{ }$ & $\sqrt{ }$ \\
\hline Who performed the circumcision? & $\sqrt{ }$ & $\sqrt{ }$ & $\sqrt{ }$ & $\sqrt{ }$ \\
\hline
\end{tabular}




\begin{tabular}{|c|c|c|c|c|}
\hline Questions & 2005 DHS & 2010-11 DHS & 2015 DHS & 2017 DHS \\
\hline $\begin{array}{l}\text { At the time of circumcision or afterwards, did } \\
\text { (NAME OF THE DAUGHTER) have any of the } \\
\text { following: } \\
\text { Excessive bleeding? } \\
\text { Difficulty in passing urine or urine retention? } \\
\text { Swelling in the genital area? } \\
\text { Infection in the genital area/wound that did not } \\
\text { heal properly? }\end{array}$ & $\sqrt{ }$ & & & \\
\hline $\begin{array}{l}\text { Do you intend to have any of your daughters } \\
\text { circumcised in the future? }\end{array}$ & $\sqrt{ }$ & & & $\sqrt{ }$ \\
\hline $\begin{array}{l}\text { What are the benefits for a girl to be cut? Any } \\
\text { other benefits? }\end{array}$ & $\sqrt{ }$ & & & \\
\hline $\begin{array}{l}\text { What are the benefits for a girl to not undergo } \\
\text { circumcision? Any other benefits? }\end{array}$ & $\sqrt{ }$ & & & $\sqrt{ }$ \\
\hline $\begin{array}{l}\text { Would you say that this practice is a way to } \\
\text { prevent a girl from having sex before marriage or } \\
\text { does it have no effect on premarital sex? }\end{array}$ & $\sqrt{ }$ & & & \\
\hline \multicolumn{5}{|c|}{ MAN'S QUESTIONNAIRE } \\
\hline Have you ever heard of female circumcision? & $\sqrt{ }$ & & & $\sqrt{ }$ \\
\hline $\begin{array}{l}\text { In some countries, there is a practice in which a } \\
\text { girl may have part of her genitals cut. Have you } \\
\text { ever heard about this practice? }\end{array}$ & $\sqrt{ }$ & & & $\sqrt{ }$ \\
\hline $\begin{array}{l}\text { What are the benefits for a girl to be cut? Any } \\
\text { other benefits? }\end{array}$ & $\sqrt{ }$ & & & \\
\hline $\begin{array}{l}\text { What are the benefits for a girl to not undergo } \\
\text { circumcision? Any other benefits? }\end{array}$ & $\sqrt{ }$ & & & \\
\hline $\begin{array}{l}\text { Would you say that this practice is a way to } \\
\text { prevent a girl from having sex before marriage or } \\
\text { does it have no effect on premarital sex? }\end{array}$ & $\sqrt{ }$ & & & \\
\hline $\begin{array}{l}\text { Do you believe that female circumcision is } \\
\text { required by your religion? }\end{array}$ & $\sqrt{ }$ & & & $\sqrt{ }$ \\
\hline $\begin{array}{l}\text { Do you think this practice is required by your } \\
\text { tradition or customs? }\end{array}$ & $\sqrt{ }$ & & & \\
\hline $\begin{array}{l}\text { Do you think circumcision should be continued, } \\
\text { or should it be discontinued? }\end{array}$ & $\sqrt{ }$ & & & $\sqrt{ }$ \\
\hline $\begin{array}{l}\text { Do you think that women want this practice to be } \\
\text { continued or abandoned (discontinued)? }\end{array}$ & $\sqrt{ }$ & & & \\
\hline
\end{tabular}


Table A2. Trends in the FGM/C prevalence among women aged 15-49 years by main demographic characteristics, Senegal 2005 - 2017.

\begin{tabular}{|c|c|c|c|c|c|c|c|c|}
\hline \multirow{2}{*}{ Demographic characteristic } & \multicolumn{2}{|c|}{2005 DHS } & \multicolumn{2}{|c|}{ 2010-11 DHS } & \multicolumn{2}{|c|}{2015 DHS } & \multicolumn{2}{|c|}{2017 DHS } \\
\hline & & Jumber & & lumber & & umber & $\%$ & Number \\
\hline Age & \multicolumn{2}{|c|}{0.394} & \multicolumn{2}{|c|}{0.323} & \multicolumn{2}{|c|}{0.256} & \multicolumn{2}{|c|}{0.078} \\
\hline $15-19$ & 24.8 & 3,556 & 24.0 & 3,429 & 22.2 & 2,003 & 21.4 & 3,728 \\
\hline $20-24$ & 28.1 & 2,844 & 24.3 & 3,220 & 22.3 & 1,641 & 23.3 & 3,080 \\
\hline $25-29$ & 28.4 & 2,379 & 26.1 & 2,746 & 24.6 & 1,667 & 24.5 & 2,808 \\
\hline $30-34$ & 30.1 & 1,953 & 24.9 & 2,148 & 25.1 & 1,247 & 23.2 & 2,590 \\
\hline $35-39$ & 30.5 & 1,613 & 29.0 & 1,817 & 24.2 & 1,030 & 27.2 & 1,878 \\
\hline $40-44$ & 30.3 & 1,249 & 26.9 & 1,379 & 29.4 & 772 & 26.9 & 1,586 \\
\hline $45-49$ & 30.6 & 1,009 & 28.5 & 949 & 27.8 & 492 & 26.1 & 1,117 \\
\hline Marital status & \multicolumn{2}{|c|}{$<0.001$} & \multicolumn{2}{|c|}{$<0.001$} & \multicolumn{2}{|c|}{$<0.001$} & \multicolumn{2}{|c|}{$<0.001$} \\
\hline Never married & 17.0 & 3,941 & 19.4 & 4,585 & 16.5 & 2,709 & 17.1 & 5,079 \\
\hline Currently married/in union & 32.7 & 9,866 & 28.2 & 10,347 & 27.8 & 5,731 & 26.8 & 10,895 \\
\hline Formerly married & 28.7 & 795 & 29.0 & 757 & 25.4 & 412 & 29.1 & 813 \\
\hline $\begin{array}{l}\text { Age difference with } \\
\text { husband/partner (currently }\end{array}$ & \multicolumn{2}{|c|}{0.929} & \multicolumn{2}{|c|}{0.936} & \multicolumn{2}{|c|}{0.266} & \multicolumn{2}{|c|}{$<0.001$} \\
\hline Wife is older & 29.8 & 138 & 25.3 & 262 & 36.1 & 170 & 10.5 & 322 \\
\hline Wife is same age & 28.0 & 76 & 26.1 & 112 & 27.9 & 77 & 22.5 & 94 \\
\hline Wife is $1-4$ years younger & 28.0 & 1,135 & 25.4 & 1,188 & 23.8 & 599 & 24.8 & 1,414 \\
\hline Wife is $5-9$ years younger & 28.7 & 2,285 & 26.8 & 2,406 & 26.4 & 1,413 & 25.7 & 2,743 \\
\hline Wife is $10+$ years younger & 28.1 & 10,968 & 25.5 & 11,719 & 23.5 & 6,592 & 23.9 & 12,213 \\
\hline $\begin{array}{l}\text { Type of union (currently married } \\
\text { women only) }\end{array}$ & \multicolumn{2}{|c|}{0.279} & \multicolumn{2}{|c|}{0.045} & \multicolumn{2}{|c|}{0.456} & \multicolumn{2}{|c|}{0.863} \\
\hline Monogamous & 32.0 & 5,942 & 27.2 & 6,757 & 27.5 & 3,911 & 26.9 & 7,428 \\
\hline Polygamous & 33.4 & 3,764 & 30.2 & 3,577 & 28.5 & 1,818 & 26.8 & 3,449 \\
\hline Residence & \multicolumn{2}{|c|}{$<0.001$} & \multicolumn{2}{|c|}{0.003} & \multicolumn{2}{|c|}{$<0.001$} & & 001 \\
\hline Urban & 21.7 & 7,117 & 23.4 & 7,738 & 18.5 & 4,205 & 19.8 & 8,349 \\
\hline Rural & 34.5 & 7,485 & 27.8 & 7,950 & 29.5 & 4,646 & 28.2 & 8,438 \\
\hline Region & & & & & & & & 001 \\
\hline Dakar & 17.3 & 3,866 & 20.1 & 4,078 & 14.8 & 2,168 & 17.8 & 4,640 \\
\hline Diourbel & 1.8 & 1,548 & 0.5 & 1,851 & 0.7 & 1,066 & 0.7 & 1,864 \\
\hline Fatick & 5.8 & 708 & 7.3 & 717 & 7.0 & 440 & 7.6 & 806 \\
\hline Kaolack & 11.3 & 1,642 & 5.6 & 1,172 & 15.7 & 666 & 9.3 & 1,094 \\
\hline Kolda & 93.8 & 1,047 & 84.8 & 640 & 84.4 & 411 & 63.6 & 729 \\
\hline Louga & 4.1 & 915 & 3.8 & 1,130 & 2.3 & 602 & 4.8 & 1,055 \\
\hline Matam & 93.3 & 543 & 87.2 & 595 & 76.0 & 328 & 73.3 & 606 \\
\hline Saint-Louis & 44.4 & 947 & 39.5 & 1,034 & 36.2 & 526 & 36.0 & 1,082 \\
\hline Tambacounda & 85.6 & 851 & 85.3 & 725 & 79.3 & 372 & 71.8 & 836 \\
\hline Thios & 7.0 & 1,974 & 3.5 & 2,030 & 4.2 & 1,216 & 5.2 & 2,198 \\
\hline Zuguinchor & 69.3 & 562 & 55.5 & 581 & 60.2 & 358 & 68.2 & 607 \\
\hline Kaffrine & na & na & 10.3 & 572 & 8.6 & 348 & 9.5 & 651 \\
\hline Kedougou & na & na & 92.0 & 115 & 82.2 & 79 & 91.0 & 158 \\
\hline Sedhiou & na & na & 86.3 & 448 & 83.0 & 271 & 75.6 & 460 \\
\hline
\end{tabular}




\begin{tabular}{|c|c|c|c|c|c|c|c|c|}
\hline \multirow{2}{*}{ Demographic characteristic } & \multicolumn{2}{|c|}{2005 DHS } & \multirow{2}{*}{\multicolumn{2}{|c|}{ 2010-11 DHS }} & \multicolumn{2}{|c|}{2015 DHS } & \multicolumn{2}{|c|}{2017 DHS } \\
\hline & $\%$ & Number & & & $\%$ & umber & & Vumber \\
\hline Woman's education & \multicolumn{2}{|c|}{$<0.001$} & \multicolumn{2}{|c|}{$<0.001$} & \multicolumn{2}{|c|}{$<0.001$} & \multicolumn{2}{|c|}{$<0.001$} \\
\hline No education & 31.8 & 8,699 & 28.4 & 9,079 & 27.6 & 4,505 & 26.2 & 7,749 \\
\hline Primary & 25.3 & 3,677 & 24.1 & 3,414 & 22.9 & 1,927 & 25.0 & 3,861 \\
\hline Secondary & 19.0 & 2,074 & 20.2 & 2,871 & 20.1 & 2,136 & 20.6 & 4,431 \\
\hline Higher & 20.3 & 152 & 14.3 & 323 & 11.5 & 283 & 16.2 & 745 \\
\hline $\begin{array}{l}\text { Husband's/partner's education } \\
\text { (currently married women only) }\end{array}$ & \multicolumn{2}{|c|}{$<0.001$} & \multicolumn{2}{|c|}{0.098} & \multicolumn{2}{|c|}{$<0.001$} & \multicolumn{2}{|c|}{$<0.001$} \\
\hline No education & 34.5 & 6,693 & 29.2 & 7,702 & 29.8 & 4,012 & 28.8 & 6,578 \\
\hline Primary & 31.0 & 1,196 & 28.7 & 1,211 & 24.7 & 648 & 20.7 & 1,484 \\
\hline Secondary & 27.8 & 1,225 & 28.1 & 940 & 24.1 & 536 & 23.9 & 1,252 \\
\hline Higher & 22.6 & 411 & 21.3 & 354 & 16.8 & 240 & 28.2 & 580 \\
\hline Religion & \multicolumn{2}{|c|}{$<0.001$} & \multicolumn{2}{|c|}{$<0.001$} & \multicolumn{2}{|c|}{$<0.001$} & \multicolumn{2}{|c|}{$<0.001$} \\
\hline Christian & 10.9 & 647 & 6.5 & 656 & 7.8 & 429 & 7.0 & 619 \\
\hline Muslim & 29.1 & 13,931 & 26.5 & 14,997 & 25.0 & 8,380 & 24.7 & 16,160 \\
\hline Ethnicity & \multicolumn{2}{|c|}{$<0.001$} & \multicolumn{2}{|c|}{$<0.001$} & \multicolumn{2}{|c|}{$<0.001$} & \multicolumn{2}{|c|}{$<0.001$} \\
\hline Wolof & 1.6 & 5,799 & 1.0 & 6,066 & 1.3 & 3,524 & 0.7 & 6,313 \\
\hline Poular & 62.1 & 3,684 & 54.5 & 4,164 & 50.7 & 2,341 & 49.3 & 4,383 \\
\hline Serer & 1.8 & 2,316 & 2.3 & 2,353 & 1.1 & 1,330 & 1.2 & 2,824 \\
\hline Mandingue & 73.7 & 674 & 81.9 & 652 & 71.1 & 548 & 74.7 & 928 \\
\hline Diola & 59.7 & 710 & 51.5 & 634 & 47.9 & 324 & 58.6 & 707 \\
\hline Soninke & 78.2 & 402 & 65.0 & 362 & 60.9 & 88 & 63.3 & 234 \\
\hline Other Senegalese & 37.6 & 758 & 32.3 & 1,140 & 31.2 & 472 & 60.1 & 410 \\
\hline Non-Senegalese & 70.7 & 253 & 57.0 & 318 & 69.1 & 224 & 29.3 & 988 \\
\hline $\begin{array}{l}\text { Woman from mixed ethnicity } \\
\text { household (husband/partner from } \\
\text { a different ethnic group; currently } \\
\text { married women only) }\end{array}$ & \multicolumn{2}{|c|}{0.844} & \multicolumn{2}{|c|}{0.126} & \multicolumn{2}{|c|}{0.801} & \multicolumn{2}{|c|}{0.598} \\
\hline Yes & 35.5 & 335 & 34.3 & 540 & 29.5 & 342 & 29.4 & 612 \\
\hline No & 33.3 & 1,125 & 27.8 & 1,276 & 28.4 & 1,106 & 29.6 & 1,863 \\
\hline Wealth Quintile & \multicolumn{2}{|c|}{$<0.001$} & \multicolumn{2}{|c|}{$<0.001$} & \multicolumn{2}{|c|}{$<0.001$} & & 001 \\
\hline Lowest & 38.6 & 2,433 & 42.6 & 2,585 & 42.4 & 1,509 & 40.8 & 2,768 \\
\hline Second & 42.6 & 2,565 & 30.4 & 2,805 & 32.0 & 1,579 & 30.0 & 2,984 \\
\hline Middle & 32.2 & 2,839 & 26.1 & 3,114 & 25.4 & 1,757 & 25.0 & 3,310 \\
\hline Higher & 22.5 & 3,154 & 20.5 & 3,494 & 15.6 & 1,886 & 17.1 & 3,581 \\
\hline Highest & 13.0 & 3,610 & 14.7 & 3,689 & 12.3 & 2,121 & 13.7 & 4,144 \\
\hline Total & 28.2 & 14,602 & 25.7 & 15,688 & 24.2 & 8,851 & 24.0 & 16,787 \\
\hline
\end{tabular}

na=data not available 
Table A3. Trends in the FGM/C prevalence among girls ages $0-14^{\star}$ by main demographic characteristics, SDHS 2005-2017

\begin{tabular}{|c|c|c|c|c|c|c|c|c|}
\hline \multirow{2}{*}{ Demographic characteristic } & \multicolumn{2}{|c|}{2005 DHS } & \multicolumn{2}{|c|}{ 2010-11 DHS } & \multicolumn{2}{|c|}{2015 DHS } & \multicolumn{2}{|c|}{2017 DHS } \\
\hline & $\%$ & Jumber & $\%$ & umber & $\%$ & umber & $\%$ & Jumber \\
\hline Girl's age & \multicolumn{2}{|c|}{$<0.001$} & \multicolumn{2}{|c|}{$<0.001$} & \multicolumn{2}{|c|}{$<0.001$} & \multicolumn{2}{|c|}{$<0.001$} \\
\hline $0-4$ & 15.8 & 4,749 & 8.1 & 5,325 & 9.0 & 3,047 & 9.6 & 5,244 \\
\hline $5-9$ & 22.4 & 3,960 & 16.5 & 4,415 & 17.3 & 2,606 & 15.5 & 5,098 \\
\hline $10-14$ & 24.9 & 3,169 & na & na & 20.1 & 1,876 & 18.1 & 3,667 \\
\hline Mother's age & \multicolumn{2}{|c|}{$<0.001$} & \multicolumn{2}{|c|}{0.068} & \multicolumn{2}{|c|}{0.011} & \multicolumn{2}{|c|}{$<0.001$} \\
\hline $15-19$ & 10.3 & 300 & 14.2 & 295 & 11.7 & 138 & 13.5 & 254 \\
\hline $20-24$ & 15.9 & 1,322 & 12.7 & 1,466 & 10.6 & 694 & 13.0 & 1,196 \\
\hline $25-29$ & 16.2 & 2,320 & 11.1 & 2,431 & 14.1 & 1,676 & 14.9 & 2,614 \\
\hline $30-34$ & 21.8 & 2,865 & 11.7 & 2,327 & 17.0 & 1,773 & 13.7 & 3,646 \\
\hline $35-39$ & 22.8 & 2,492 & 10.8 & 1,852 & 12.3 & 1,684 & 14.1 & 2,901 \\
\hline $40-44$ & 23.5 & 1,656 & 12.0 & 989 & 16.1 & 1,122 & 13.7 & 2,192 \\
\hline $45-49$ & 24.6 & 924 & 18.4 & 380 & 19.9 & 442 & 14.0 & 1,205 \\
\hline Mother's marital status & \multicolumn{2}{|c|}{0.020} & \multicolumn{2}{|c|}{0.118} & \multicolumn{2}{|c|}{0.007} & \multicolumn{2}{|c|}{0.003} \\
\hline Never married & 2.3 & 74 & 5.2 & 201 & 9.9 & 104 & 4.7 & 203 \\
\hline Currently married/in union & 20.7 & 11,214 & 12.1 & 9,186 & 14.8 & 7,122 & 14.1 & 13,149 \\
\hline Formerly married & 17.6 & 590 & 10.3 & 353 & 13.7 & 302 & 15.0 & 656 \\
\hline $\begin{array}{l}\text { Mother's age difference with } \\
\text { husband/partner (currently } \\
\text { married women only) }\end{array}$ & \multicolumn{2}{|c|}{$<0.001$} & \multicolumn{2}{|c|}{0.360} & \multicolumn{2}{|c|}{0.326} & & 03 \\
\hline Wife is older & 25.9 & 152 & 14.6 & 183 & 16.2 & 217 & 5.9 & 385 \\
\hline Wife is same age & 11.6 & 76 & 11.1 & 123 & 7.2 & 91 & 11.1 & 105 \\
\hline Wife is $1-4$ years younger & 14.6 & 1,176 & 12.3 & 1,013 & 13.3 & 668 & 11.4 & 1,617 \\
\hline Wife is $5-9$ years younger & 15.6 & 2,544 & 11.1 & 2,043 & 15.1 & 1,737 & 14.4 & 3,123 \\
\hline Wife is $10+$ years younger & 22.8 & 7,930 & 12.0 & 6,378 & 14.8 & 4,816 & 14.7 & 8,778 \\
\hline Mother's type of union & & 16 & & & & & & 11 \\
\hline Monogamous & 19.5 & 6,251 & 10.9 & 5,818 & 13.6 & 4,507 & 13.2 & 8,219 \\
\hline Polygamous & 22.5 & 4,821 & 14.2 & 3,367 & 16.8 & 2,612 & 15.5 & 4,919 \\
\hline Residence & & 01 & & & & & & 01 \\
\hline Urban & 11.7 & 4,452 & 7.6 & 3,733 & 7.5 & 2,824 & 6.2 & 5,321 \\
\hline Rural & 25.7 & 7,426 & 14.6 & 6,007 & 19.0 & 4,704 & 18.7 & 8,687 \\
\hline Region & & 001 & & & & & & 01 \\
\hline Dakar & 7.1 & 2,302 & 5.6 & 1,888 & 2.1 & 1,322 & 3.8 & 2,752 \\
\hline Diourbel & 0.8 & 1,364 & 0.2 & 1,216 & 0.0 & 931 & 0.2 & 1,822 \\
\hline Fatick & 2.9 & 737 & 0.5 & 563 & 2.8 & 436 & 1.1 & 754 \\
\hline Kaolack & 4.0 & 1,569 & 0.2 & 821 & 7.1 & 647 & 1.6 & 938 \\
\hline Kolda & 68.8 & 1,054 & 40.9 & 506 & 51.8 & 466 & 34.6 & 753 \\
\hline Louga & 3.2 & 832 & 3.4 & 709 & 0.0 & 578 & 1.6 & 956 \\
\hline Matam & 78.4 & 482 & 41.4 & 409 & 57.1 & 278 & 60.6 & 610 \\
\hline Saint-Louis & 41.1 & 785 & 20.6 & 637 & 29.6 & 477 & 31.8 & 897 \\
\hline Tambacounda & 54.8 & 840 & 44.1 & 561 & 41.8 & 418 & 44.0 & 875 \\
\hline Thios & 2.6 & 1,503 & 0.6 & 1,214 & 0.3 & 963 & 1.2 & 1,757 \\
\hline Zuguinchor & 51.9 & 411 & 19.1 & 315 & 42.3 & 251 & 38.5 & 464 \\
\hline Kaffrine & na & na & 2.7 & 466 & 2.6 & 403 & 2.4 & 770 \\
\hline Kedougou & na & na & 17.3 & 96 & 35.7 & 76 & 45.4 & 165 \\
\hline Sedhiou & na & na & 50.3 & 340 & 54.8 & 283 & 43.0 & 494 \\
\hline Mother's education & & 001 & & & & & & 01 \\
\hline No education & 23.7 & 8,796 & 14.0 & 7,134 & 17.4 & 5,270 & 16.3 & 9,313 \\
\hline Primary & 13.5 & 2,215 & 7.1 & 1,905 & 9.8 & 1,574 & 11.0 & 3,053 \\
\hline Secondary & 5.0 & 801 & 3.5 & 654 & 5.6 & 601 & 7.0 & 1,400 \\
\hline Higher & 1.4 & 66 & 0.0 & 47 & 0.8 & 83 & 0.9 & 241 \\
\hline
\end{tabular}




\begin{tabular}{|c|c|c|c|c|c|c|c|c|}
\hline \multirow{2}{*}{ Demographic characteristic } & \multicolumn{2}{|c|}{2005 DHS } & \multicolumn{2}{|c|}{ 2010-11 DHS } & \multicolumn{2}{|c|}{2015 DHS } & \multicolumn{2}{|c|}{2017 DHS } \\
\hline & $\%$ & Number & $\%$ & umber & $\%$ & umber & $\%$ & Number \\
\hline Husband's/partner's education & \multicolumn{2}{|c|}{$<0.001$} & \multicolumn{2}{|c|}{$<0.001$} & \multicolumn{2}{|c|}{$<0.001$} & \multicolumn{2}{|c|}{$<0.001$} \\
\hline No education & 23.3 & 8,111 & 13.7 & 6,848 & 17.9 & 5,164 & 17.2 & 8,630 \\
\hline Primary & 16.5 & 1.275 & 9.0 & 1.068 & 7.1 & 767 & 8.0 & 1.715 \\
\hline Secondary & 12.0 & 1,121 & 7.8 & 699 & 5.2 & 501 & 7.2 & 1,185 \\
\hline Higher & 7.0 & 319 & 5.7 & 223 & 4.5 & 241 & 4.8 & 521 \\
\hline Mother's religion & \multicolumn{2}{|c|}{0.177} & \multicolumn{2}{|c|}{$<0.001$} & \multicolumn{2}{|c|}{0.232} & \multicolumn{2}{|c|}{0.051} \\
\hline Christian & 8.1 & 389 & 2.2 & 302 & 7.2 & 237 & 3.1 & 394 \\
\hline Muslim & 20.8 & 11,467 & 12.2 & 9,385 & 14.8 & 7,236 & 14.3 & 13,605 \\
\hline Mother's ethnicity & \multicolumn{2}{|c|}{$<0.001$} & \multicolumn{2}{|c|}{$<0.001$} & \multicolumn{2}{|c|}{$<0.001$} & \multicolumn{2}{|c|}{$<0.001$} \\
\hline Wolof & 0.7 & 4,461 & 0.3 & 3,596 & 0.5 & 2,901 & 0.3 & 5,052 \\
\hline Poular & 46.2 & 3,301 & 28.0 & 2,794 & 31.1 & 2,254 & 31.1 & 3,949 \\
\hline Serer & 0.8 & 1,992 & 0.5 & 1,514 & 0.5 & 1,126 & 0.1 & 2,500 \\
\hline Mandingue & 50.1 & 557 & 31.7 & 475 & 36.8 & 446 & 39.0 & 871 \\
\hline Diola & 34.8 & 524 & 13.5 & 297 & 37.5 & 170 & 26.2 & 452 \\
\hline Soninke & 54.3 & 309 & 18.5 & 169 & 38.7 & 66 & 32.3 & 185 \\
\hline Other Senegalese & 26.8 & 508 & 13.5 & 657 & 13.9 & 333 & 31.5 & 320 \\
\hline Non-Senegalese & 38.8 & 220 & 19.2 & 239 & 35.5 & 233 & 13.5 & 679 \\
\hline $\begin{array}{l}\text { Woman from mixed ethnicity } \\
\text { household (husband/partner } \\
\text { from a different ethnic group; } \\
\text { currently married women only) }\end{array}$ & \multicolumn{2}{|c|}{0.238} & \multicolumn{2}{|c|}{0.544} & \multicolumn{2}{|c|}{0.089} & \multicolumn{2}{|c|}{$<0.001$} \\
\hline Yes & 20.2 & 378 & 8.7 & 527 & 9.7 & 409 & 9.3 & 754 \\
\hline No & 22.6 & 1,445 & 12.1 & 1.343 & 16.7 & 1,494 & 17.3 & 2,575 \\
\hline Wealth Quintile & \multicolumn{2}{|c|}{$<0.001$} & \multicolumn{2}{|c|}{$<0.001$} & \multicolumn{2}{|c|}{$<0.001$} & \multicolumn{2}{|c|}{$<0.001$} \\
\hline Lowest & 26.8 & 2,639 & 21.2 & 2,292 & 25.4 & 1,777 & 25.8 & 3,291 \\
\hline Second & 31.6 & 2,669 & 13.7 & 2,125 & 19.2 & 1,636 & 18.3 & 3,122 \\
\hline Middle & 21.2 & 2,492 & 11.3 & 1,898 & 15.3 & 1,531 & 11.5 & 2,821 \\
\hline Higher & 12.6 & 2,201 & 6.8 & 1,909 & 5.0 & 1,359 & 5.3 & 2,564 \\
\hline Highest & 3.5 & 1,877 & 2.4 & 1,516 & 2.8 & 1,225 & 3.5 & 2,211 \\
\hline Total & 20.4 & 11,878 & 11.9 & 9,740 & 14.6 & 7,529 & 14.0 & 14,008 \\
\hline
\end{tabular}

*Note: In the 2005 Senegal DHS, the FGM/C questions were asked about the most recently cut daughters of any age; for this analysis, sample size is limited to most recently cut girls aged 0-14. In the 2010-11 Senegal DHS, the FGM/C questions were asked for all daughters aged 0-10 years old. In the 2015 and 2017 Senegal DHS, the FGM/C questions were asked for all daughters aged $0-14$ years old.

na=data not available 
Table A4. Distribution of the person who performed cutting for women aged 15-49 year and girls aged $0-14^{\star}$ years, Senegal 2005-2017.

\begin{tabular}{|c|c|c|c|c|c|c|c|c|}
\hline $\begin{array}{l}\text { Survey and year: } \\
\text { Senegal }\end{array}$ & Doctor & $\begin{array}{l}\text { Nurse/Midwife/ } \\
\text { Other health } \\
\text { worker }\end{array}$ & $\begin{array}{l}\text { Traditional } \\
\text { circumciser }\end{array}$ & $\begin{array}{c}\text { Other traditional } \\
\text { practitioners/ } \\
\text { TBA }\end{array}$ & Other & $\begin{array}{c}\text { Don't } \\
\text { know/ } \\
\text { Missing }\end{array}$ & Total & Number \\
\hline \multicolumn{9}{|l|}{2005 DHS } \\
\hline Women & 0.1 & 0.5 & 90.8 & 1.7 & na & 6.9 & 100.0 & 4,123 \\
\hline Girls & 0.1 & 0.9 & 97.8 & 1.0 & na & 0.2 & 100.0 & 2,423 \\
\hline \multicolumn{9}{|l|}{ 2010-11 DHS } \\
\hline Women & 0.0 & 0.0 & 91.4 & 8.6 & na & 0.0 & 100.0 & 4,025 \\
\hline Girls & 0.0 & 0.0 & 96.1 & 2.7 & 1.1 & 0.2 & 100.0 & 1,157 \\
\hline \multicolumn{9}{|l|}{2015 DHS } \\
\hline Women & 0.0 & 0.0 & 93.9 & 6.1 & na & 0.0 & 100.0 & 2,146 \\
\hline Girls & 0.0 & 0.0 & 99.3 & 0.7 & na & 0.0 & 100.0 & 1103.0 \\
\hline \multicolumn{9}{|l|}{2017 DHS } \\
\hline Women & 0.0 & 0.0 & 95.2 & 4.8 & na & 0.0 & 100.0 & 4,030 \\
\hline Girls & 0.0 & 0.0 & 98.6 & 1.1 & na & 0.4 & 100.0 & 1,956 \\
\hline
\end{tabular}

Table A5. Comparison of age at cutting between women aged 15-49 years and girls aged 0-14* years, Senegal 2005-2017.

\begin{tabular}{|lcccccccc|}
\hline & \multicolumn{2}{l}{ 2005 SDHS } & \multicolumn{2}{c}{ 2010 SDHS } & \multicolumn{2}{c|}{ 2015 SDHS } & \multicolumn{2}{c|}{ 2017 SDHS } \\
& Women & Girls & Women & Girls & Women & Girls & \multicolumn{2}{c|}{ Women } \\
Median Age (years) & 0 & 1 & 0 & 1 & 0 & 1 & 0 & 0 \\
Range (min-max) & $0-27$ & $0-14$ & $0-29$ & $0-8$ & $0-27$ & $0-10$ & $0-25$ & $0-14$ \\
Total cut (unweighted) & 4,954 & 2,993 & 5,280 & 1,720 & 2,981 & 1,772 & 5,569 & 3,046 \\
\hline
\end{tabular}

Table A6. Type of FGM/C among women aged $15-49$ year and girls aged $0-14^{\star}$ years, Senegal 2005-2017.

\begin{tabular}{|c|c|c|c|c|c|}
\hline $\begin{array}{l}\text { Survey and year: } \\
\text { Senegal }\end{array}$ & $\begin{array}{l}\text { Sewn } \\
\text { closed }\end{array}$ & $\begin{array}{l}\text { Type of FGM/C } \\
\text { Not sewn } \\
\text { closed }\end{array}$ & $\begin{array}{l}\text { Don't know/ } \\
\text { Missing }\end{array}$ & otal & $\begin{array}{l}\text { Number of circumcised } \\
\text { women/girls }\end{array}$ \\
\hline \multicolumn{6}{|l|}{2005 DHS } \\
\hline Women & 11.9 & 74.3 & 13.8 & 100.0 & 4,123 \\
\hline Girls & 9.7 & 84.5 & 5.8 & 100.0 & 2,423 \\
\hline \multicolumn{6}{|l|}{ 2010-11 DHS } \\
\hline Women & na & na & na & 100.0 & 4,123 \\
\hline Girls & 21.3 & 71.7 & 7.0 & 100.0 & 1,157 \\
\hline \multicolumn{6}{|l|}{2015 DHS } \\
\hline Women & 7.0 & 79.5 & 13.6 & 100.0 & 2,146 \\
\hline Girls & 3.4 & 84.6 & 12.0 & 100.0 & 1,103 \\
\hline \multicolumn{6}{|l|}{2017 DHS } \\
\hline Women & 10.3 & 75.4 & 14.3 & 100.0 & 4,030 \\
\hline Girls & 15.4 & 84.6 & na & 100.0 & 1,956 \\
\hline
\end{tabular}

*Note: In the 2003 DHS, 2007 MICS, and 2008 DHS, FGM/C questions were asked about the most recently cut daughters of any age. For this analysis, sample size is limited to most recently cut girls aged 0-14. In the 2015 and 2017 Senegal DHS, the FGM/C questions were asked for all daughters aged 0-14 years. 
Table A7. FGM/C prevalence by regions among women aged $15-49$ years and girls aged $0-14^{\star}$ years, Senegal 2005-2017

\begin{tabular}{|c|c|c|c|c|c|c|c|c|}
\hline \multirow[b]{2}{*}{ Region } & \multicolumn{3}{|c|}{ Women } & \multicolumn{5}{|c|}{ Girls } \\
\hline & $\begin{array}{l}2005 \\
\text { DHS }\end{array}$ & $\begin{array}{c}2010-11 \\
\text { DHS }\end{array}$ & $\begin{array}{l}2015 \\
\text { DHS }\end{array}$ & $\begin{array}{l}2017 \\
\text { DHS }\end{array}$ & $\begin{array}{l}2005 \\
\text { DHS }\end{array}$ & $\begin{array}{c}2010-11 \\
\text { DHS }\end{array}$ & $\begin{array}{l}2015 \\
\text { DHS }\end{array}$ & $\begin{array}{l}2017 \\
\text { DHS }\end{array}$ \\
\hline Dakar & 17.3 & 20.1 & 14.8 & 17.8 & 7.1 & 5.6 & 2.1 & 3.8 \\
\hline Diourbel & 1.8 & 0.5 & 0.7 & 0.7 & 0.8 & 0.2 & 0.0 & 0.2 \\
\hline Fatick & 5.8 & 7.3 & 7 & 7.6 & 2.9 & 0.5 & 2.8 & 1.1 \\
\hline Kaffrine & - & 10.3 & 8.6 & 9.5 & - & 2.7 & 2.6 & 2.4 \\
\hline Kaolack & 11.3 & 5.6 & 15.7 & 9.3 & 4.0 & 0.2 & 7.1 & 1.6 \\
\hline Kedougou & - & 92.0 & 82.2 & 91.0 & - & 17.3 & 35.7 & 45.4 \\
\hline Kolda & 93.8 & 84.8 & 84.4 & 63.6 & 68.8 & 40.9 & 51.8 & 34.6 \\
\hline Louga & 4.1 & 3.8 & 2.3 & 4.8 & 3.2 & 3.4 & 0.0 & 1.6 \\
\hline Matam & 93.3 & 87.2 & 76.0 & 73.3 & 78.4 & 41.4 & 57.1 & 60.6 \\
\hline Saint-Louis & 44.4 & 39.5 & 36.2 & 36.0 & 41.1 & 20.6 & 29.6 & 31.8 \\
\hline Sedhiou & - & 86.3 & 83.0 & 75.6 & - & 50.3 & 54.8 & 43.0 \\
\hline Tambacounda & 85.6 & 85.3 & 79.3 & 71.8 & 54.8 & 44.1 & 41.8 & 44.0 \\
\hline Thios & 7.0 & 3.5 & 4.2 & 5.2 & 2.6 & 0.6 & 0.3 & 1.2 \\
\hline Zuguinchor & 69.3 & 55.5 & 60.2 & 68.2 & 51.9 & 19.1 & 42.3 & 38.5 \\
\hline
\end{tabular}

